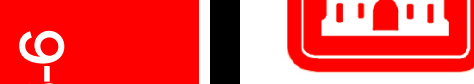

US Army Corps of Engineers ${ }_{\circledast}$ Engineer Research and Development Center

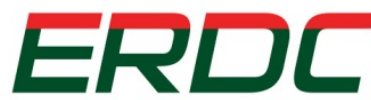

INNOVATIVE SOLUTIONS for a safer, better world

Base Facilities Environmental Quality

\title{
Application of Maxent Multivariate Analysis to Define Reptile Species Distributions and Changes Related to Climate Change
}

Robert C. Lozar and James D. Westervelt

June 2016

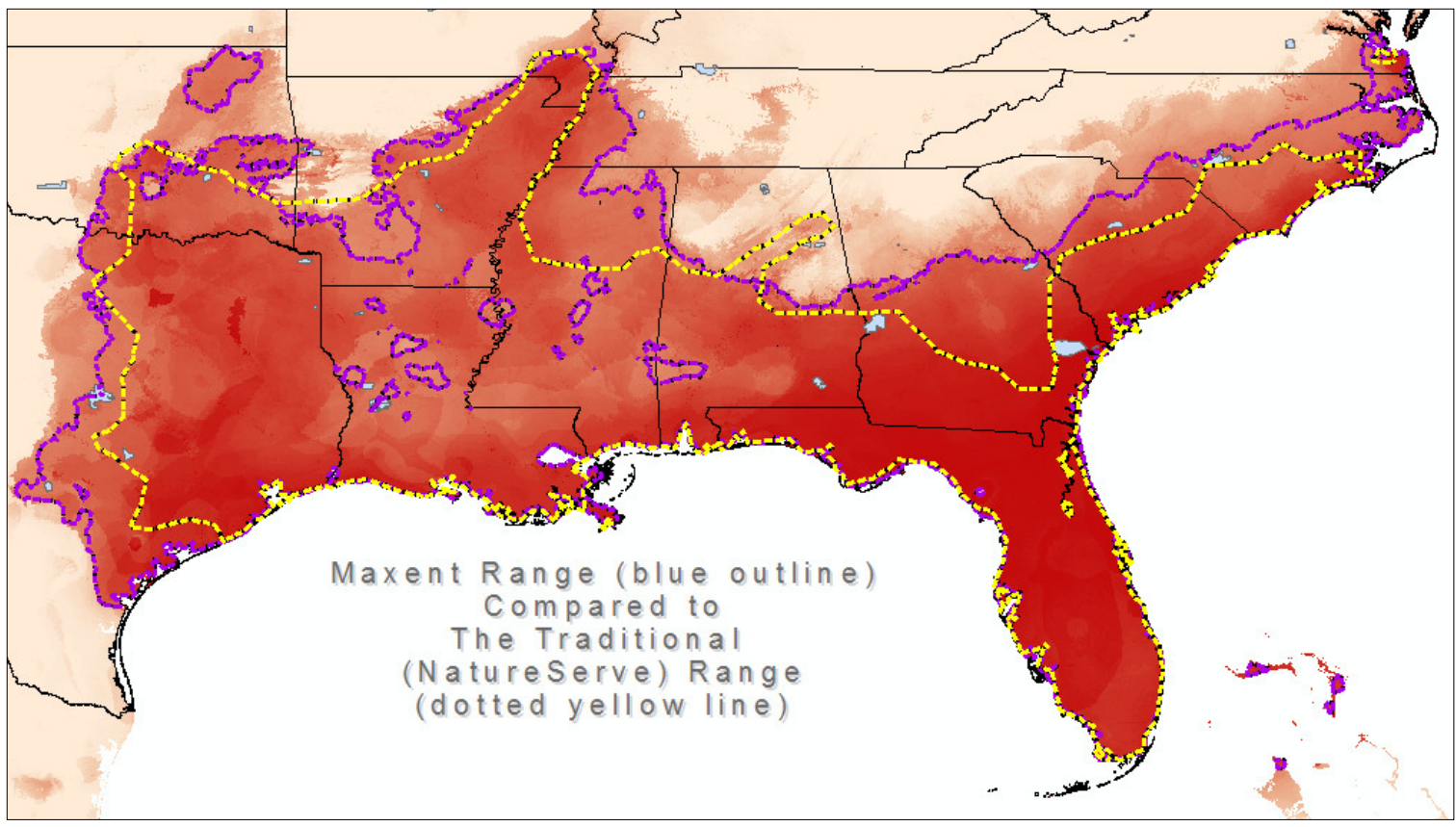


The U.S. Army Engineer Research and Development Center (ERDC) solves the nation's toughest engineering and environmental challenges. ERDC develops innovative solutions in civil and military engineering, geospatial sciences, water resources, and environmental sciences for the Army, the Department of Defense, civilian agencies, and our nation's public good. Find out more at www.erdc.usace.army.mil.

To search for other technical reports published by ERDC, visit the ERDC online library at http://acwc.sdp.sirsi.net/client/default. 


\section{Application of Maxent Multivariate Analysis to Define Reptile Species Distributions and Changes Related to Climate Change}

Robert C. Lozar and James D. Westervelt

Construction Engineering Research Laboratory

U.S. Army Engineer Research and Development Center

2902 Newmark Drive

Champaign, IL 61822

Final report

Approved for public release; distribution is unlimited.

Prepared for Office of the Assistant Secretary of the Army for Acquisition, Logistics, and Technology (ASA(ALT))

Washington, DC 20314-1000

Under Project 335114, "Framework for Forecasting Climate Change Effects on Installation Natural Resources" 


\section{Abstract}

The maximum entropy (Maxent) statistical technique was applied to determine the habitat extent of seven reptile species and to objectively delineate distributions and bioclimatic thresholds. For each species, Maxent ranked the relative importance of each of the input bioclimatic concerns and provided charts which were used to define species bioclimatic survival thresholds. It was discovered that the thresholds corresponded with the spatial distribution of the bioclimatic factors almost exactly at those threshold levels through much of the range for each of the species. As a result, it can be shown with a high degree of assurance that the majority of a reptile's range can be delineated with just a few bioclimatic concerns specific to that species and that the northern boundaries of the seven reptiles in this study are all controlled by temperature and the western boundaries are all controlled by the amount of precipitation.

DISCLAIMER: The contents of this report are not to be used for advertising, publication, or promotional purposes. Citation of trade names does not constitute an official endorsement or approval of the use of such commercial products. All product names and trademarks cited are the property of their respective owners. The findings of this report are not to be construed as an official Department of the Army position unless so designated by other authorized documents. 


\section{Contents}

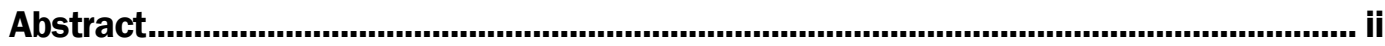

Figures and Tables........................................................................................................

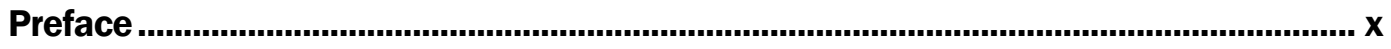

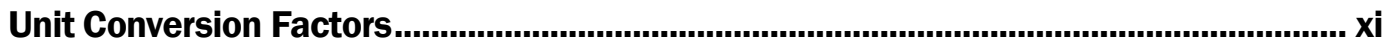

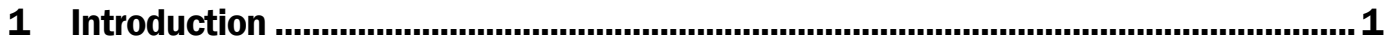

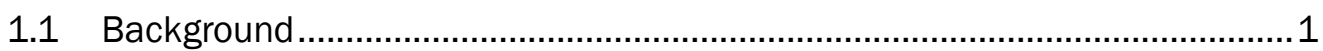

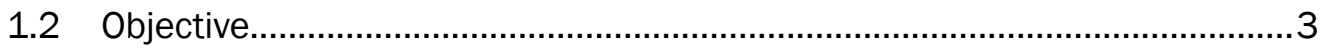

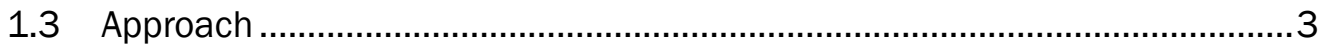

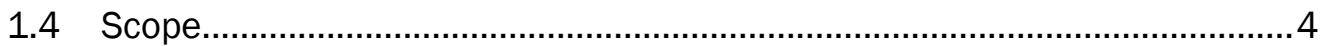

1.5 Mode of technology transfer ................................................................... 4

2 Problems with the Current Species Range Maps................................................. 5

3 Description of the Maxent Application ................................................................. 6

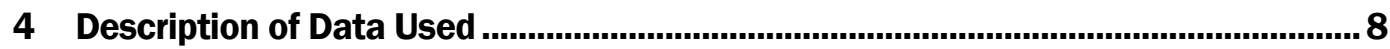

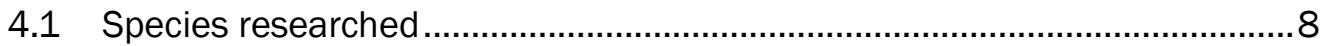

4.2 Species sample (point) locations ............................................................ 8

4.3 Bioclimatic parameters (raster layers) …....................................................... 9

4.4 Non-climatic parameters (raster layers) ...................................................10

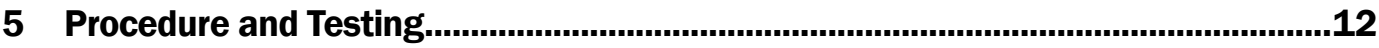

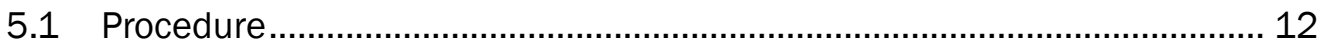

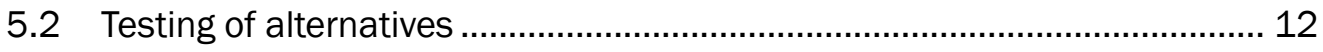

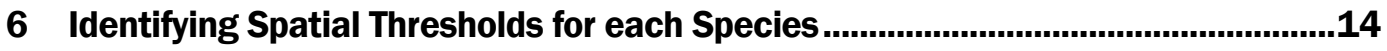

6.1 Chicken Turtle (Deirochelys reticularia) ........................................................14

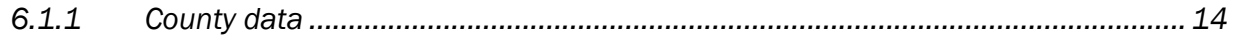

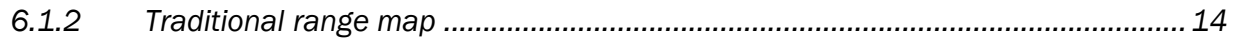

6.1.3 Critical mapping guidance issues .................................................................. 14

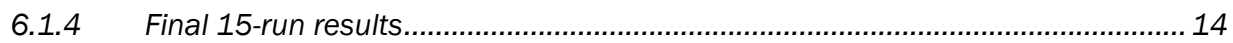

6.1.5 Spatial conclusions for the Chicken Turtle ........................................................... 24

6.2 Eastern Mud Turtle (Kinosternon subrubrum) ...........................................24

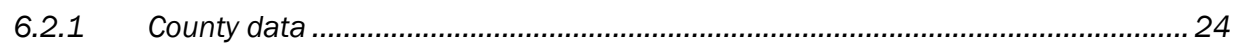

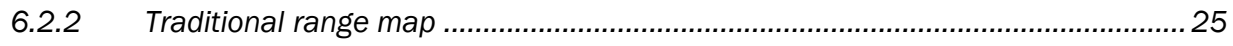

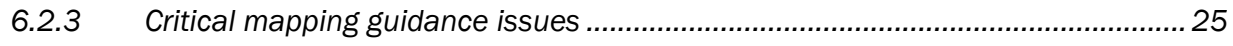

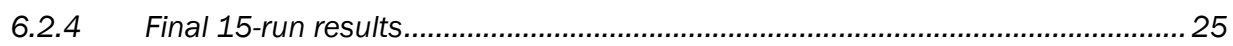

S.2.5 Spatial conclusions for the Mud Turtle............................................................... 32

6.3 Eastern Green Watersnake (Nerodia floridana) ....................................... 33 


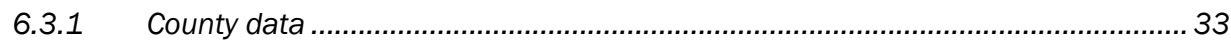

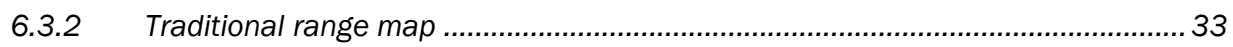

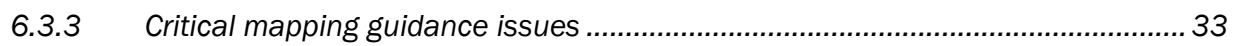

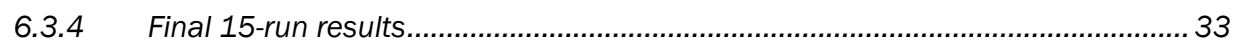

6.3.5 Spatial conclusions for the Eastern Green Watersnake........................................ 42

6.4 Banded Watersnake (Nerodia fasciata) ............................................ 42

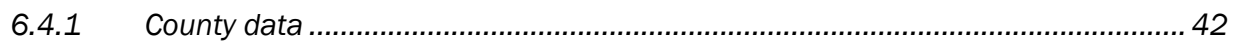

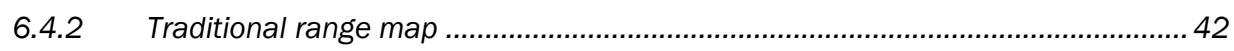

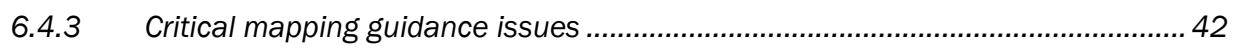

F.4.4 Final 15-run results...................................................................................... 43

6.4.5 Spatial conclusions for the Banded Watersnake................................................ 51

6.5 Glossy Crayfish Snake (Regina rigida)........................................... 52

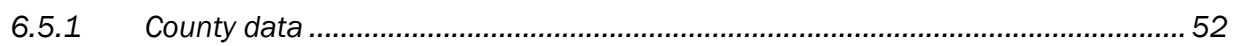

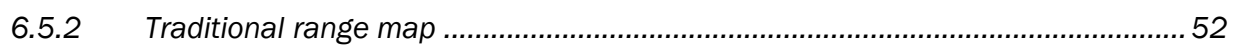

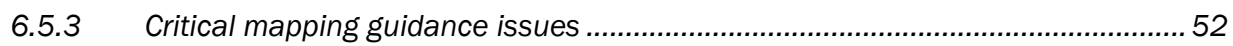

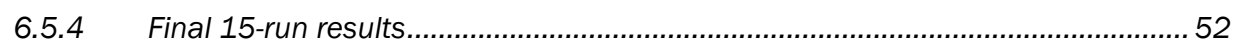

6.5.5 Spatial conclusions for the Glossy Crayfish Snake ..............................................61

6.6 Black Swampsnake (Seminatix pygaea) ..............................................61

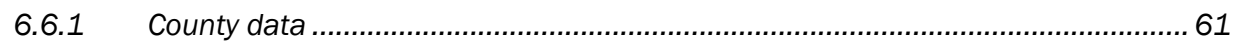

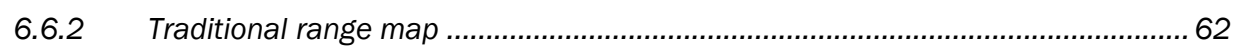

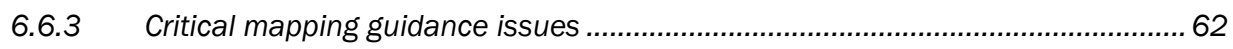

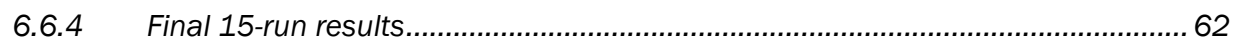

6.6.5 Spatial conclusions for the Black Swampsnake ...................................................68

6.7 Common Musk Turtle (Sternotherus odoratus) ........................................ 68

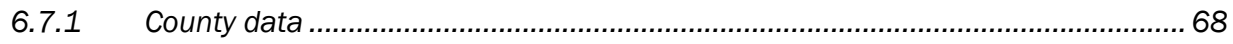

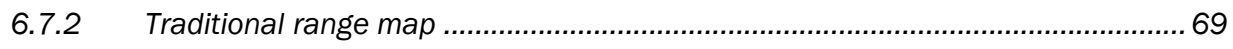

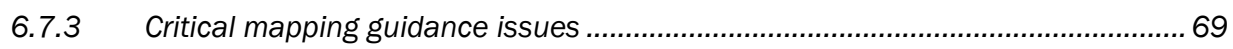

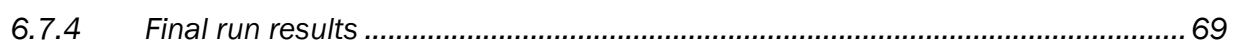

S.7.5 Spatial conclusions for the Musk Turtle ............................................................... 76

7 Comparisons Among the Different Models and Thresholds .................................. 77

8 Application of Findings to Climate Change Modeling............................................82

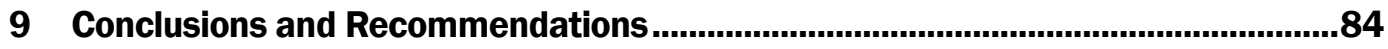

9.1 Conclusions................................................................................... 84

9.1.1 Conclusions regarding Maxent............................................................................ 84

9.1.2 Conclusions regarding the testing of alternative inputs for the Maxent program 84

9.1.3 Conclusions regarding the individual species .................................................... 85

9.1.4 Conclusions regarding all of the reptiles as a group........................................... 86

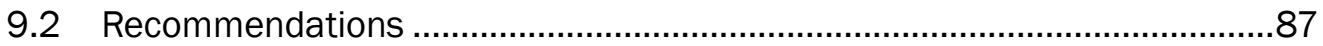

References.........................................................................................................88

Appendix: Example of Alternatives Testing on Seminatrix pygaea.....................................91 
Report Documentation Page 


\section{Figures and Tables}

\section{Figures}

Figure 1. Darker red is better Chicken Turtle range. The blue outline is the 0.1 probability in the Maxent 15 runs model. The yellow line is the traditional range.

Figure 2. Standard deviations of the 15 model runs for $D$. reticularia..............................16

Figure 3. Coordinated marginal response curves for Chicken Turtle.

Figure 4. The mean temperature of warmest quarter at the $25.5^{\circ} \mathrm{C}$ threshold for the Chicken Turtle.

Figure 5. The western range of the Chicken Turtle is controlled by precipitation of driest quarter.

Figure 6 . Annual mean temperature only roughly relates to the northern limit of the Chicken Turtle at $15.0{ }^{\circ} \mathrm{C}$

Figure 7. The 0.1 probability level corresponds with $330 \mathrm{~mm}$ of summer rain.

Figure 8. At the 0.1 probability level, the corresponding value would be $120 \mathrm{~mm}$ of summer rain, which poorly matches the turtle's range.

Figure 9. Red is the Eastern Mud Turtle range above the 0.1 probability level, and the yellow outline is the traditional range.

Figure 10. The standard deviation among 15 model runs for the Eastern Mud Turtle. 26

Figure 11. Coordinated marginal response curves for Eastern Mud Turtle.

Figure 12. Precipitation of driest quarter at the $106 \mathrm{~mm}$ threshold for the Eastern Mud Turtle. 30

Figure 13. Mean temperature of warmest quarter for the Eastern Mud Turtle.

Figure 14. Minimum temperature of coldest month for the Eastern Mud Turtle. 31

Figure 15. Annual precipitation at the $700 \mathrm{~mm}$ level for the Eastern Mud Turtle 32

Figure 16. Maxent range for $N$. floridana. The 0.1 probability level is shown with the blue chained outline, while the traditional range is the yellow dashed line.

Figure 17. Closeup of Eastern Green Watersnake range. Darker red is better. The blue outline is the 0.1 probability in the Maxent 15-run model, and the red line shows the one-model run.

Figure 18. Coordinated marginal response curves for Eastern Green Watersnake............37

Figure 19. Precipitation of warmest quarter at the $360 \mathrm{~mm}$ threshold for $\mathrm{N}$. floridana.

Figure 20. Mean temperature of wettest quarter at the $26{ }^{\circ} \mathrm{C}$ level for $\mathrm{N}$. floridana.

Figure 21. Isothermality at about the ratio of 42 for $N$. floridana.

Figure 22. Minimum temperature of coldest month at the 12 degree threshold for $N$. floridana. 
Figure 23. Maxent probability result of the 15 runs; the dotted red/yellow line is the 0.1 probability edge, and yellow dotted line shows the NatureServe traditional boundary.

Figure 24. Average omission rate for Banded Watersnake.

Figure 25. The standard deviation for the 15 model runs for Banded Watersnake. .........45

Figure 26. Coordinated marginal response curves for Banded Watersnake.

Figure 27. The mean temperature of the warmest quarter at the $24.5^{\circ} \mathrm{C}$.

threshold for N. fasciata. 49

Figure 28. Precipitation of wettest month at the 0.1 probability level...............................50

Figure 29. Annual mean temperature at the $15.0^{\circ} \mathrm{C}$. threshold.......................................50

Figure 30. Precipitation of driest month at the $37.5 \mathrm{~mm}$ threshold.

Figure 31. The multi-run probability distribution for Glossy Crayfish Snake. The dotted red/yellow line is the 15 model run result, and the yellow dotted line shows the NatureServe traditional boundary.

Figure 32. Average omission rate for Glossy Crayfish Snake. .53

Figure 33. The standard deviation for the 15 model runs for $R$. rigida...............................54

Figure 34. Coordinated marginal response curves for Glossy Crayfish Snake. ..................57

Figure 35. The annual mean temperature at the $16{ }^{\circ} \mathrm{C}$. threshold for $R$. rigida................59

Figure 36. Precipitation of driest month at the $48 \mathrm{~mm}$ threshold for $R$. rigida.

Figure 37. Annual precipitation at the $110 \mathrm{~cm}$ threshold for $R$. rigida.

Figure 38. Precipitation of the wettest month at the $120 \mathrm{~mm}$ threshold for $R$.

rigida.

Figure 39. The 15 run probability distribution Maxent output for S. pygaea. The dotted red/yellow line is the 15 model run result, and the yellow dotted line shows the NatureServe traditional boundary.

Figure 40. The standard deviation for the model 15 runs for S. pygaea. Blue dots are county sightings.

Figure 41. Coordinated marginal response curves for Black Swampsnake.

Figure 42.Spatial distribution of precipitation of warmest quarter at the $350 \mathrm{~mm}$ threshold for S. pygaea.

Figure 43. Mean temperature of the wettest quarter at the $25^{\circ} \mathrm{C}$ level for $\mathrm{S}$. pygaea.

Figure 44. The difference between the Maxent distributions at the 0.1 probability (red-yellow dotted line) to the traditional range (yellow dotted line) for S. odoratus. 69

Figure 45. Coordinated marginal response curves for Musk Turtle.

Figure 46. Mean temperature of warmest quarter at the $19^{\circ} \mathrm{C}$ threshold defines the northern edge of the Musk Turtle's range.

Figure 47. Precipitation of driest month at the $23.0 \mathrm{~mm}$ threshold level for $\mathrm{S}$. odoratus

Figure 48. Precipitation of driest month for the Musk Turtle at the $90.0 \mathrm{~mm}$ threshold.

Figure 49. Climate change test for S. odoratus. Left: Range for 1990 (red-yellow dotted line) and the comparable range for 2025 as the red area. Top right: the 
range for 1990 at the 0.1 probability level (red-yellow dotted line) and the 2025 prediction for $\mathrm{BIO} 10$ mean temperature of warmest quarter as the dark edge at the $19^{\circ} \mathrm{C}$ threshold. Bottom right: Turtle range for 1990 at the 0.1 probability level (red-yellow dotted line) and the 2025 prediction for BIO 14 precipitation of the driest month at the $23 \mathrm{~mm}$ level (dark edge).

Figure 50. Maxent test results for S. pygaea using only the county sightings.

Figure 51. Detail within the range for $S$. pygaea shows that additional layers, particularly land cover and accumulation, made a difference at the local level.

Figure 52. For S. pygaea this map shows the wet lands within the counties where the species was observed.

Figure 53. S. pygaea Maxent range after only wetland areas within a county were used as sample points (blue dots).

Figure 54. Maxent model showing the S. pygaea distribution refined particularly by using hydrology.

Figure 55. Detail area (same location as in Figure 51 above), showing that accumulation enhances riverine areas and deemphasizes land cover types. 96

Figure 56. County-based distribution for S. pygaea using hydrology but leaving the accumulation layer out of the list of input layers.

Figure 57. The Maxent test model with accumulation layer integrated into the submitted layers.

\section{Tables}

Table 1. Reptile species studied. .8

Table 2. Bioclimatic concerns used as Maxent input layers. ................................................. 9

Table 3. Non-bioclimatic concerns used as Maxent input layers. ......................................11

Table 4. Variable importance averaged from 15 model runs for Chicken Turtle................17

Table 5. Bioclimatic thresholds for the occurrence of the Chicken Turtle.

Table 6. Variable Importance, averaged from 15 model runs for Eastern Mud

Turtle.

Table 7. Bioclimatic thresholds of the Eastern Mud Turtle. .29

Table 8. Variable importance averaged from 15 model runs for N. floridana.....................36

Table 9. Bioclimatic thresholds for the occurrence of Eastern Green Watersnake.............37

Table 10. Variable Importance averaged from 15 model runs for $N$. fasciata....................46

Table 11. Bioclimatic thresholds for the occurrence of the Banded Watersnake. .............48

Table 12. Variable Importance for Glossy Crayfish Snake. ................................................56

Table 13. Bioclimatic thresholds for the occurrence of Glossy Crayfish Snake..................58

Table 14. Variable importance averaged from 15 model runs for Black

Swampsnake. 65

Table 15. Bioclimatic thresholds for the occurrence of Black Swampsnake. .66

Table 16. Variable importance, averaged from 15 model runs for Musk Turtle. 71

Table 17. Bioclimatic thresholds of the Musk Turtle. 
Table 18. Comparison of the occurrence of controlling bioclimatic concerns on

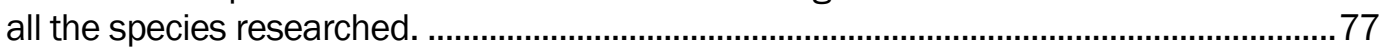

Table 19. Amount of the range edges determined for each of the species from the bioclimatic concerns................................................................................................8 


\section{Preface}

This study was conducted for the Office of the Assistant Secretary of the Army for Acquisition, Logistics, and Technology (ASA(ALT)) under Research, Development, Test, and Evaluation Program Element 896, "Base Facilities Environmental Quality"; Project number 335114, "Framework for Forecasting Climate Change Effects on Installation Natural Resources." This project was part of the work package titled "Prediction and Adaptation of Military Natural Infrastructure in Response to Climate Change," led by Dr. Jinelle Sperry. The technical monitor was Mr. Alan B. Anderson, CEERD-CZT.

The work was performed by the Environmental Processes Branch (CNN) of the Facilities Division (CF), U.S. Army Engineer Research and Development Center, Construction Engineering Research Laboratory (ERDCCERL). The ERDC-CERL Principal Investigator was Dr. James Westervelt. At the time of publication, Dr. Chris C. Rewerts was Chief, CEERD-CNN; Ms. Michelle J. Hanson was Chief, CEERD-CN; and Mr. Alan B. Anderson, CEERD-CZT, was the Technical Director for Sustainable Ranges and Lands. The Deputy Director of ERDC-CERL was Dr. Kirankumar Topudurti, and the Director was Dr. Ilker Adiguzel.

The Commander of ERDC was COL Bryan S. Green, and the Director was Dr. Jeffery P. Holland. 


\section{Unit Conversion Factors}

\begin{tabular}{|c|c|c|}
\hline Multiply & By & To Obtain \\
\hline acres & $4,046.873$ & square meters \\
\hline cubic feet & 0.02831685 & cubic meters \\
\hline cubic inches & 1.6387064 E-05 & cubic meters \\
\hline degrees Fahrenheit & $(\mathrm{F}-32) / 1.8$ & degrees Celsius \\
\hline feet & 0.3048 & meters \\
\hline gallons (U.S. liquid) & 3.785412 E-03 & cubic meters \\
\hline inches & 0.0254 & meters \\
\hline miles (U.S. statute) & $1,609.347$ & meters \\
\hline pounds (force) & 4.448222 & newtons \\
\hline square feet & 0.09290304 & square meters \\
\hline square miles & $2.589998 E+06$ & square meters \\
\hline tons (force) & $8,896.443$ & newtons \\
\hline yards & 0.9144 & meters \\
\hline
\end{tabular}


(This page intentionally blank.) 


\section{Introduction}

\subsection{Background}

The military recognizes that climate change is occurring, and that climate change will affect the military mission in training and materials testing (U.S. Secretary of Defense 2010). To ensure the Army will meet its training and materials testing requirements in the future, it must know and be able to deal with climate changes that may affect the activities at each of its major installations. The stated purpose for the work package of which this research is a part is to "...analyze the influence of climate change on environmental impacts of interest to military planners and decision makers. The analytical framework integrates rigorous, large-scale models of the global climate system with analytically tractable model linkages to regional assessments of climatic change, weather, ecological stressors, watershed processes, and landscape evolution.” To accomplish this, current climatic factors must be determined that determine the range of militarily important species at an installation.

Previous research conducted by the Engineer Research and Development Center, Construction Engineering Research Laboratory (ERDC-CERL) under a work package titled "Framework for Forecasting Climate Change Effects on Installation Natural Resources" (referred to here as "Uncertain Futures" for brevity) has shown the utility of applying the maximum entropy statistical approach (Phillips et al. 2006), as implemented in the Maxent computer program, to issues of climate change effecting species of Army concern (Lozar and Westervelt 2014).

Others have been working elsewhere, applying their specialized expertise to different subsections of the overall umbrella effort. As part of the "Uncertain Futures" work package, Savannah River Ecology Laboratory (SREL) conducted a multi-species vulnerability assessment for reptiles and amphibians occurring in the Sandhills Ecoregion, using the NatureServe Climate Change Vulnerability Index (CCVI) ${ }^{*}$. SREL identified several species with predicted increased vulnerability to climate change. But SREL researchers also felt that the CCVI tool did not adequately capture all of

\footnotetext{
* https://connect.natureserve.org/science/climate-change/ccvi
} 
the unique physiological and behavioral attributes of reptiles and amphibians that may affect their vulnerability.

Since both efforts were under the same project, it seemed logical to generate a closer cooperative research relationship and maximize the value of both efforts.

As a prototype, SREL provided ERDC-CERL detailed distribution maps for three aquatic turtle species (Deirochelys reticularia, Sternotherus odoratus, and Kinosternon subrubrum). SREL believed these species were likely to be vulnerable, even though only the first was predicted to be vulnerable by CCVI. For $S$. odoratus, ERDC-CERL demonstrated the ability to apply spatially explicit bioclimatic data to statistically determine limiting bioclimatic thresholds for species distributions as they exist now and then using those to predict future distributions. The method uses the Maxent statistical program.

Maxent applies the technique called Maximum Entropy Analysis. Entropy is a measure of image information content. Maxent is designed to determine the maximum information content expressed by the data submitted to it. Maxent defines the ranges of species, based on a multivariate approach. In addition, it offers a suite of statistical analysis tools that are highly useful in evaluating the quality of the resulting range map and ancillary outputs.

ERDC-CERL tested the procedure on $S$. odoratus with initial success. SREL $^{*}$ and ERDC-CERL ${ }^{\dagger}$ then proposed an in-tandem research effort. ERDC-CERL would apply the Maxent approach to several species to determine their bioclimatic thresholds. SREL would perform laboratory tests on the same reptile species to quantify evaporative water loss and standard metabolic rates over a range of temperatures that would encompass the species-specific threshold values predicted by maximum entropy. The focus was on a combination of species identified as vulnerable during the CCVI analysis as well as on species predicted to be stable under future climate scenarios. Because the maximum entropy approach required detailed

\footnotetext{
* An FY14 research thrust: Tracey D. Tuberville and Kimberly M. Andrews, Savanna River Laboratory (SREL). "Testing the Bioclimatic Thresholds Previously Identified by CERL using Maximum Entropy Approach."

† An FY14 research thrust: Robert Lozar and James Westervelt, ERDC-CERL. "Bioclimatic Thresholds Identified by CERL using Maximum Entropy Approach."
} 
distribution maps, the selection of species was necessarily limited by the availability of such data. Specifically, the target species included species that could be captured and maintained for laboratory experiments on the Savannah River site. The presumption is that if Maxent works for a good percentage of these species, then its results could be used with higher confidence for species of greater importance to the Army for which little or no laboratory data was available.

As part of the test effort, some surprising consistencies between the species range limits as determined by the Maxent probability thresholds and the spatial distribution of the important bioclimatic concerns were noticed. This report is intended to document those observed consistencies. It is believed that the clear demonstration of the consistencies will help support the validation efforts being carried out by SREL. The hypothesis is that if the distributions of the controlling bioclimatic factors for a species are known, then as climate changes, there may not be a need to remodel a species habitat. Rather, the need is only to identify how the single bioclimatic concern will reposition itself due to climatic change.

\subsection{Objective}

The objective of this project was to demonstrate the existence of a spatial relationship between bioclimatic threshold parameters and the boundaries of species ranges, as defined through the application of the Maxent modeling approach.

\subsection{Approach}

The issues outlined in relation to modeling species ranges that led to adoption of the Maxent approach are briefly described. Maxent requires specific input formats that are described in terms of the species investigated, their locations, and the environmental parameters (both bioclimatic and non-bioclimatic) used to characterize the species habitat. Many tests were carried out to discover which environmental parameters provided the best combination for delineating an individual species range. An example of the testing process on one of the species studied is presented in the Appendix.

As background for each of the species investigated: the county sighting data used was discussed, where the "traditional map" used to compare to "testing alternatives" was obtained, and the critical spatial issues were determined that might affect the range determination process. 
For each of the final adopted model results: the characteristics of the Maxent-generated probability distribution was discussed, the importance of each input environmental variable to that species distribution determination was examined, the coordinated Marginal Response Curves were used to define thresholds, and the distribution of the bioclimatic input parameters in relationship to those thresholds were spatially compared.

Finally, the individual species were compared as a group, the resulting consistencies characterized, and conclusions were submitted based on the data summary results.

All findings in this research were shared with the SREL colleagues so that they could carry out their portion of the research.

\subsection{Scope}

The primary thrust of the overall research was to examine the effects of climate change on species of importance to Army land managers. To do this, it was necessary to generate species distributions and comparable changes in those distributions over time. The generation of those distributions was accomplished by using a rigorous statistical approach. The primary goal does not include the submission of a new standard distribution map for each species studied; the distribution maps are a means to the end of defining the effects of climate change.

This investigation uses the data and analysis techniques already available. There was no attempt to generate new climatic predictions or to program new software. Also, this report deals with scientifically validated climate change data, not weather or weather extremes.

\subsection{Mode of technology transfer}

The developers of the Maxent application offer freely downloadable, compiled versions of the software for Microsoft Windows users that is available at http://www.cs.princeton.edu/ schapire/maxent/.

The results of the efforts by SREL will be published independently. 


\section{Problems with the Current Species Range Maps}

To determine bioclimatic thresholds, the areal extent of a species is needed. The intent was to use the "standard range" for each species. However, adopting the standard range became an issue immediately because there are several different versions. The choices were to start from the potential range, from the current plus previous range, or from locations where the species was sighted. The existing sources of species areal distribution lack full representation because current distributions have been modified by agriculture and urbanization. Historical distributions are spotty, inconsistent, and lack adequate occurrence data. Historic county sightings are not part of a professional systematic survey. Many variables could influence the data. Land use change (e.g., to agriculture) could make a difference to the range of a species. Some of the data could be redundant so areas are overweighed. The presence of outlier counties could be real, or the species could be misidentified in those locations. There could be holes in the coverage or just a lack of observation. Are the denser clusters of sightings due to greater species density or due to a clustering of observers (as from a nearby university)?

The lack of consistency and comparability negated the ability to use this information to determine species bioclimatic thresholds. Determining these thresholds requires consistency and objectivity in the definition of the species range. 


\section{Description of the Maxent Application}

Maxent is a software program based on the maximum entropy analysis technique. The software was developed to define the ranges of species based on a multivariate approach.

Entropy in this context is a measure of image information content. Maxent is designed to determine the maximum information content expressed by the data submitted to it. Shannon (1948) described entropy as "a measure of how much 'choice' is involved in the selection of an event." Edward T. Jaynes suggested that the best approach for approximating an unknown probability distribution is to ensure that the approximation satisfies any constraints on the unknown distribution and that, subject to those constraints, the distribution should have maximum entropy (Jaynes 1957).

The maximum entropy approach is theoretically derived from the Second Law of Thermodynamics, which states that in closed systems, processes move toward greater entropy (disorder). As applied to the distribution of a species, the hypothesis is that the sum of the species' population behavior will also tend to follow this constraint, and thus result in habitat usage that reflects maximum entropy for it. Since there may be outside influences not included in the input data for a species, the distribution is likely to be larger than the observed delineation. Thus, the maximum entropy approach can be expected to generate a "potential distribution" for each species, based on the inputs available.

The Maxent technique develops unbiased probability distribution on the basis of partial knowledge (Phillips et al. 2006). It uses a "presence only" approach, called an unconditional model, rather than including data that reflect known-absence sighting (a conditional model). In addition, the Maxent technique provides a collection of statistical analysis tools that are highly useful in evaluating the quality of the resulting range map and ancillary outputs. Maxent "takes as input a set of layers or environmental variables (such as elevation, precipitation, etc.) as well as a set of georeferenced occurrence locations, and produces a model of the range of the given species" (Phillips and Dudík 2008). The idea behind Maxent is to estimate a target probability distribution by finding the probability distribution of maximum entropy (i.e., that is most spread out or closest to uniform sur- 
face), subject to a set of constraints that represent the incomplete information about the target distribution. This is accomplished using a deterministic sequential-update algorithm (Dudík et al. 2004). The process iteratively adjusts a weight so as to minimize the resulting regularized log loss. The algorithm is guaranteed to converge to the Maxent probability distribution. Probabilities must sum to 1 , so that each "raw" probability is typically extremely small. The Maxent software by default presents a "cumulative" probability distribution where the value assigned to a pixel is the sum of the probabilities of that pixel and all other pixels with equal or lower probability, multiplied by 100 to give a percentage.

The advantages of using Maxent for the current work (based on Phillips et al. 2006) are included below.

- Maps of ranges are generated based on natural, not human-restricted, concerns.

- Efficient deterministic algorithms have been developed that are guaranteed to converge to the optimal (maximum entropy) probability distribution.

- Modelers are allowed to use the original data values.

- Maps have numerical variations based on objective data.

- Statistical evaluations demonstrate the relative importance of each of the inputs.

- Statistical evaluations show species tolerance levels objectively.

- The selection of specific input layers becomes less important, because the output indicates how important each one was to the analysis.

- It is well suited for defining the potential ranges of invasive species, so land managers can find out if their installation is prime habitat for a noxious invasive species and can prevent or prepare for its appearance.

- Maxent is used by other government agencies (Kumar 2009), which facilitates the sharing of data and analyses. 


\section{Description of Data Used}

\subsection{Species researched}

The species examined include seven reptiles: three turtles and four snakes (Table 1).

Table 1. Reptile species studied.

\begin{tabular}{|l|l|}
\hline Species Scientific Name & Common Name \\
\hline Deirochelys reticularia & Chicken Turtle \\
\hline Kinosternon subrubrum & Eastern Mud Turtle \\
\hline Nerodia floridana & Eastern Green Watersnake \\
\hline Nerodia fasciata & Banded Watersnake \\
\hline Regina rigida & Glossy Crayfish Snake \\
\hline Seminatrix pygaea & Black Swampsnake \\
\hline Sternotherus odoratus & Common Musk Turtle \\
\hline
\end{tabular}

\subsection{Species sample (point) locations}

Maxent requires point sightings as sample input data. The data available for species' locations were usually county locations in which they were historically sighted. For the species being studied, sightings by county name were available from museum and personal records. At first it was thought that more precise locations would be necessary. An example is that for water snakes, the county centroids were known, but sample locations within the county that would occur only on wet areas could also be used. This would result in greater detail within the animal's range, but would not significantly modify the extent of a range. After a good deal of testing (see Appendix for an example), however, it became apparent that the county sighting information was roughly compatible with the climatic data used so, surprisingly, counties are (in general) adequate for determining the ranges among these species. For this reason, it was eventually decided that county centroids were adequate for this purpose.

The data for this study covers the continental United States. All Maxent models are run for that entire area. The maximum practical extent of the study area for a species is a region slightly larger than the traditional 
range. If possible, the traditional range is taken from a reliable source such as that available from the NatureServe website. The Maxent probability range is a potential habitat, so it is usually more extensive than the traditional range.

\subsection{Bioclimatic parameters (raster layers)}

To represent current climatic conditions, the WorldClim dataset was used which represents downscaled data from weather stations averaged over a period of 1950-2000 (available directly from the WorldClim site at http://www.worldclim.org/current).

The WorldClim dataset includes 20 bioclimatic concerns useful in characterizing the biological environment. These 20 parameters (Table 2) represent many of the concerns that characterize the living environment in a locality. They are derived directly from the historical temperature and precipitation data. Characteristics of the data are well documented at the WorldClim website. These are the bioclimatic data types used in these analyses.

Table 2. Bioclimatic concerns used as Maxent input layers.

\begin{tabular}{|c|}
\hline Derived from maximum and minimum temperat \\
\hline BIO1 = Annual Mean Temperature \\
\hline $\mathrm{BIO} 2=$ Mean Diurnal Range (mean of monthly $(\mathrm{m}$ \\
\hline $\mathrm{BIO}=$ Isothermality (mean diurnal range/tempe \\
\hline BIO4 = Temperature Seasonality (standard deviat \\
\hline BI05 = Max Temperature of Warmest Month \\
\hline BIO6 = Min Temperature of Coldest Month \\
\hline BIO7 = Temperature Annual Range (P5-P6) \\
\hline BI08 = Mean Temperature of Wettest Quarter \\
\hline BI09 = Mean Temperature of Driest Quarter \\
\hline BI010 = Mean Temperature of Warmest Quarter \\
\hline BI011 = Mean Temperature of Coldest Quarter \\
\hline
\end{tabular}




\begin{tabular}{|l|}
\hline Derived from precipitation (usually in millimeters): \\
\hline BI012 = Annual Precipitation \\
\hline BIO13 = Precipitation of Wettest Month \\
\hline BI014 = Precipitation of Driest Month \\
\hline BI015 = Precipitation Seasonality (coefficient of variation) \\
\hline BI016 = Precipitation of Wettest Quarter \\
\hline BI017 = Precipitation of Driest Quarter \\
\hline BI018 = Precipitation of Warmest Quarter \\
\hline BI019 = Precipitation of Coldest Quarter \\
\hline $\begin{array}{l}\text { BIO20 = Consecutive Months - the maximum number of consecutive dry } \\
\text { months of < }<100 \text { mm in a year }\end{array}$ \\
\hline
\end{tabular}

It was found that using similar concerns would cause the identification of importance in Maxent to be spread between the similar concerns, therefore potentially obscuring important issues. Consequently, to avoid redundancies in general in these analyses, it was preferred to use Bio13 precipitation of wettest month instead of Bio16 precipitation of wettest quarter, and Bio14 precipitation of driest month instead of Bio17 precipitation of the dry quarter.

It should be noted as a caveat that the bioclimatic concerns used here represent average values over many years and over wide temporal horizons (e.g., a month or a quarter of a year). These values probably define a species range over a lifetime or over several generations. It is fair to ask if the Maxent results given here can be checked by using laboratory experiments on a few individuals over a short period of time. Positive results would support the hypotheses; negative results are likely to leave the question open to more extensive research.

\subsection{Non-climatic parameters (raster layers)}

Although climate influences are the major factors in controlling the distribution of living species, it important to try other inputs that might be vital in determining limits to species ranges. As the project went on, more of these were added to the mix of inputs (Table 3). All were tested, but not all were used in all of the models for different species. 
Table 3. Non-bioclimatic concerns used as Maxent input layers.

\begin{tabular}{|l|l|}
\hline dem & Digital Elevation Model/Topography \\
\hline dem_acc & Hydrological Accumulation (water flow) from DEM \\
\hline dem_3up & Accumulation of 3 or greater cells from dem_acc \\
\hline dem_morph & Morphology (Landforms) derived from dem \\
\hline dem_order & Stream Order (Strahler) derived from dem_acc \\
\hline dem_orderO & $\begin{array}{l}\text { Stream Order O (Strahler) meaning not a stream } \\
\text { derived from dem_acc }\end{array}$ \\
\hline dem_upland & Upland Landform only derived from dem_morph \\
\hline fao_soils & $\begin{array}{l}\text { Soil types from the UN Food and Agricultural } \\
\text { Organization }\end{array}$ \\
\hline gaplc & Land Cover from the GAP project \\
\hline globlc & Land Cover from the United Nations \\
\hline natgaplu_mod & Simplified Land Cover influences decreased \\
\hline ornl_forest_type & Forest Types from Oak Ridge National Laboratory \\
\hline physiographic_regions & Physiographic Regions \\
\hline
\end{tabular}

One result that soon became obvious was that if one of these additional parameters did not vary smoothly over the study area, it had little or no influence in determining a threshold. An example would be the land form data layer. Uplands and valleys occur in Florida and Ohio, so this layer had no input to defining a range threshold. Instead, it would provide interesting detail within the range. On the other hand, some parameters might vary somewhat smoothly over a large area; for example, soils might be considered a combination of geology (a parameter that does not vary smoothly) and climate (which then might make it a redundant input). The end result is that a great deal of testing led to the conclusion that the nonbioclimatic parameters were never very important inputs for determining spatial range limits for the species investigated. 


\section{$5 \quad$ Procedure and Testing}

\subsection{Procedure}

The following steps were carried out for each species.

1. The traditional range of the particular species was found and translated into a geographic information system (GIS) (vector) format.

2. A file containing the county sightings was translated to GIS (point) format to be used as Maxent sample locations.

3. A series of tests of these alternatives was carried out to identify which set of conditions would be most likely to provide a range compatible with the traditional range.

4. Maxent was run 15 times, the results were averaged, ${ }^{*}$ and a general discussion of the results was developed.

5. An examination and discussion of the importance of each of the parameters to the final probability model.

6. The most important coordinated marginal response curves were examined and discussed.

7. From the most important coordinated marginal response curves, bioclimatic thresholds were extracted.

8. The important bioclimatic thresholds were spatially identified and discussed.

\subsection{Testing of alternatives}

The greatest amount of effort expended in this research was in trying to determine the best combination of input layers to submit for the final multi-run of the Maxent program. Several test alternatives were pursued, usually in an attempt to determine which combination would provide a probability distribution outcome that would best match the sense of the traditional range. The difference between a single test run and the corresponding multi-model run were always small, so the tests were taken to be sufficiently representative of the final model.

\footnotetext{
* The model was run once, then 15 times, then 21 times and averaged the results for $K$. subrubrum. The range distribution of the Mud Turtle was little changed among the single run, the 15 runs, and the 21 runs. Therefore for purposes here, the results of the 15 run models will be reviewed.
} 
Instead of presenting all the tests for each of the species (as the procedure for each varied based on its individual habitat requirements) in the Appendix, the process and outcome was presented by using one species (S. pygaea) as an example for the others.

The conclusion from this effort is that on the whole, it was not necessary to present all the test results. During a Maxent run, the program statistics would determine which input layers were the most important. Further layers other than the bioclimatic inputs never were shown to be important or to be spatially determining for the range extent (in this case identifying that at the 0.1 probability level). Additional layers increased the local detail within the range but had little influence in modifying the 0.1 probability boundary. 


\section{Identifying Spatial Thresholds for each Species}

\subsection{Chicken Turtle (Deirochelys reticularia)}

\subsubsection{County data}

County names based on a recent study (Buhlmann 2009) were received in a Microsoft Excel file.

\subsubsection{Traditional range map}

The traditional range map was derived from the map (created June 2008) presented on the NatureServe website.

\subsubsection{Critical mapping guidance issues}

D. reticularia always resides near water (about $0.165 \mathrm{~km}$ ) and often travels overland. Therefore, distance from small streams and small water bodies is important.

\subsubsection{Final 15-run results}

The average omission rate for $D$. reticularia shows a wider one standard deviation spread than was evident for K. Subrubrum. For the measure called the area under curve (AUC), the larger its value, the better the model is at predicting the distribution suggested in the test sample of the data model. The mean AUC for $D$. reticularia was much higher (0.965) than for $K$. Subrubrum (at 0.908), so the model for D. reticularia is considered more descriptive. The range is well defined and coordinates reasonably with the NatureServe range map. The accumulation layer was at the very bottom of the list of important inputs in determining the range. Locally, the accumulation layer is important in enhancing the better-quality areas, but it barely influences range. In all jackknife tests, the accumulation input alone explained the turtle distribution the poorest, while all climate layers contributed much more to the probability distribution.

Figure 1 shows the difference between the Maxent distributions at the 0.1 probability as marked by the dotted blue line to the traditional (NatureServe) range marked by the dashed yellow/black line. They are similar ex- 
cept that Maxent tends to be more inclusive, particularly in northern Mississippi and central Georgia. The Maxent range includes Fort Gordon, Fort Bragg, Fort Jackson, Fort Hood, and Camp Bullis, while the traditional range does not.

Figure 1. Darker red is better Chicken Turtle range. The blue outline is the 0.1 probability in the Maxent 15 runs model.

The yellow line is the traditional range.

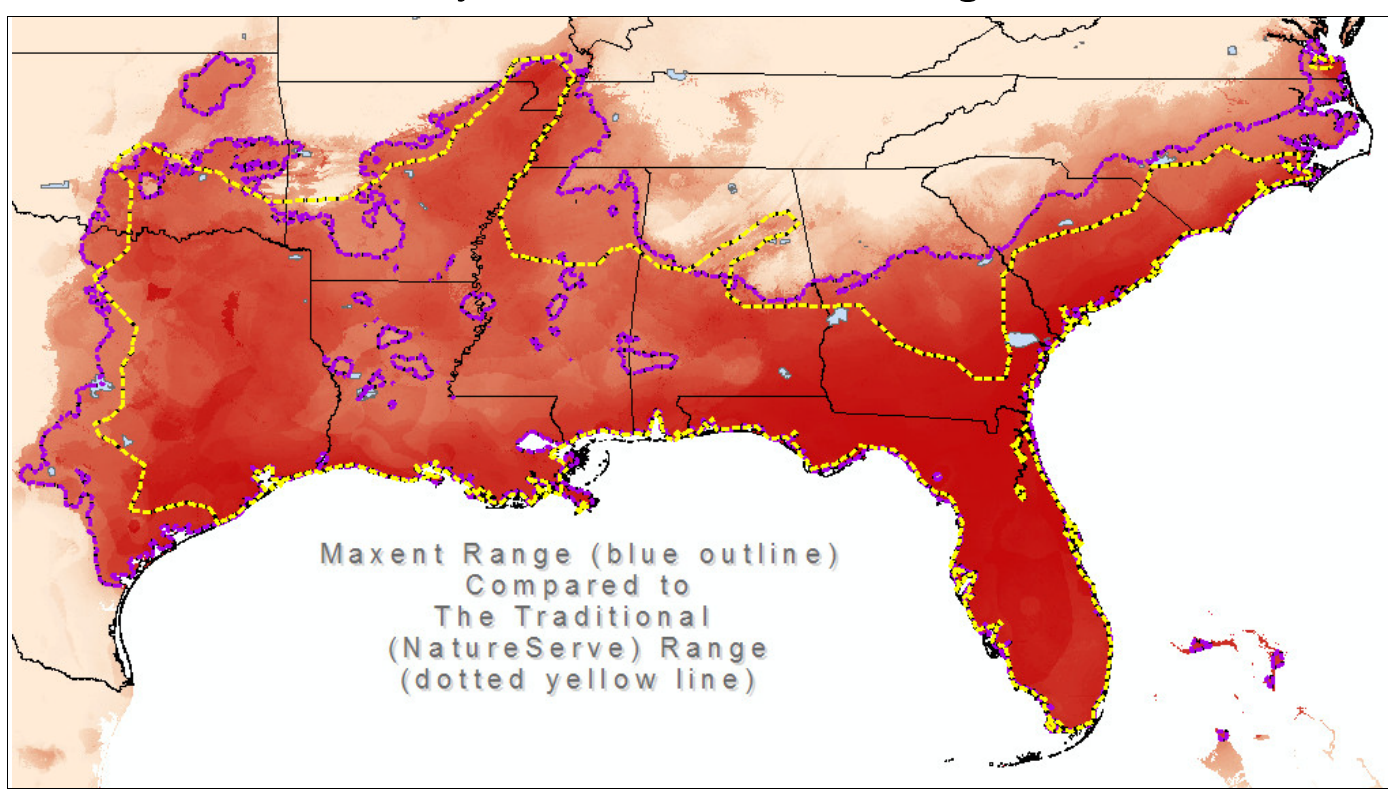

In the 15-run model, the standard deviation was calculated for all the different model runs (Figure 2). The histogram of the color table was exaggerated to show the highest deviations (i.e., those locations that varied the most among the 15 models). Figure 2 shows that some northern edges are variable, but so are some of the habitat interior areas. So in general, the discrepancies between the traditional and Maxent ranges seem only marginally related to the standard deviations of the 15 model runs. There is almost no variation for northern Mississippi, so that area should almost certainly be Chicken Turtle habitat. There is more variability in the questionable central-Georgia region. 
Figure 2. Standard deviations of the 15 model runs for $D$. reticularia.

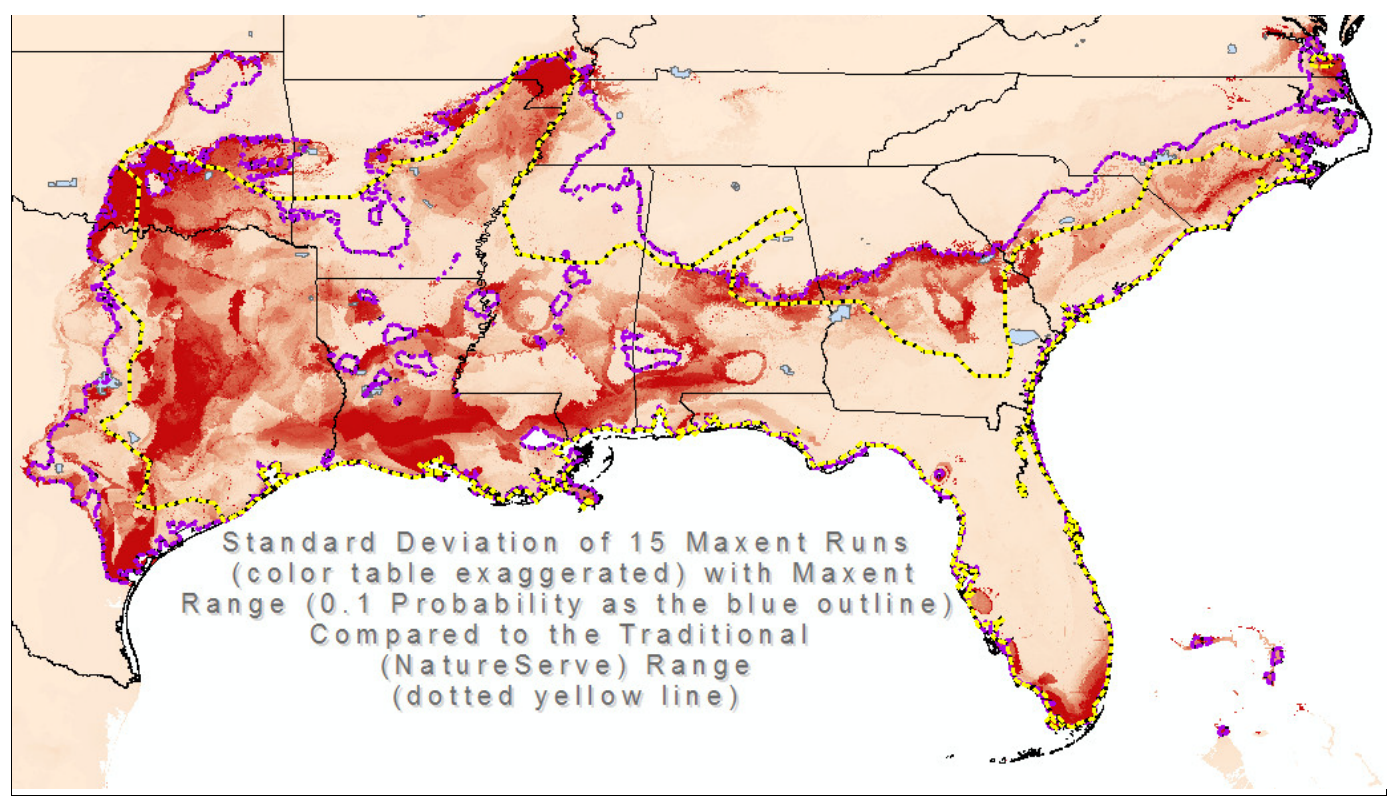

6.1.4.1 Variable importance averaged from 15 model runs for Chicken Turtle

Table 4 shows that mean temperature of the warmest quarter, precipitation of the dry quarter, annual temperature, precipitation of the warmest quarter and precipitation of the wettest month are the most important concerns for the Chicken Turtle. They account for $86.5 \%$ of the Maxent model. No matter what, mean temperature of warmest quarter, precipitation of warmest quarter, and precipitation of wettest month will always be among the top five concerns. Precipitation of driest quarter and annual mean temperature may or may not be among the most important concerns. None of the other bioclimatic concerns have the potential to contribute more than $5.4 \%$, so this cut off for the top at $8.9 \%$ contribution is logical. Thus, the mean temperature of the summer is certainly a controlling factor for the Chicken Turtle, and the minimum winter rain and a specific yearly temperature range probably are also. 
Table 4. Variable importance averaged from 15 model runs for Chicken Turtle.

\begin{tabular}{|l|r|r|r|r|}
\hline Variable & $\begin{array}{c}\text { Percent } \\
\text { Contribution }\end{array}$ & $\begin{array}{c}\text { Permutation } \\
\text { Importance }\end{array}$ & $\begin{array}{c}\text { Contribution } \\
\text { Range Low }\end{array}$ & $\begin{array}{c}\text { Contribution } \\
\text { Range High }\end{array}$ \\
\hline Bio10_MeanTempWarmQtr & 33.2 & 0.5 & 32.7 & 33.7 \\
\hline Bio17_PrecipDryQtr & 21.9 & 18.3 & 3.6 & 40.2 \\
\hline Bio1_AnnTemp & 11.9 & 63.1 & 0.0 & 75.0 \\
\hline Bio18_PrecipWarmQtr & 10.6 & 1.9 & 8.7 & 12.5 \\
\hline Bio13_PrecipWetMnth & 8.9 & 0.1 & 8.8 & 9.0 \\
\hline Bio20_ConsecDryMnth & 3.0 & 1.4 & 1.6 & 4.4 \\
\hline Bio4_TempSeasonality & 2.9 & 1.3 & 1.6 & 4.2 \\
\hline Bio8_MeanTempWetQtr & 1.7 & 0.6 & 1.1 & 2.3 \\
\hline Bio14_PrecipDryMnth & 1.5 & 0.8 & 0.7 & 2.3 \\
\hline Bio19_PrecipColdQtr & 0.8 & 0.4 & 0.4 & 1.2 \\
\hline Bio6_MinTempColdMnth & 0.8 & 0.4 & 0.4 & 1.2 \\
\hline Bio3_Isothermality & 0.7 & 4.7 & 0.0 & 5.4 \\
\hline Bio7_AnnTempRange & 0.6 & 0.8 & 0.0 & 1.4 \\
\hline Bio12_AnnPrecip & 0.5 & 0.3 & 0.2 & 0.8 \\
\hline Bio9_MeanTempDryQtr & 0.4 & 4.3 & 0.0 & 4.7 \\
\hline Bio5_MaxTempWarmMnth & 0.2 & 0.0 & 0.2 & 0.2 \\
\hline Bio11_MeanTempColdQtr & 0.2 & 0.1 & 0.1 & 0.3 \\
\hline Bio2_DiurnalRange & 0.2 & 0.3 & 0.0 & 0.5 \\
\hline Bio15_PrecipSeasonality & 0.1 & 0.2 & 0.0 & 0.3 \\
\hline Bio16_PrecipWetQtr & 0.1 & 0.4 & 0.0 & 0.5 \\
\hline dem_acc & 0.1 & 0.0 & 0.1 & 0.1 \\
\hline
\end{tabular}

\subsubsection{Coordinated marginal response curves}

A caveat is appropriate when dealing with the coordinated marginal response curves, because the curves represent the spread of the environmental data in which the turtle exists. The thresholds, however, may not be causal. That is, a bioclimatic concern may be related to a critical food source that only grows within the range indicated. So if the food source is removed but the climate remains unchanged, Maxent will still represent the species as being present, although the percentage of importance to the model will probably suffer. The five controlling factors for the Chicken Turtle are shown in Figure 3. 
Figure 3. Coordinated marginal response curves for Chicken Turtle.
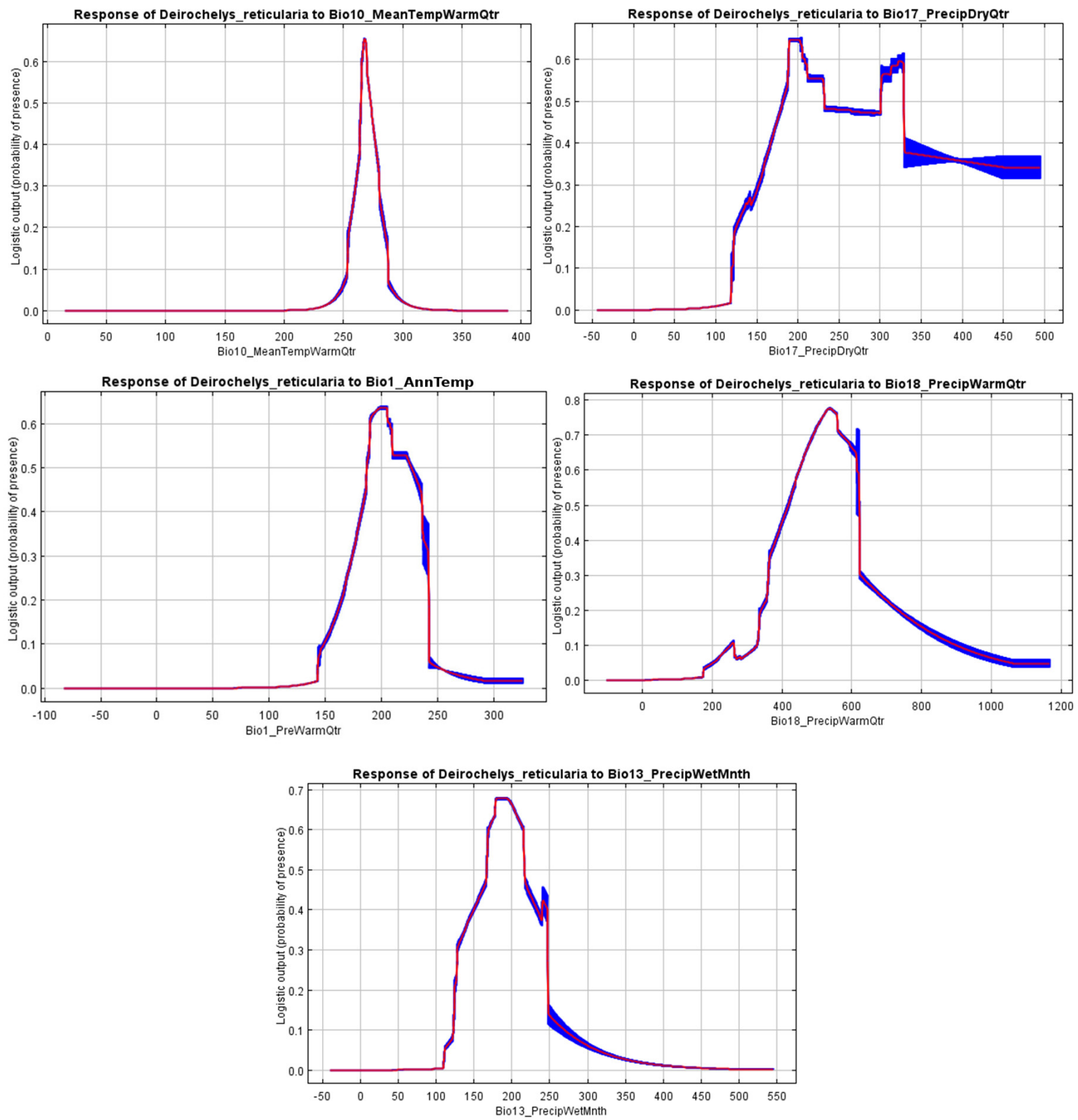

\subsubsection{Bioclimatic thresholds of the Chicken Turtle}

For this section concerning the Chicken Turtle and in all the following similar sections for each of the species studied, the probability level of 0.1 is used on each of these charts as the threshold (and this would coordinate with the 0.1 threshold used on the $D$. reticularia probability map (shown in Figure 1), to objectively define the results as shown in Table 5. It should be noted that in some cases, a threshold will be meaningless. For example, 
precipitation of driest quarter upper limit reflects the highest value found within the turtle's range, not that it cannot exist above this upper limit. Also important to note is the blue area in the coordinated marginal response curves above indicating one standard deviation. There is very little variation among the 15 models for these five top bioclimatic concerns, so the values in Table 5 are very stable.

Table 5. Bioclimatic thresholds for the occurrence of the Chicken Turtle.

\begin{tabular}{|c|c|c|c|c|c|c|c|c|}
\hline \multicolumn{9}{|c|}{ Bioclimatic Thresholds For the Occurence of Deirochelys reticularia (Chicken Turtle) } \\
\hline $\begin{array}{l}\text { Bio } \\
\text { Num }\end{array}$ & Bioclimatic Concern & $\begin{array}{c}\text { Lower } \\
\text { Threshold } \\
\text { (when } \\
\mathrm{P}=0.1 \text { ) }\end{array}$ & Severity & \begin{tabular}{|c|} 
Occurs \\
below \\
Threshold? \\
(Limiting?)
\end{tabular} & \begin{tabular}{|c}
$\begin{array}{c}\text { Upper } \\
\text { Threshold } \\
\text { (when } \\
\mathrm{P}=0.1 \text { ) }\end{array}$ \\
\end{tabular} & Severity & $\begin{array}{c}\text { Occurs } \\
\text { above } \\
\text { Threshold? }\end{array}$ & $\begin{array}{c}\% \\
\text { Importance } \\
\text { in Model }\end{array}$ \\
\hline $\mathrm{BIO10}$ & $\begin{array}{l}\text { Mean Temperature of } \\
\text { Warmest Quarter (deg C) }\end{array}$ & 25.5 & Extreme & No & 28.5 & Extreme & No & 33.2 \\
\hline $\mathrm{BIO17}$ & $\begin{array}{l}\text { Precipitation of Driest } \\
\text { Quarter }(\mathrm{mm})\end{array}$ & 120.0 & Extreme & No & None & & Yes & 21.9 \\
\hline $\mathrm{BIO1}$ & $\begin{array}{l}\text { Annual Mean Temperature } \\
\text { (deg C) }\end{array}$ & 15.0 & Extreme & No & 24.0 & Extreme & A little & 11.9 \\
\hline $\mathrm{BIO18}$ & $\begin{array}{l}\text { Precipitation of Warmest } \\
\text { Quarter }(\mathrm{mm})\end{array}$ & 329.0 & High & Barely & 900.0 & Low & A little & 10.6 \\
\hline $\mathrm{BIO13}$ & $\begin{array}{l}\text { Precipitation of Wettest } \\
\text { Month }(\mathrm{mm})\end{array}$ & 125.0 & Extreme & No & 250.0 & Low & Yes & 8.9 \\
\hline
\end{tabular}

The concern of the mean temperature of warmest quarter is a pointed peak. This suggests that the turtle has an optimum temperature centered at about $27.0^{\circ} \mathrm{C}$, and its survival falls off sharply when the summer temperatures are not within this range. Evidently the species is highly sensitive to this most important concern; it is also an indisputably important bioclimatic concern.

- The precipitation of driest quarter shows the turtle quickly begins to flourish when the rainfall rises above $120 \mathrm{~mm}$ minimum (in the southeastern United States this would normally be in the winter period). The Chicken Turtle does well at any amounts above this threshold.

- The concern of the annual mean temperature presents a range threshold from $15.0-24.0^{\circ} \mathrm{C}$. These thresholds are both high to severe, and they are meaningful as a potential survival test.

- Precipitation of warmest quarter exhibits a very high cutoff threshold at $329 \mathrm{~mm}$ (below which the Chicken Turtle will not survive well), and an upper limit of $624 \mathrm{~mm}$ at which survival precipitously plummets to a 0.3 probability and then more slowly falls to reach the 0.1 probability level. This suggests that the 0.3 level may be a more critical threshold for the turtle. Basically, above 0.3 the Chicken Turtle's survival changes slowly, decreasing to almost nothing. This means in the southeastern 
United States, summer rain amounts are important to the Chicken Turtle.

- Precipitation of wettest month shows the Chicken Turtle quickly begins to flourish when the rainfall rises above the $120 \mathrm{~mm}$ minimum. Since this is the same value found for precipitation of driest quarter, it is a real threshold in a shorter period of time. Therefore it is more restrictive, or it means the turtle does not exist outside of this amount of rainfall because something else caused by the rainfall is controlling the range of the species. In the southeastern United States, this rainfall would normally occur in the summer period. Since it is a water-loving animal, having more rain in the summer is unlikely to present problems unless the greater rainfall encourages another problem such as an enhanced detrimental fungus or bacteria infestation.

In summary, the Chicken Turtle's critical concerns really are at least $106 \mathrm{~mm}$ of rain in any three-month period, summer average temperature between $22.0^{\circ} \mathrm{C}$ and $29.0^{\circ} \mathrm{C}$, a winter low temperature above $-6.0^{\circ} \mathrm{C}$, and a yearly expected rainfall in the range of $80-1800 \mathrm{~mm}$.

\subsubsection{Spatially explicit thresholds of the Chicken Turtle}

To carry out the work in this section, it was assumed that the Maxentdefined range at the 0.1 probability level best represented the limits for the species. In fact, for several other species tested, the following limits were noted.

- The 0.1 probability level seems to coordinate well with traditional range distributions.

- Once the 0.1 probability level is passed, usually the probability drops dramatically.

Thus the 0.1 probability level seems to be a natural threshold. In this section, it was determined at what level the bioclimatic concern best matched that 0.1 probability level. In fact, usually the best match was extremely close to the 0.1 level for each of the individual bioclimatic concerns, as shown by the threshold charts above.

The mean temperature of warmest quarter at the $25.5{ }^{\circ} \mathrm{C}$ threshold defines the northern boundary almost exactly from South Carolina to central Arkansas (Figure 4). The upper threshold of $28.0{ }^{\circ} \mathrm{C}$ seems to have no influence on the boundary definition. 
Figure 4. The mean temperature of warmest quarter at the $25.5^{\circ} \mathrm{C}$ threshold for the Chicken Turtle.

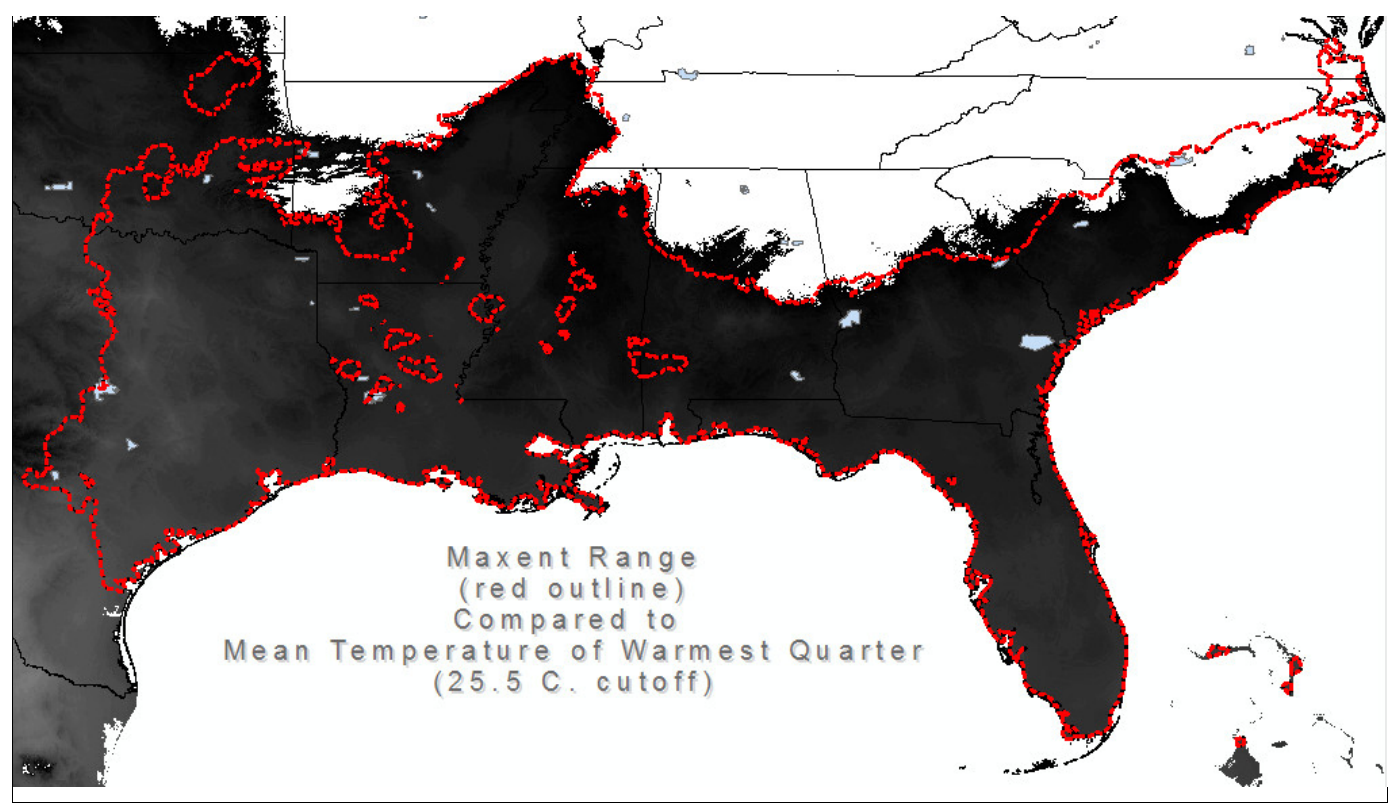

In Texas and Oklahoma, it is clear that the western range of the Chicken Turtle is controlled by precipitation of driest quarter at the $120 \mathrm{~mm}$ threshold (Figure 5).

Figure 5. The western range of the Chicken Turtle is controlled by precipitation of driest quarter.

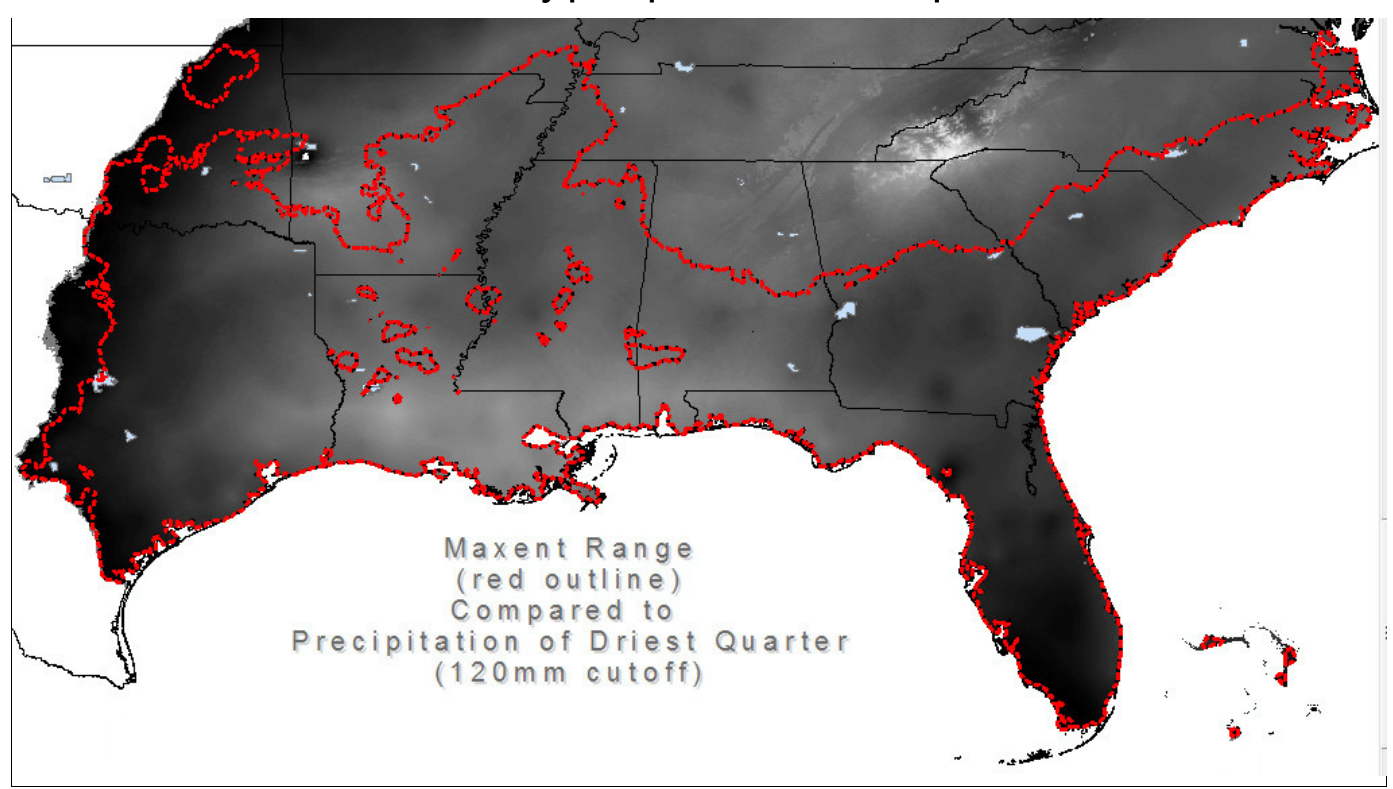

The third most important concern, annual mean temperature, only roughly relates to the northern limit of the Chicken Turtle at the $15.0{ }^{\circ} \mathrm{C}$ cut off defined in the table by the 0.1 probability level (Figure 6). The upper limit 
of $24{ }^{\circ} \mathrm{C}$ covers the entire region, so it has no relevance in defining the range extent.

Figure 6. Annual mean temperature only roughly relates to the northern limit of the Chicken Turtle at $15.0^{\circ} \mathrm{C}$.

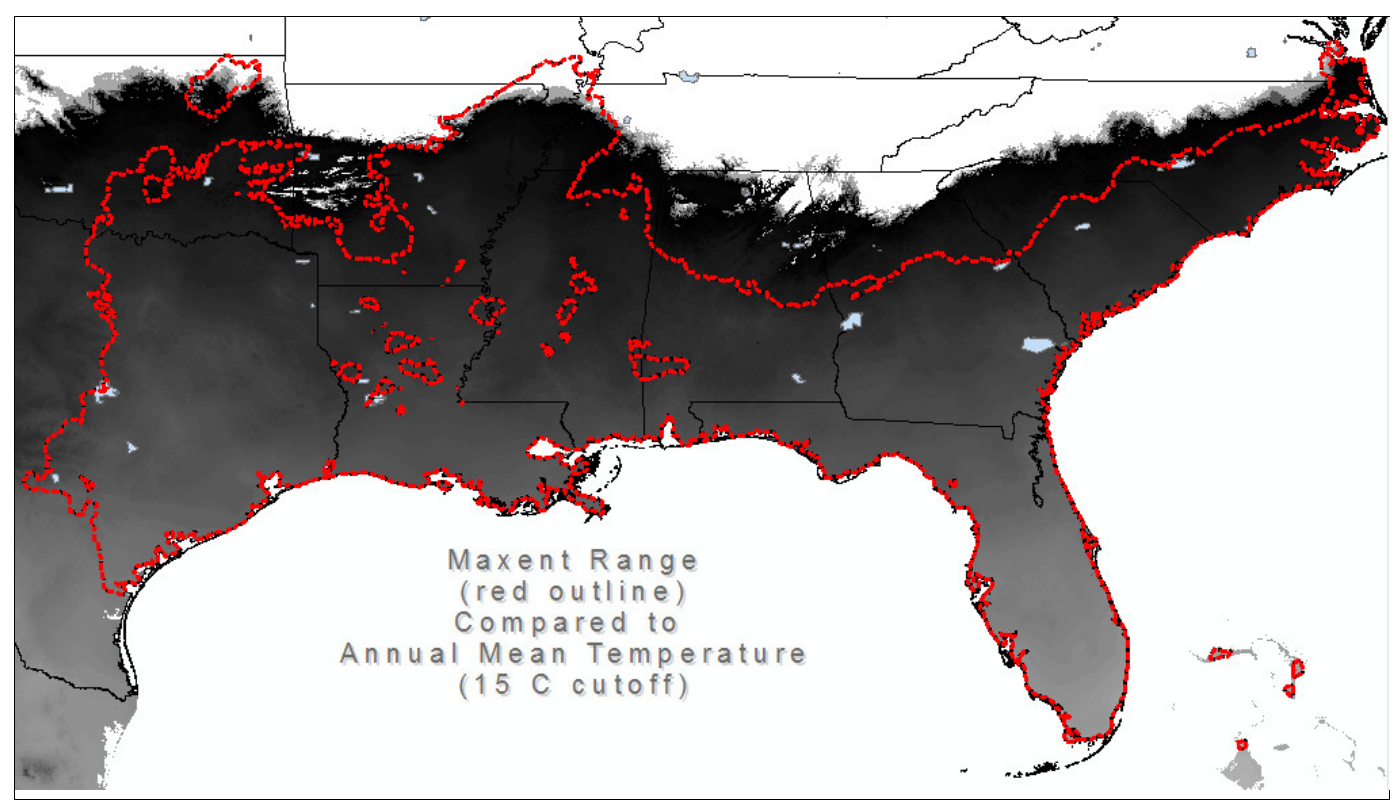

Precipitation of warmest quarter is the fourth highest in importance among the bioclimatic concerns. At the 0.1 probability level, the corresponding value would be $330 \mathrm{~mm}$ of summer rain (Figure 7). However, when presented as a spatial distribution, the $360 \mathrm{~mm}$ level exhibited the best correlation with the Chicken Turtle range through the mid-Carolinas. A $360 \mathrm{~mm}$ level puts the probability level at 0.2 rather than the 0.1 level. Above the observation was made that for the upper threshold, a 0.3 probability might be more pertinent. A case might be made for the lower limit also to be at the 0.3 level, as the slope is still very steep until about the 0.37 probability. Furthermore, even in the Carolinas the match is not impressive and the importance of the precipitation of warmest quarter is only $11.9 \%$, so forcing the cut off to 0.3 may not gain much in the ability to explain the species range; on the other hand, the proposed level could also be only a coincidence. A greater level of importance would make a variation on the standard probability level more important. For this bioclimatic concern, it probably is not worth the extra justifications. Thus it seems that the contribution of the precipitation of warmest quarter to the Chicken Turtle distribution is marginal at best. 
Figure 7. The 0.1 probability level corresponds with $330 \mathrm{~mm}$ of summer rain.

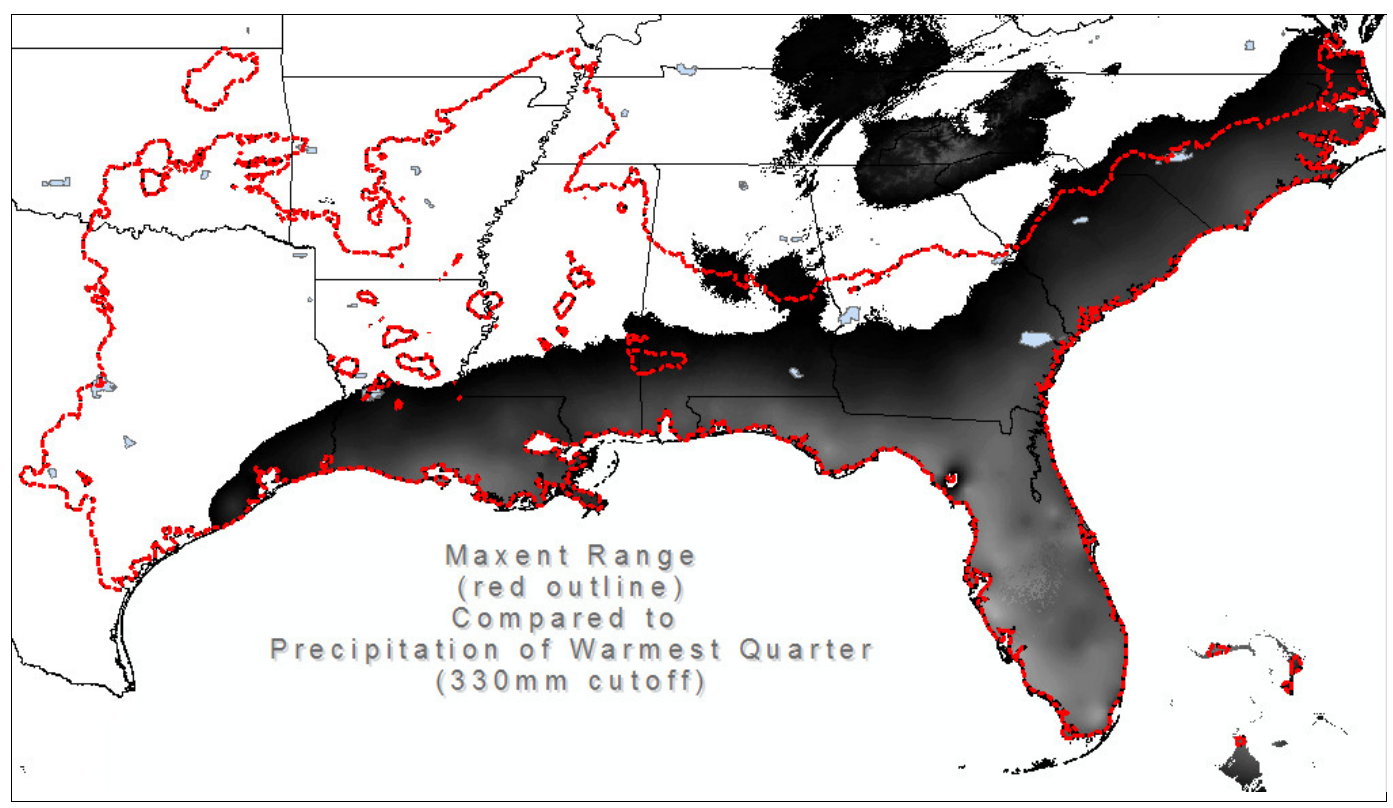

Precipitation of wettest month is the fifth-highest importance bioclimatic concern. The discussion here is similar to the previous concern, precipitation of warmest quarter. At the 0.1 probability level, the corresponding value would be $120 \mathrm{~mm}$ of summer rain (Figure 8)-that is roughly a little more than one-third of the amount for the three-month (quarter) evaluation above. Although rain during wettest month and rain during warmest quarter might be considered redundant for the U.S. Southeast, it is not necessarily so elsewhere. In this case, the combined importance of the two, if they are independent, would be about 20\%. Since in this case they are likely redundant, each would not be additive. For precipitation of wettest month when presented as a spatial distribution, the $129 \mathrm{~mm}$ level exhibited the best correlation with the Chicken Turtle range through the midCarolinas. This is almost exactly one-third of the $360 \mathrm{~mm}$ level of the proposed revised precipitation of warmest quarter threshold, further suggesting these two concerns are redundant. The $129 \mathrm{~mm}$ level puts the probability level below 0.1, so precipitation of warmest month seems less meaningful than precipitation of warmest quarter. Again, even in the Carolinas the match is not impressive and the importance of the precipitation of wettest month is only $8.9 \%$. So forcing a cutoff change may not gain much in the ability to explain the species range, and the proposed level could also be only a coincidence. For this bioclimatic concern, it probably is not worth the extra justifications. Thus it seems that the contribution of precipitation of wettest month to the Chicken Turtle distribution is marginal at best as well as being redundant. For these reasons, it is proposed 
that precipitation of wettest month be dropped from the most important bioclimatic concerns. That means the top four concerns contribute $77.6 \%$ to the model.

Figure 8. At the 0.1 probability level, the corresponding value would be $120 \mathrm{~mm}$ of summer rain, which poorly matches the turtle's range.

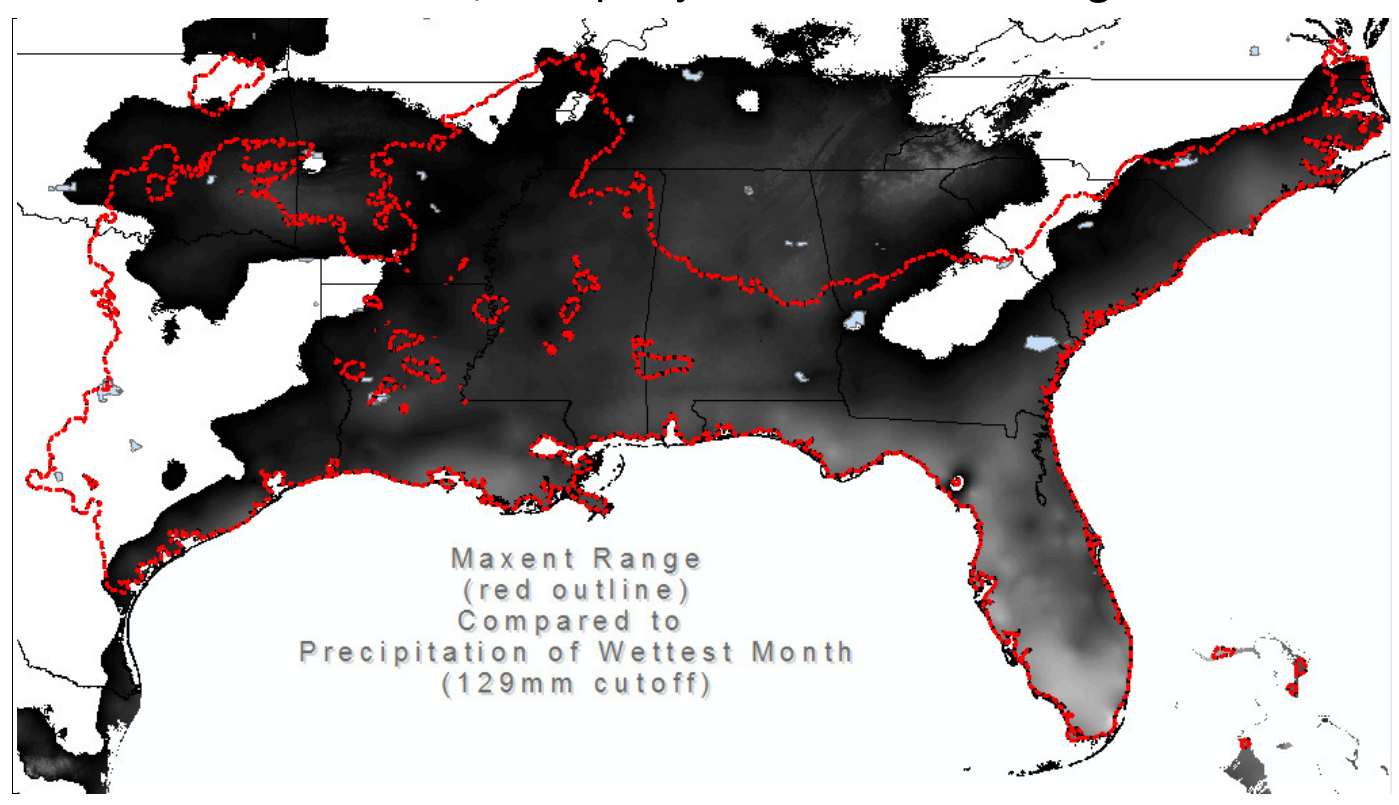

\subsubsection{Spatial conclusions for the Chicken Turtle}

In summary, after this spatial review the suggestion is that only the first two bioclimatic concerns are significant in clearly defining the Chicken Turtle's range. Spatially, the controlling threshold factors for the Chicken Turtle are a $25.5{ }^{\circ} \mathrm{C}$ threshold of mean temperature of warmest quarter for the northern limit, and $120 \mathrm{~mm}$ minimum precipitation of driest quarter along the western edge of its range. There seems to be no clear controlling factor that defines the range from North Carolina to mid-South Carolina, though there exist a few candidates. There no candidates that exist to define the northern boundary from central Arkansas to central Oklahoma.

\subsection{Eastern Mud Turtle (Kinosternon subrubrum)}

\subsubsection{County data}

County names were received in a Microsoft Excel file based on a recent study (Buhlmann 2009). 


\subsubsection{Traditional range map}

The traditional range map was derived from the map (created June 2008) presented on the NatureServe website.

\subsubsection{Critical mapping guidance issues}

Eastern Mud Turtle always resides near water (about $0.5 \mathrm{~km}$ ) but travels overland beyond its home watershed (at least $2 \mathrm{~km}$ and as great as $8 \mathrm{~km}$ ). Therefore, distance from small streams and small water bodies is important and may be reflected in the hydrology accumulation map layer.

\subsubsection{Final 15-run results}

The model was run 15 times, and the results were averaged (Figure 9).

Figure 9. Red is the Eastern Mud Turtle range above the 0.1 probability level, and the yellow outline is the traditional range.

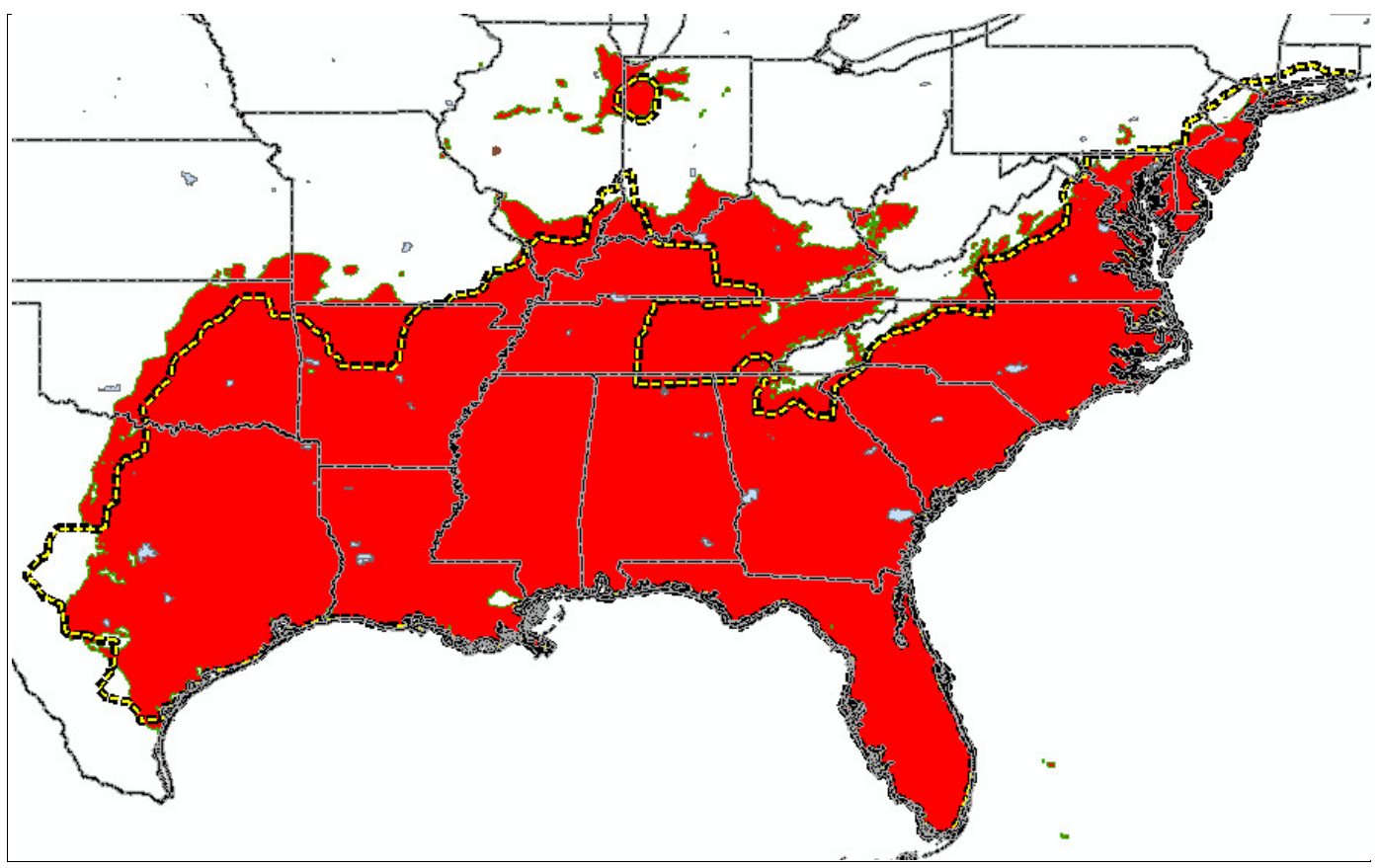

For the 15 model runs, the standard deviation was calculated and Figure 10 presents that data. The histogram of the color table was exaggerated to show the highest deviations (i.e., those locations that varied the most among the 15 models). Figure 10 shows those areas that are on the edge of the distributions are the most variable. Particularly note that the outlier population just south of Chicago falls into the highest standard deviation distribution. However, the highest values on the standard deviation are 
about a magnitude less than the corresponding Maxent probability, so even the highest standard deviations change the average distribution only minimally.

Figure 10. The standard deviation among 15 model runs for the Eastern Mud Turtle.

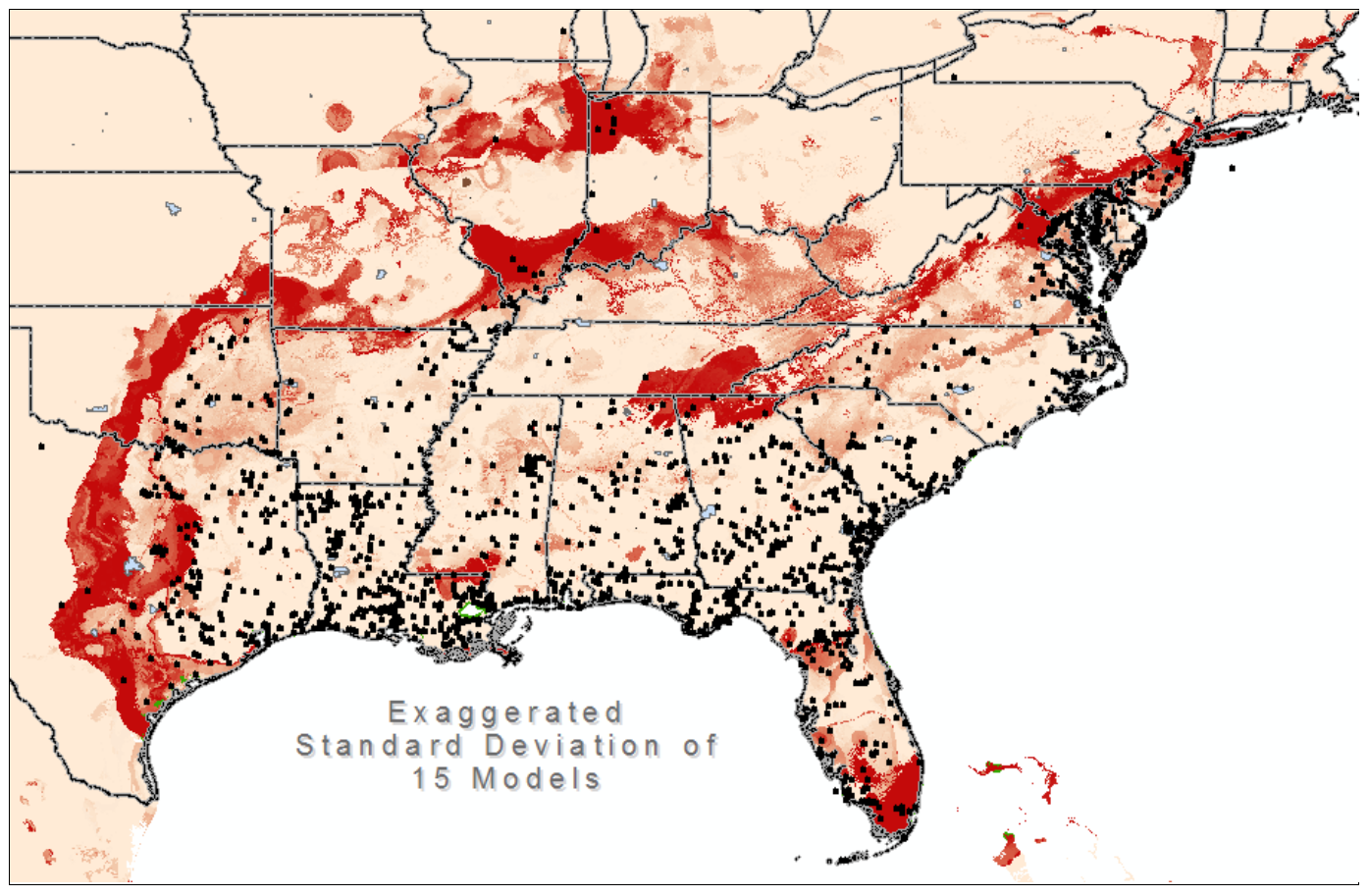

6.2.4.1 Variable importance averaged from 15 model runs

Table 6 shows that the most important concerns for the Mud Turtle are precipitation of driest quarter, mean temperature of warmest quarter, minimum temperature of coldest month, and annual precipitation; together they account for $88.3 \%$ of the Maxent model. No matter what, both precipitation of the driest quarter and mean temperature of warmest quarter will always be among the top four concerns. Minimum temperature of coldest month may always be the third most important concern; or it may not be of any concern. Only annual precipitation could possibly rise to $16.9 \%$ contribution, but it could feasibly contribute zero to the model. It is feasible that isothermality could become the third or fourth concern, but it could also be of no consequence at all. Thus, potential lack of precipitation and the mean temperature of the summer are certainly controlling factors for the Mud Turtle, and the minimum winter temperature probably is also. 
Table 6. Variable Importance, averaged from 15 model runs for Eastern Mud Turtle.

\begin{tabular}{|l|r|r|r|r|}
\hline Variable & $\begin{array}{c}\text { Percent } \\
\text { Contribution }\end{array}$ & $\begin{array}{c}\text { Permutation } \\
\text { Importance }\end{array}$ & $\begin{array}{c}\text { Contribution } \\
\text { Range Low }\end{array}$ & $\begin{array}{c}\text { Contribution } \\
\text { Range High }\end{array}$ \\
\hline Bio17_PrecipDryQtr & 33.5 & 19.1 & 14.4 & 52.6 \\
\hline Bio10_MeanTempWarmQtr & 27.3 & 15.9 & 11.4 & 43.2 \\
\hline Bio6_MinTempColdMnth & 20.0 & 22.6 & 0.0 & 42.6 \\
\hline Bio12_AnnPrecip & 7.5 & 9.4 & 0.0 & 16.9 \\
\hline Bio20_ConsecDryMnth & 3.8 & 0.6 & 3.2 & 4.4 \\
\hline Bio3_Isothermality & 1.5 & 7.7 & 0.0 & 9.2 \\
\hline Bio4_TempSeasonality & 1.5 & 1.5 & 0.0 & 3.0 \\
\hline Bio1_AnnualMeanTemp & 1.0 & 1.5 & 0.0 & 2.5 \\
\hline Bio7_AnnTempRange & 0.8 & 5.6 & 0.0 & 6.4 \\
\hline Bio8_MeanTempWetQtr & 0.6 & 0.2 & 0.4 & 0.8 \\
\hline Bio2_DiurnalRange & 0.5 & 6.1 & 0.0 & 6.6 \\
\hline Bio5_MaxTempWarmMnth & 0.5 & 0.6 & 0.0 & 1.1 \\
\hline Bio19_PrecipColdQtr & 0.5 & 0.6 & 0.0 & 1.1 \\
\hline Bio11_MeanTempColdQtr & 0.4 & 1.8 & 0.0 & 2.2 \\
\hline Bio15_PrecipSeasonality & 0.3 & 0.9 & 0.0 & 1.2 \\
\hline Bio9_MeanTempDryQtr & 0.3 & 1.9 & 0.0 & 2.2 \\
\hline Bio18_PrecipWarmQtr & 0.2 & 3.1 & 0.0 & 3.3 \\
\hline dem_acc & 0.0 & 0.1 & 0.0 & 0.1 \\
\hline Bio16_PrecipWetQtr & 0.0 & 0.3 & 0.0 & 0.3 \\
\hline Bio13_PrecipWetMnth & 0.0 & 0.8 & 0.0 & 0.8 \\
\hline
\end{tabular}

\subsubsection{Coordinated marginal response curves}

The charts for the four controlling factors are shown in Figure 11. 
Figure 11. Coordinated marginal response curves for Eastern Mud Turtle.
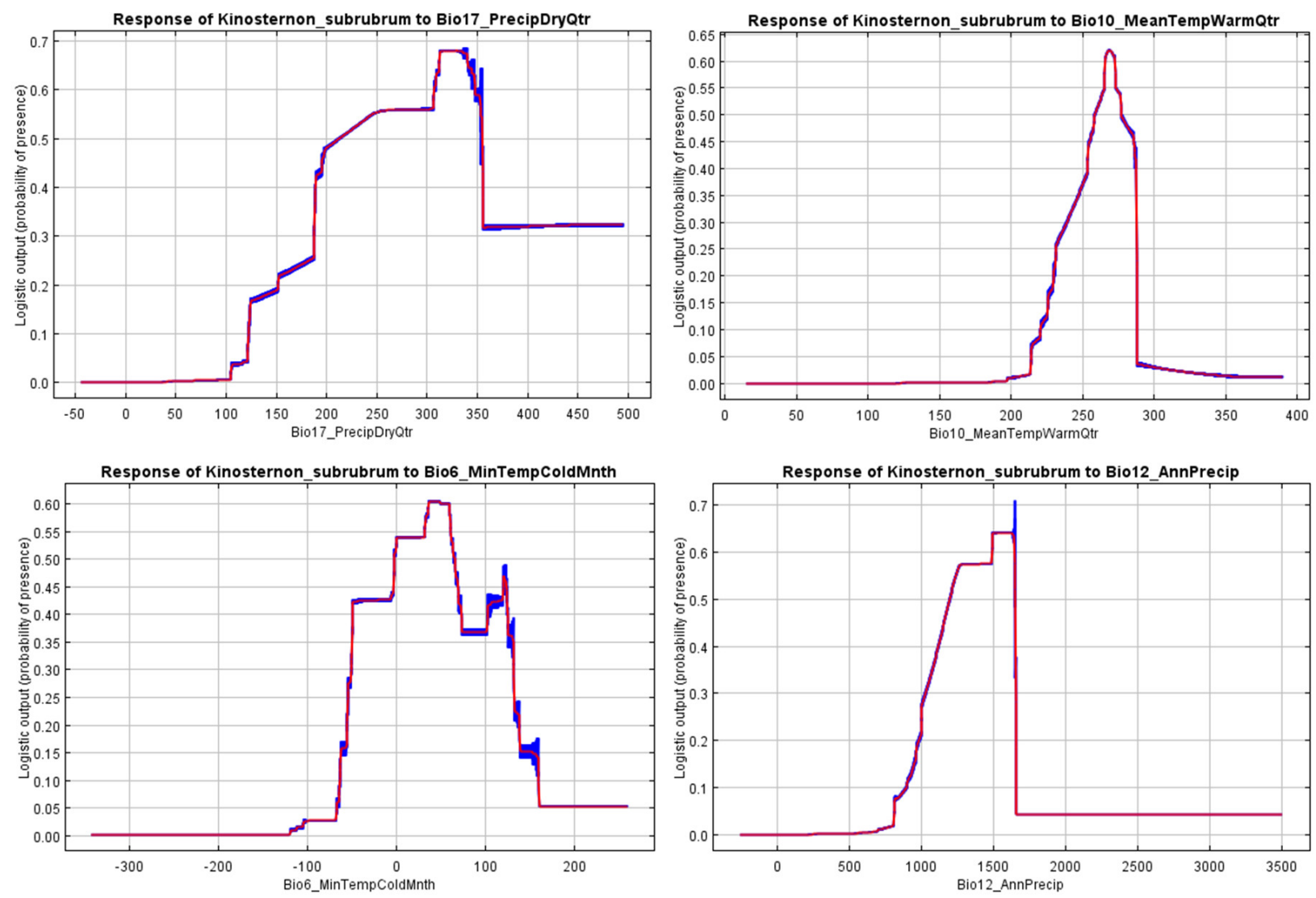

\subsubsection{Bioclimatic thresholds of the Eastern Mud Turtle}

Using the standard probability level of 0.1 on each of these charts as the threshold (coordinating with the 0.1 threshold used on the K. subrubrum probability map in Figure 8), bioclimatic thresholds are objectively defined in Table 7. It might be noted that the blue area, indicating one standard deviation, is very small. This shows there is very little variation among the models for these four top bioclimatic concerns, and the values in Table 7 are very stable. 
Table 7. Bioclimatic thresholds of the Eastern Mud Turtle.

\begin{tabular}{|l|l|r|r|r|r|r|r|r|}
\hline \multicolumn{2}{|c|}{ Bioclimatic Thresholds For the Occurance of Kinosternon subrubrum (Mud Turtle) } \\
\hline Num & \multicolumn{1}{|c|}{ Bioclimatic Concern } & $\begin{array}{c}\text { Lower } \\
\text { Threshold } \\
\text { (when } \\
\mathrm{P}=0.1)\end{array}$ & Severity & $\begin{array}{c}\text { Occurs } \\
\text { below } \\
\text { Threshold? } \\
\text { (Limiting?) }\end{array}$ & $\begin{array}{c}\text { Upper } \\
\text { Threshold } \\
\text { (when P=0.1) }\end{array}$ & $\begin{array}{l}\text { Severity } \\
\text { Occurs } \\
\text { above } \\
\text { Threshold? }\end{array}$ & $\begin{array}{c}\text { Importance } \\
\text { in Model }\end{array}$ \\
\hline BI017 & $\begin{array}{l}\text { Precipitation of Driest Quarter } \\
\text { (mm) }\end{array}$ & 106.0 & Moderate & No & None & - & Yes & 33.5 \\
\hline BI010 & $\begin{array}{l}\text { Mean Temperature of Warmest } \\
\text { Quarter (deg C) }\end{array}$ & 22.0 & High & No & 28.5 & Extreme & No & 27.3 \\
\hline BI06 & $\begin{array}{l}\text { Min Temperature of Coldest } \\
\text { Month (deg C) }\end{array}$ & -6.0 & Extreme & No & Meaningless & Very High & Barely & 20 \\
\hline
\end{tabular}

- The concern of precipitation of driest quarter suggests that over a longer period, the turtle can survive only at the lower threshold of $106 \mathrm{~mm}$, suggesting that some precipitation is expected to occur during the seasonal time interval.

- The mean temperature of warmest quarter shows the Mud Turtle does best around $27^{\circ} \mathrm{C}$. The turtle is not used to warmest multi-month average temperatures below $22{ }^{\circ} \mathrm{C}$ or above $28.5{ }^{\circ} \mathrm{C}$. Since this relates to the mean temperature over a long period, mean temperature of warmest quarter is not a good test for Mud Turtle survival.

- The concern of minimum temperature of coldest month presents a severe lower threshold of $-6.0^{\circ} \mathrm{C}$. This threshold is both severe and meaningful as a potential survival test.

- Annual precipitation exhibits a very high cutoff threshold at $800 \mathrm{~mm}$, below which the Mud Turtle does not occur, and an upper limit of $1300 \mathrm{~mm}$, above which it also does not occur.

In summary, the Mud Turtle's critical concerns are at least $106 \mathrm{~mm}$ of rain in any three-month period, summer average temperature between $22{ }^{\circ} \mathrm{C}$ and $29{ }^{\circ} \mathrm{C}$, a winter low temperature above $-6{ }^{\circ} \mathrm{C}$, and maybe a yearly expected rainfall in the range of $800-1700 \mathrm{~mm}$.

\subsubsection{Spatially explicit thresholds of the Eastern Mud Turtle}

Precipitation of driest quarter at the $106 \mathrm{~mm}$ threshold defines the western boundary almost exactly (Figure 12). 
Figure 12. Precipitation of driest quarter at the $106 \mathrm{~mm}$ threshold for the Eastern Mud Turtle.

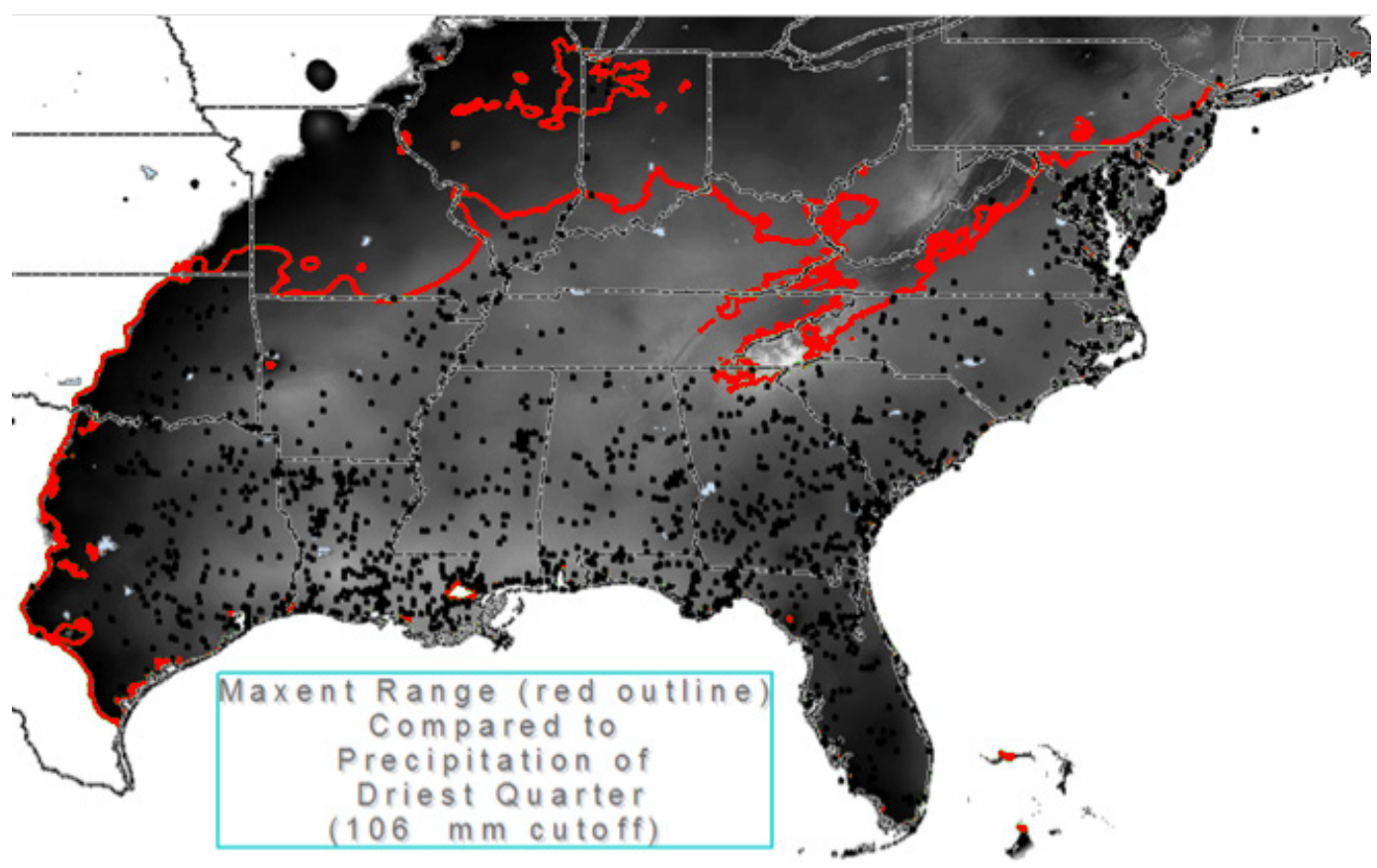

It is clear that in the east to mid-Georgia, the range of the Mud Turtle is controlled by mean temperature of warmest quarter (Figure 13). There is almost a 1:1 correspondence in the edges. It controls the turtle range along the Appalachians in Virginia.

Figure 13. Mean temperature of warmest quarter for the Eastern Mud Turtle.

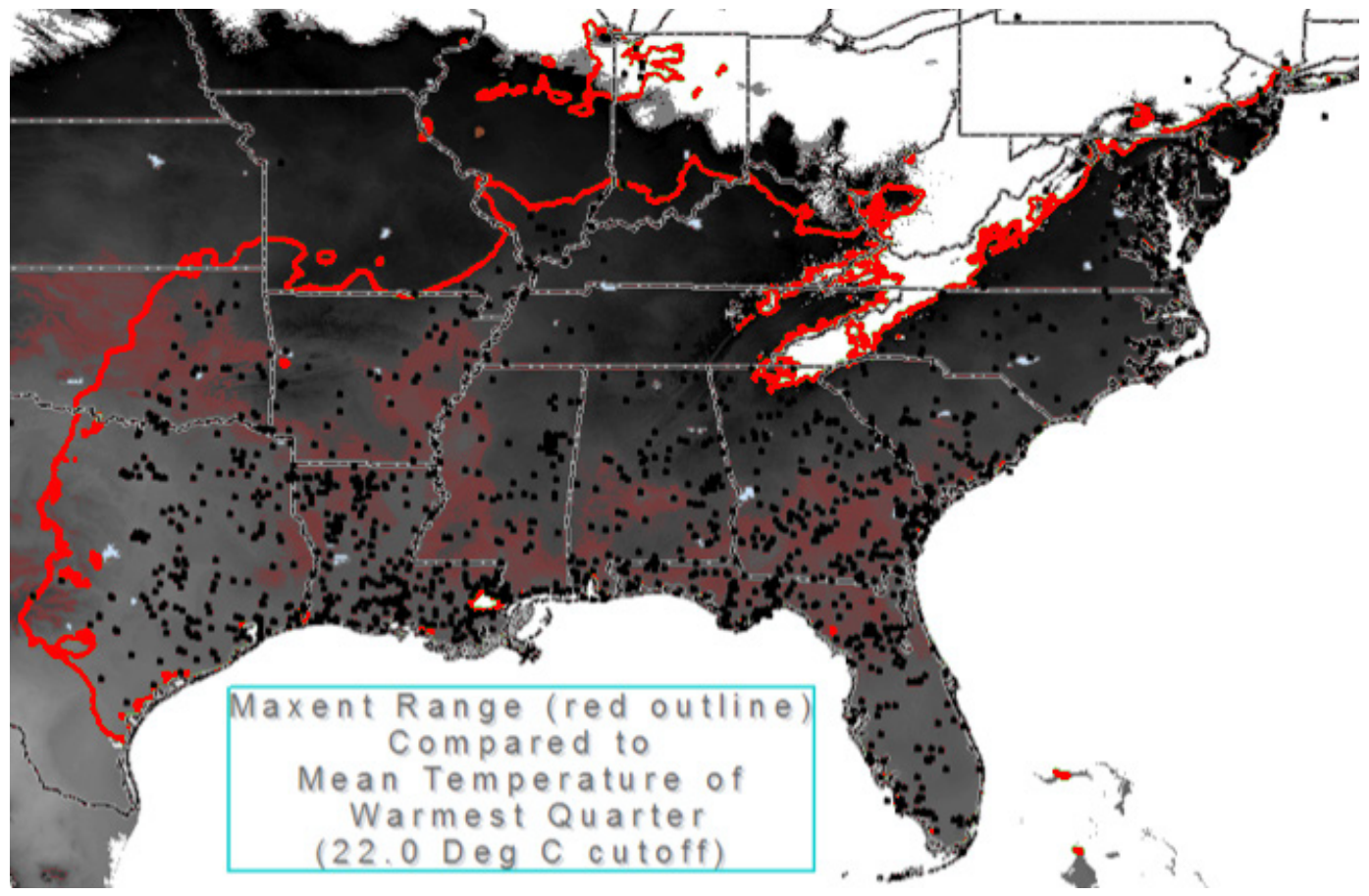


The third most important concern, minimum temperature of coldest month, exactly controls the northern limit of the Mud Turtle at the $-6.0^{\circ} \mathrm{C}$ cut off, defined in Table 7 by the 0.1 probability level (Figure 14). In this case, the coincidence is so remarkable that one might believe it is more important than mean temperature of warmest quarter. Although Table 7 suggests that this bioclimatic concern potentially has no relevance, it is clear from this image that it controls most of the northern boundary of the Mud Turtle. According to Table 7, mean temperature of warmest quarter could drop as low as $11.4 \%$ contribution to the model or this concern could be as great as $42.2 \%$. Because of this, it is feasible that this bioclimatic concern might be second or even first in importance.

Figure 14. Minimum temperature of coldest month for the Eastern Mud Turtle.

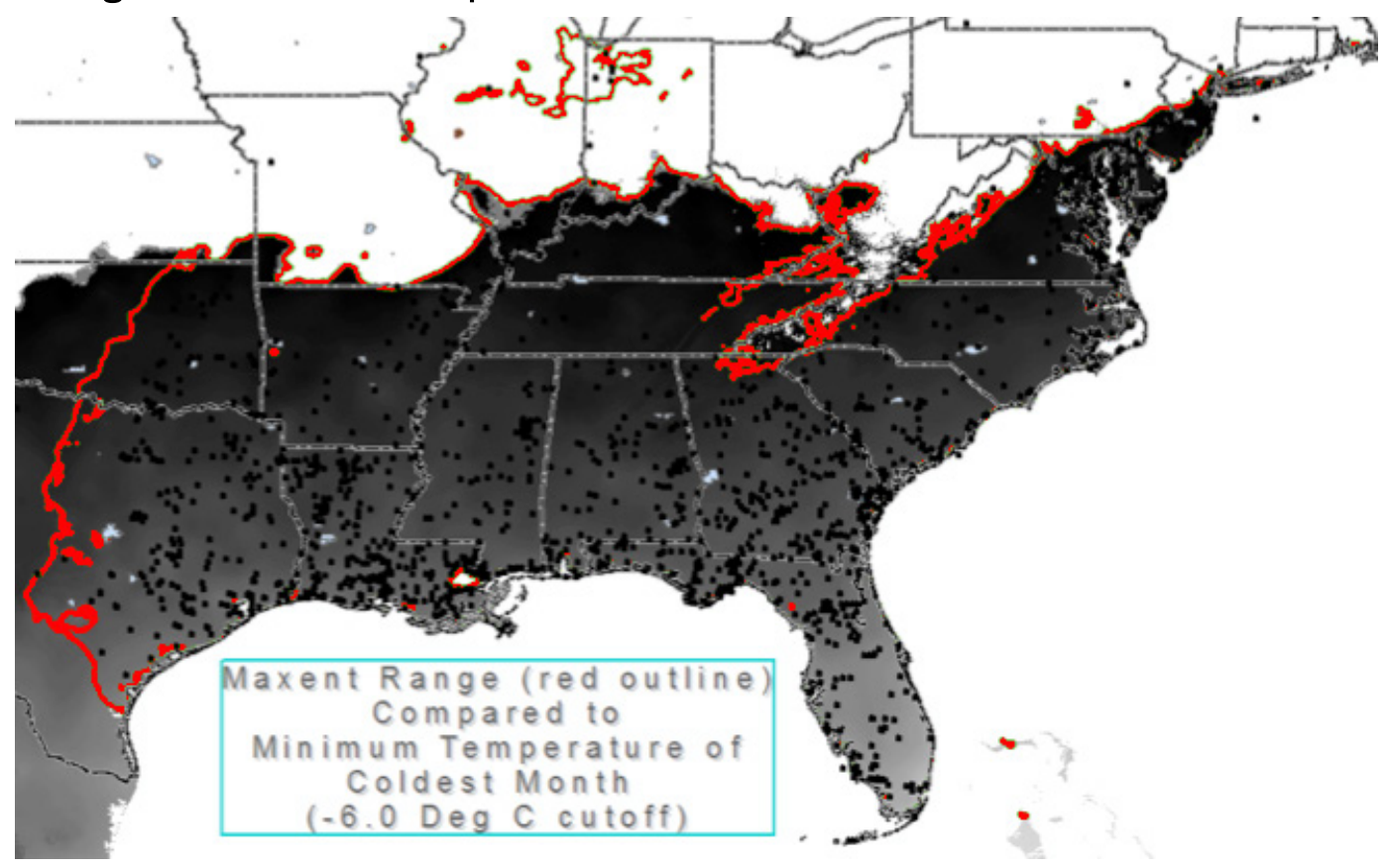

Annual precipitation is the fourth highest bioclimatic concern. At the 0.1 probability level the corresponding value would be $800 \mathrm{~mm}$ of yearly rain. However, when presented as a spatial distribution, the $700 \mathrm{~mm}$ level exhibited the best correlation with the Mud Turtle range (Figure 15). Even at that level, it only roughly defined the southwestern boundary but not nearly as well as the previous bioclimatic concerns. Examining the upper limit around $1700 \mathrm{~mm}$ seemed to have little or no correlation to the Mud Turtle range. Thus the contribution of annual precipitation to the Mud Turtle distribution is marginal at best; its importance of only $7.5 \%$ coordinates well with this conclusion. 
Figure 15. Annual precipitation at the $700 \mathrm{~mm}$ level for the Eastern Mud Turtle.

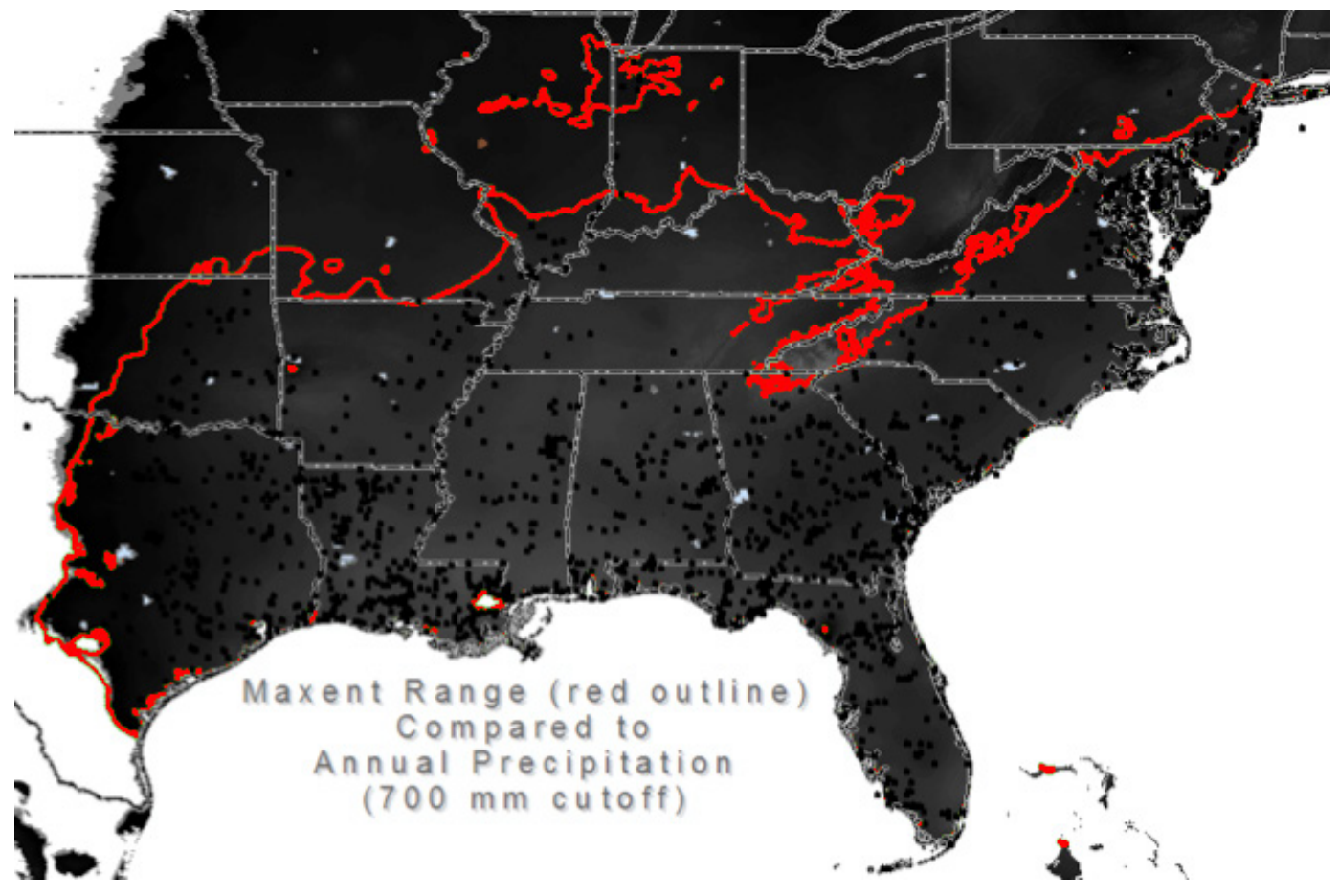

\subsubsection{Spatial conclusions for the Mud Turtle}

Spatially, the controlling threshold factors for the Mud Turtle are a $106 \mathrm{~mm}$ threshold of precipitation of driest quarter along the western edge of its range, $-6.0^{\circ} \mathrm{C}$ minimum temperature of coldest month for the northern limit, and a mean temperature of warmest quarter of $22.0^{\circ} \mathrm{C}$ around the Appalachians.

Note that the outlier locations south of Chicago may need some additional examination. They do not coordinate well with the thresholds from the top four bioclimatic concerns. The level of probability is low in these locations (never rising above 0.25). Thus they might be considered marginal habitat. On the other hand, if the cut off were revised to the 0.25 level, then the range does not coordinate well with the "traditional" range. Since this is the case, it would be best to consider these locations truly within the Mud Turtle range, however marginal. It might also be noted that the area south of Chicago also lies in a high standard deviation location, so on this criteria it is once again a marginal habitat identification. 


\subsection{Eastern Green Watersnake (Nerodia floridana)}

\subsubsection{County data}

Sightings from 64 counties were received from project collaborators ${ }^{*}$ and recorded in a Microsoft Excel file.

\subsubsection{Traditional range map}

The traditional range map (compiled 2005) was derived from the map presented on the NatureServe website.

\subsubsection{Critical mapping guidance issues}

The eastern Green Watersnake resides in most wetlands of any variety.

\subsubsection{Final 15-run results}

Figure 16 compares the Maxent prediction of the maximum extent of the Green Watersnake (blue-chained outline) with the traditional range (yellow-dashed line).

The zoomed-in area in Figure 17 shows little change in the resultant probability distribution, as compared to that derived from the single modeling run. The dotted blue line marks the 15-run result and the red line shows the one model run, both at the 0.1 probability level. The area in Figure 17 contains the greatest variation between the single-run model and the 15run model, but there is little difference.

* Tracey Tuberville and Kimberly Andrews from Savannah River Ecology Laboratory (SREL). 
Figure 16. Maxent range for $N$. floridana. The 0.1 probability level is shown with the blue chained outline, while the traditional range is the yellow dashed line.

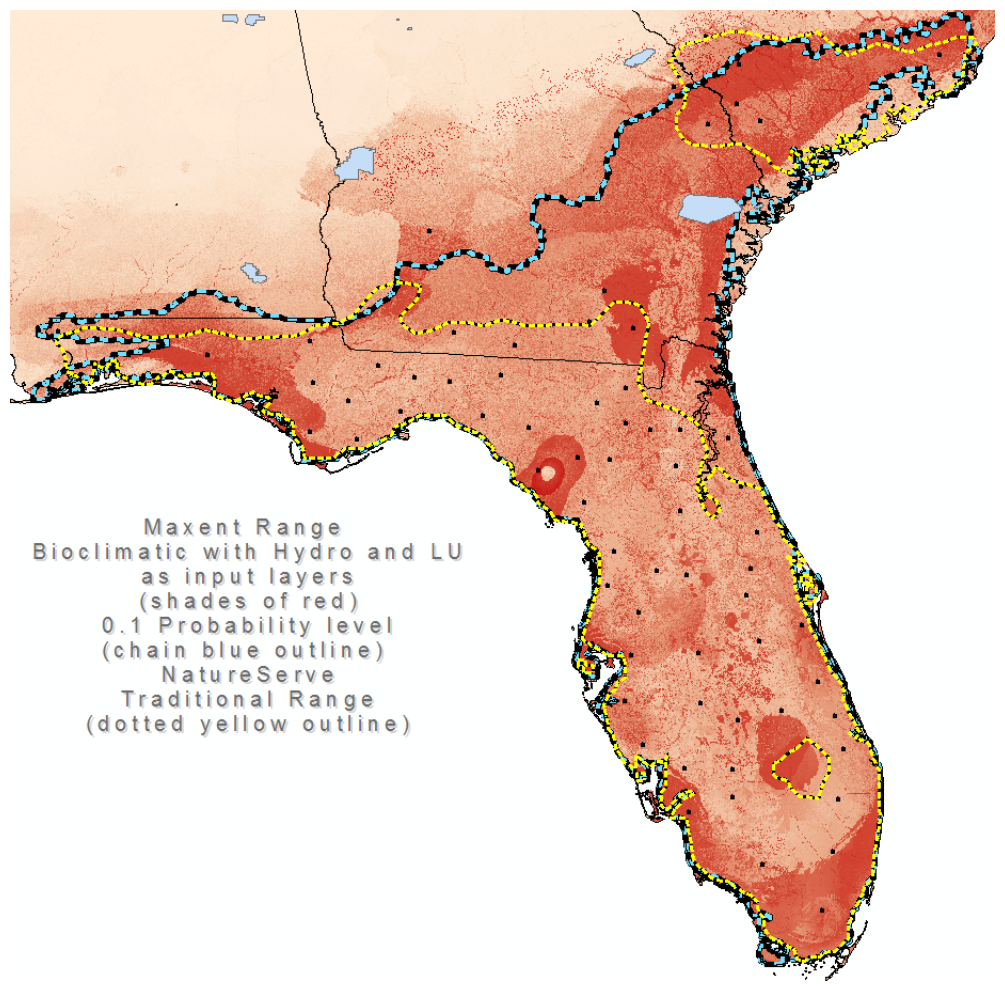

Figure 17. Closeup of Eastern Green Watersnake range. Darker red is better.

The blue outline is the 0.1 probability in the Maxent 15-run model, and the red line shows the one-model run.

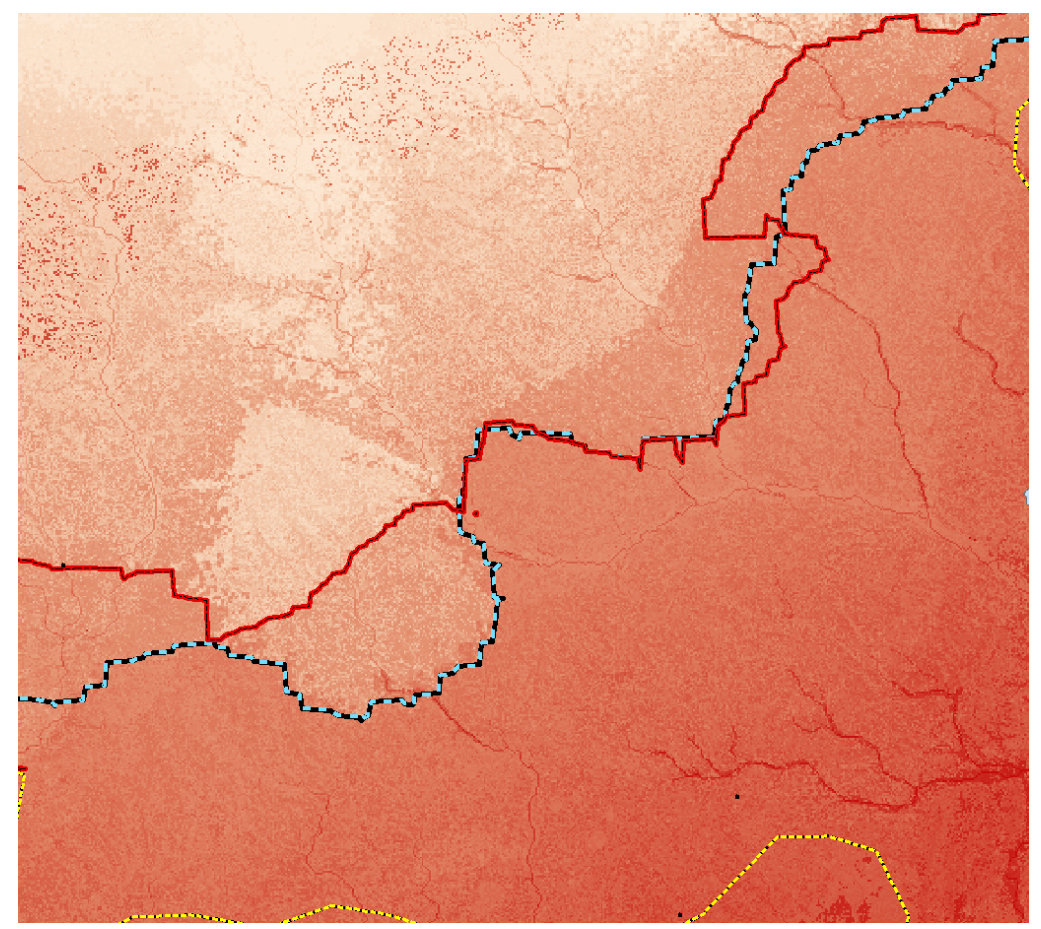


The average omission rate for $N$. floridana shows a wider one standard deviation spread than was evident for any of the other turtle 15 model runs. Also, the mean AUC for N. floridana (0.983) was much higher than for D. reticularia (0.965) or for K. subrubrum (at 0.908), so the model for $N$. floridana is considered more descriptive. The range is well defined and coordinates reasonably with the NatureServe range map.

The GAP land cover was fourth in the list of importance in determining the range. The marginal response curves show several preferred land uses. Land covers here show a gradient related to climate. In all jackknife tests, GAP land cover alone explained the snake distribution at the low to middling level, compared to the climate layers.

The water accumulation layer (dem_acc) was near the bottom of the list of importance in determining the range. Locally, water accumulation is important in enhancing the better-quality areas for the snake, but it barely influences the range. The reason is because the accumulation layer data covers the entire area of North America and does not change in relation to the snake distribution, while climate does. In all jackknife tests the water accumulation layer alone explained the turtle distribution the poorest, while all climate layers contributed much more to the probability distribution.

\subsubsection{Variable importance averaged after 15 models for Eastern Green Watersnake}

Table 8 shows that precipitation of warmest quarter, mean temperature of wettest quarter, and isothermality are the most important concerns for the Green Watersnake; they account for $84 \%$ of the Maxent model. Mean temperature of the wettest quarter will always be found in the top two concerns. Precipitation of warmest quarter and isothermality may or may not be among the most important concerns. Only GAP land cover (in table as gaplc) and minimum temperature of coldest month have the potential to contribute more than $6.2 \%$. 
Table 8. Variable importance averaged from 15 model runs for $N$. floridana.

\begin{tabular}{|l|r|r|r|r|}
\hline Variable & $\begin{array}{c}\text { Percent } \\
\text { Contribution }\end{array}$ & $\begin{array}{c}\text { Permutation } \\
\text { Importance }\end{array}$ & $\begin{array}{c}\text { Contribution } \\
\text { Range Low }\end{array}$ & $\begin{array}{c}\text { Contribution } \\
\text { Range High }\end{array}$ \\
\hline Bio18_PrecipWarmQtr & 50.4 & 62.0 & 0.0 & 100.0 \\
\hline Bio8_MeanTempWetQtr & 27.4 & 0.6 & 26.8 & 28.0 \\
\hline Bio3_Isothermality & 6.2 & 6.5 & 0.0 & 12.7 \\
\hline gaplc & 2.4 & 4.4 & 0.0 & 6.8 \\
\hline Bio10_MeanTempWarmQtr & 1.9 & 0.6 & 1.3 & 2.5 \\
\hline Bio4_TempSeasonality & 1.8 & 2.1 & 0.0 & 3.9 \\
\hline Bio1_AnnTemp & 1.5 & 0.0 & 1.5 & 1.5 \\
\hline Bio11_MeanTempColdQtr & 1.3 & 0.3 & 1.0 & 1.6 \\
\hline Bio19_PrecipColdQtr & 1.2 & 3.7 & 0.0 & 4.9 \\
\hline Bio16_PrecipWetQtr & 0.9 & 0.0 & 0.9 & 0.9 \\
\hline Bio20_ConsecDryMnth & 0.8 & 2.4 & 0.0 & 3.2 \\
\hline Bio2_DiurnalRange & 0.6 & 0.2 & 0.4 & 0.8 \\
\hline Bio17_PrecipDryQtr & 0.6 & 0.1 & 0.5 & 0.7 \\
\hline Bio7_AnnTempRange & 0.5 & 1.1 & 0.0 & 1.6 \\
\hline Bio9_MeanTempDryQtr & 0.4 & 0.5 & 0.0 & 0.9 \\
\hline Bio12_AnnPrecip & 0.4 & 0.6 & 0.0 & 1.0 \\
\hline Bio6_MinTempColdMnth & 0.3 & 12.8 & 0.0 & 13.1 \\
\hline Bio5_MaxTempWarmMnth & 0.3 & 0.2 & 0.1 & 0.5 \\
\hline dem_acc & 0.3 & 0.7 & 0.0 & 1.0 \\
\hline Bio15_PrecipSeasonality & 0.3 & 0.7 & 0.0 & 1.0 \\
\hline Bio14_PrecipDryMnth & 0.3 & 0.5 & 0.0 & 0.8 \\
\hline Bio13_PrecipWetMnth & 0.1 & 0.0 & 0.1 & 0.1 \\
\hline
\end{tabular}

While GAP land cover is interesting for its importance, it is significant that minimum temperature of coldest month, the seventeenth in the list, has the potential to rise to second in the list of importance. Since this is a snake whose range is mostly confined to Florida, a good argument could be made for taking a closer look at this enigmatic concern. Thus the mean temperature of the summer is certainly a controlling factor for the Green Watersnake, while the amount of the summer rain and isothermality (the mean diurnal range divided by the annual temperature range) are probably also controlling factors. The minimum temperature of coldest month will be checked, just in case it could be important.

\subsubsection{Coordinated marginal response curves}

The charts for the three controlling factors (plus one, as explained above) are shown below in Figure 18. 
Figure 18. Coordinated marginal response curves for Eastern Green Watersnake.
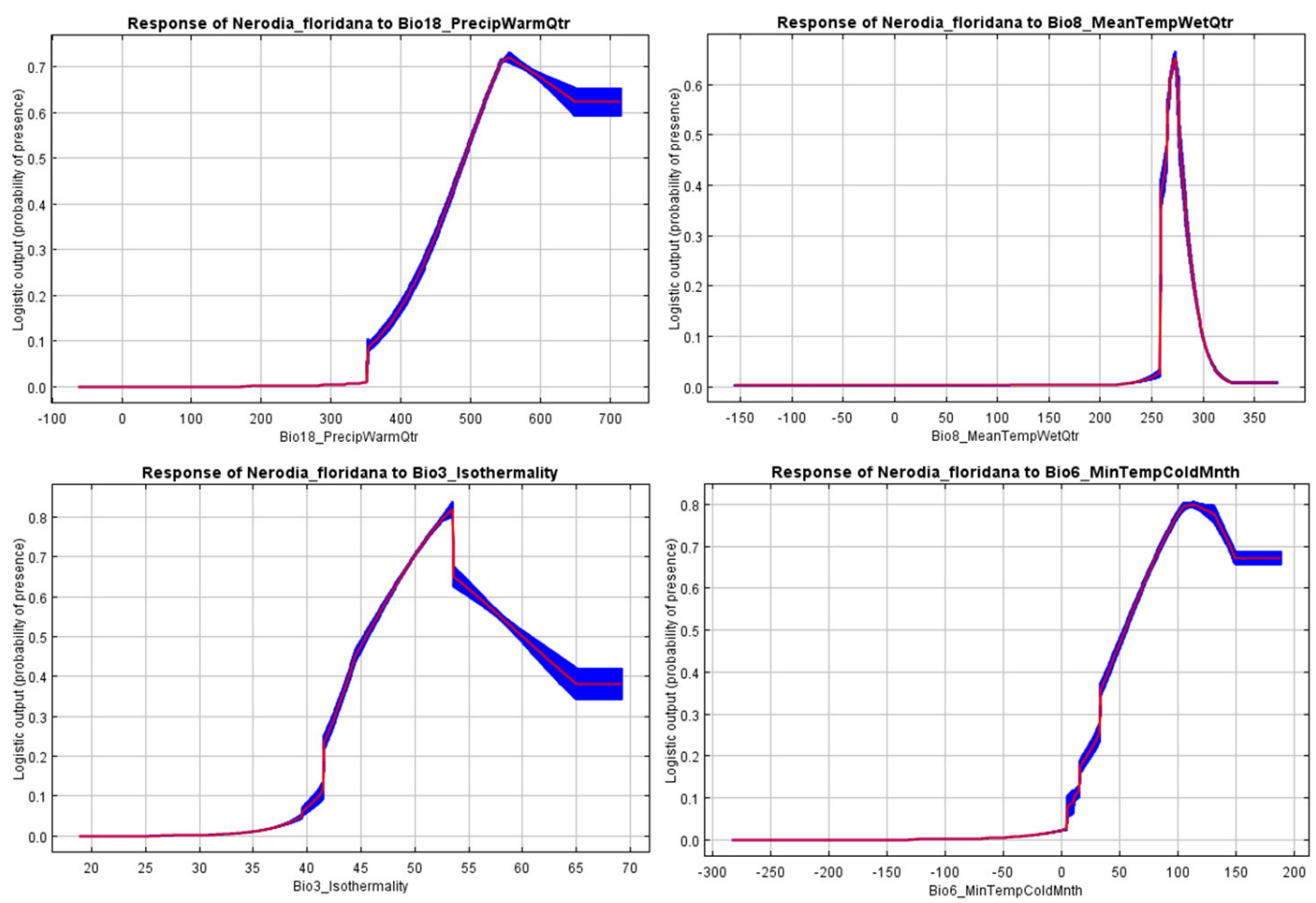

\subsubsection{Bioclimatic thresholds of the Eastern Green Watersnake}

The probability level of 0.1 is used on each of these charts as the threshold, coordinating with the 0.1 threshold used on the $N$. floridana probability map in Figure 16 above, to objectively define the results in Table 9. It should be noted that in some cases a threshold will be meaningless; for example, precipitation of warmest quarter's upper limit reflects the highest value found within the snake's range, but it does not indicate that the snake cannot exist above this minimum upper limit.

Table 9. Bioclimatic thresholds for the occurrence of Eastern Green Watersnake.

\begin{tabular}{|c|c|c|c|c|c|c|c|c|}
\hline \multicolumn{9}{|c|}{ Bioclimatic Thresholds For the Occurence of Nerodia floridana (Eastern Green Watersnake) } \\
\hline $\begin{array}{l}\text { Bio } \\
\text { Num }\end{array}$ & Bioclimatic Concern & $\begin{array}{l}\text { Lower } \\
\text { Threshol } \\
d \text { (when } \\
P=0.1 \text { ) }\end{array}$ & Severity & $\begin{array}{c}\text { Occurs } \\
\text { below } \\
\text { Threshold? } \\
\text { (Limiting?) }\end{array}$ & $\begin{array}{c}\text { Upper } \\
\text { Threshold } \\
\text { (when } \\
P=0.1 \text { ) }\end{array}$ & Severity & $\begin{array}{c}\text { Occurs } \\
\text { above } \\
\text { Threshold? }\end{array}$ & $\begin{array}{c}\% \\
\text { Importance } \\
\text { in Model }\end{array}$ \\
\hline $\mathrm{BIO18}$ & $\begin{array}{l}\text { Precipitation of Warmest } \\
\text { Quarter }(\mathrm{mm})\end{array}$ & 360.0 & Extreme & No & None & - & Yes & 50.4 \\
\hline $\mathrm{BIO8}$ & $\begin{array}{l}\text { Mean Temperature of Wettest } \\
\text { Quarter (deg C) }\end{array}$ & 26.0 & Extreme & No & 29.5 & Extreme & No & 27.4 \\
\hline $\mathrm{BIO} 3$ & $\begin{array}{l}\text { Isothermality (mean diurnal } \\
\text { range/temperature annual } \\
\text { range) }\end{array}$ & 42.0 & Moderate & A Little & None & - & Yes & 6.2 \\
\hline BIO6 & $\begin{array}{l}\text { Min Temperature of Coldest } \\
\text { Month (deg C) }\end{array}$ & 12.0 & High & No & None & - & - & 0.3 \\
\hline
\end{tabular}


The lower threshold for the Green Watersnake for precipitation in warmest quarter is a sharp cut off. Since this is the most important variable of any, it suggests that the snake absolutely requires at least $360 \mathrm{~mm}$ of rain in the summer and it will continue to flourish as the amount increases to an optimum of about $550 \mathrm{~mm}$. It will continue to exist with more precipitation, so no upper limit is observed. Since the species is called a watersnake, this is not surprising.

The mean temperature of wettest quarter shows the snake has a very limited range for summer temperatures. (Summer is usually the wettest time in the U.S. Southeast.) One might expect that a cold-blooded reptile responds to temperature variations. Its temperature range for the threemonth period is only $3.5^{\circ} \mathrm{C}$, centered on an optimum near $27.0^{\circ} \mathrm{C}$. Since this is the second most important parameter, this temperature range has to be significant. Both precipitation of warmest quarter and mean temperature of wettest quarter are summer-centered parameters, so the summer in the Southeast is critical to the watersnake. Both of these thresholds are meaningful as a potential survival test.

Isothermality (i.e., mean diurnal range/temperature annual range) is significant in only its lower threshold. Evidently when the day-to-day temperature range is low compared to the yearly range, then the Green Watersnake does well; it prefers less temperature change within a day. When the day-to-day temperature range is higher compared to the yearly range, for a range up to about $53.0^{\circ} \mathrm{C}$, the Green Watersnake does even better. As the day-to-day temperature range becomes even higher compared to the yearly range, the watersnake does less well but within its temperature range isothermality never becomes a limiting factor.

Although minimum temperature of coldest month is $16^{\text {th }}$ on the list of bioclimatic concerns, according to Maxent it could feasibly rise to second or third place. No other bioclimatic concern exhibits this potential rise in importance. More importantly, its response curve (rather than the table) clearly illustrates a characteristic one would expect for this species. Specifically, it does not live at temperatures below freezing $\left(\mathrm{o}^{\circ} \mathrm{C}\right)$. Because the response curve for this bioclimatic concern is telling, it has the potential to be among the important concerns, and it is easily testable; this concern is examined in the spatial thresholds section, 6.3.4.4. 
In summary, the critical needs of the Eastern Green Watersnake are a summer rainfall of at least $360 \mathrm{~mm}$ and a temperature of $26.0-29.5^{\circ} \mathrm{C}$. The minimum temperature of coldest month not falling below freezing may also rise to an important level of concern.

\subsubsection{Spatially explicit thresholds of the Eastern Green Watersnake}

The precipitation of warmest quarter at the $360 \mathrm{~mm}$ threshold defines the northern boundary through the east-central portion of Georgia for the Eastern Green Watersnake (Figure 19).

Figure 19. Precipitation of warmest quarter at the $360 \mathrm{~mm}$ threshold for $N$. floridana.

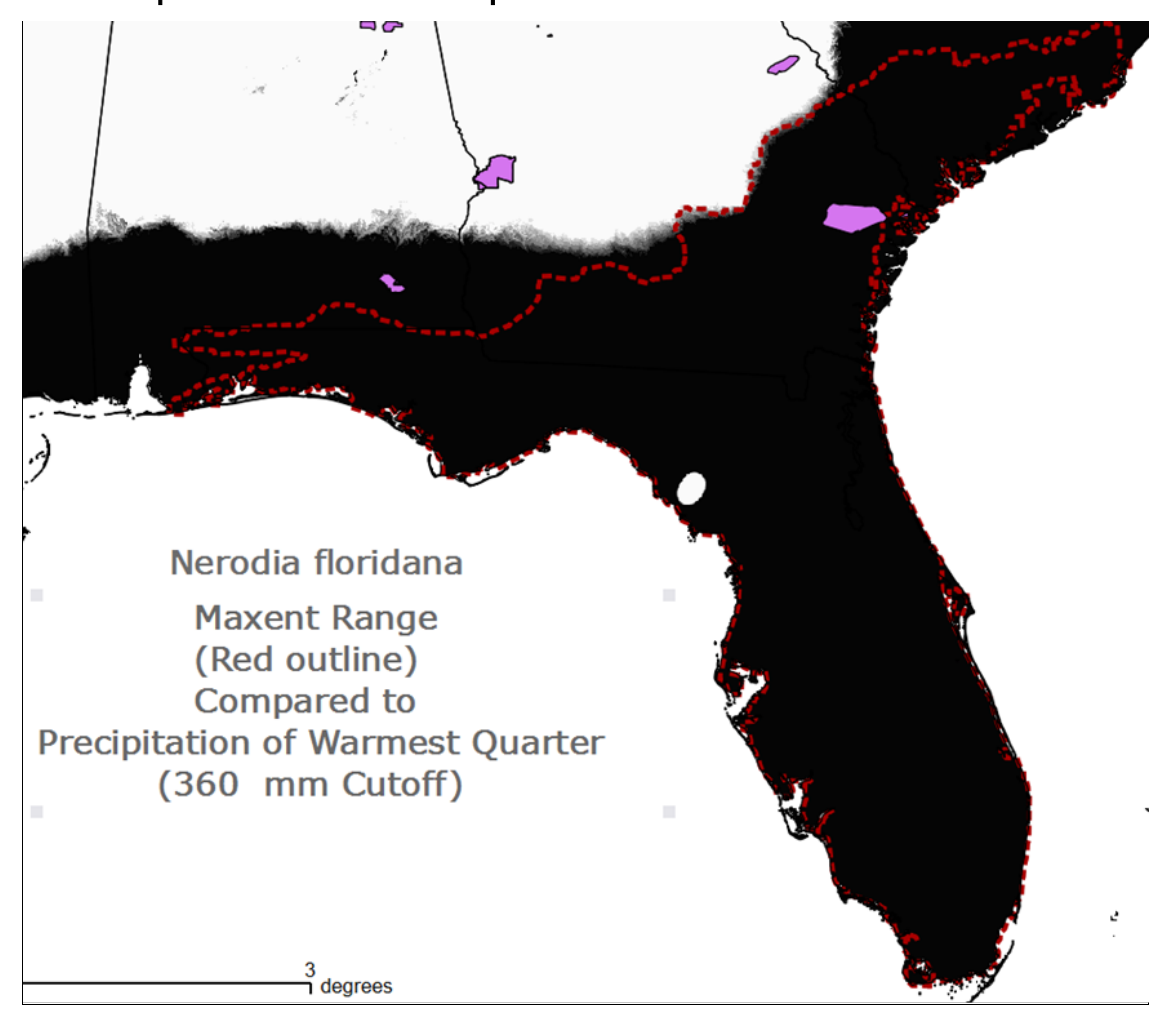

It appears that much of the northern edge of the Watersnake's range from central Georgia to the middle of Alabama is controlled by mean temperature of wettest quarter at the $26^{\circ} \mathrm{C}$ level (Figure 20). 
Figure 20. Mean temperature of wettest quarter at the $26^{\circ} \mathrm{C}$ level for $N$. floridana.

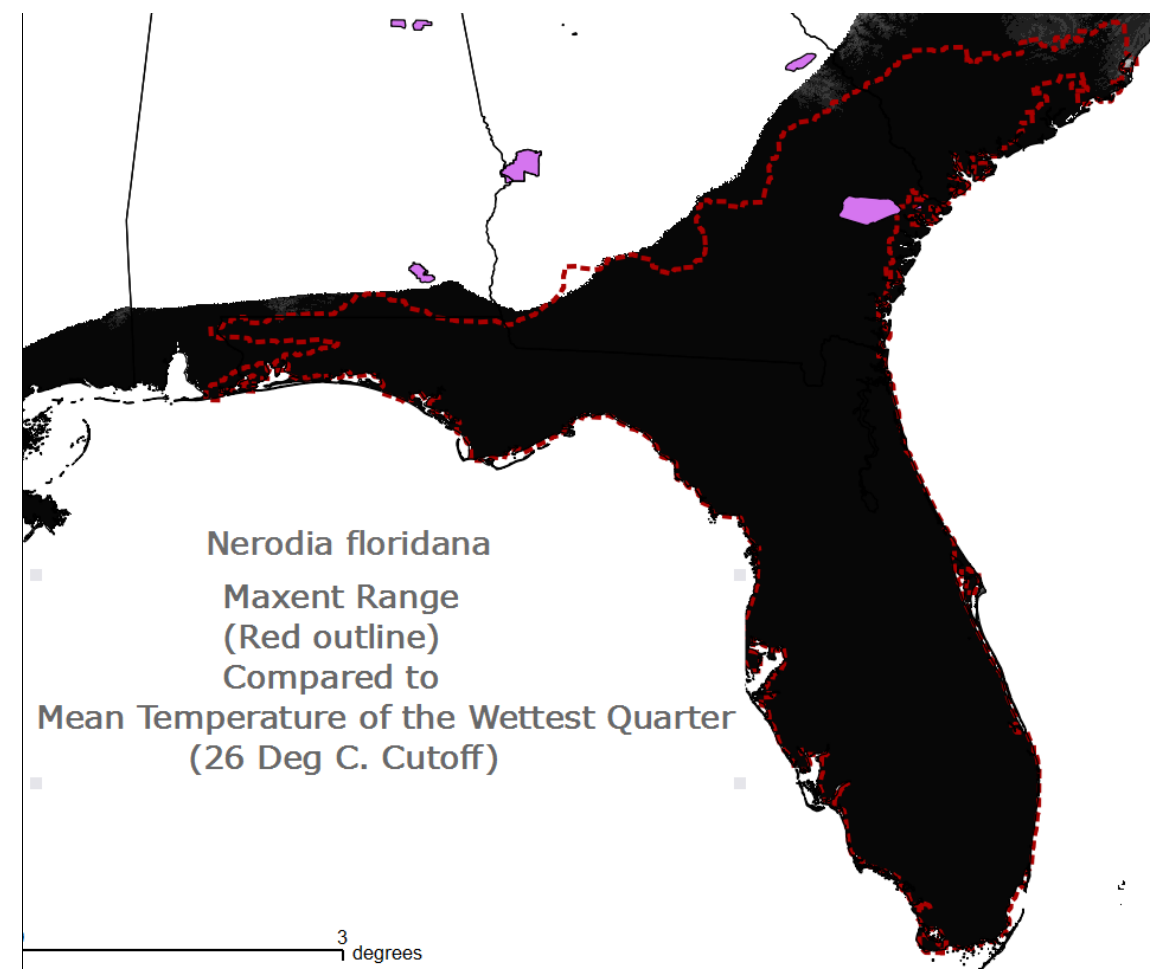

At about a value of 42, the third most important concern, isothermality, seems to barely control the range of the Eastern Green Watersnake at two locations: the central-Georgia indentation and along a sliver above the gulf coast between Bay Minette, Alabama, and Santa Rosa, Florida (Figure 21).

Minimum temperature of coldest month has the potential to rise to second- or third-highest in importance among the bioclimatic concerns. At the 0.1 probability level, the corresponding value would be $12{ }^{\circ} \mathrm{C}$ during the winter months. The cut off for $\mathrm{a} \mathrm{o}^{\circ} \mathrm{C}$ threshold would put the northern edge roughly $75 \mathrm{~km}$ farther north than is shown in black in Figure 22. Also there is a difference between the two values because $12{ }^{\circ} \mathrm{C}$ is more relevant to the watersnake than is $0{ }^{\circ} \mathrm{C}$. The $12{ }^{\circ} \mathrm{C}$ threshold seems to limit the snake's range in South Carolina, but the hypothesis that freezing is important is disproved here. 
Figure 21. Isothermality at about the ratio of $\mathbf{4 2}$ for $\mathbf{N}$. floridana.

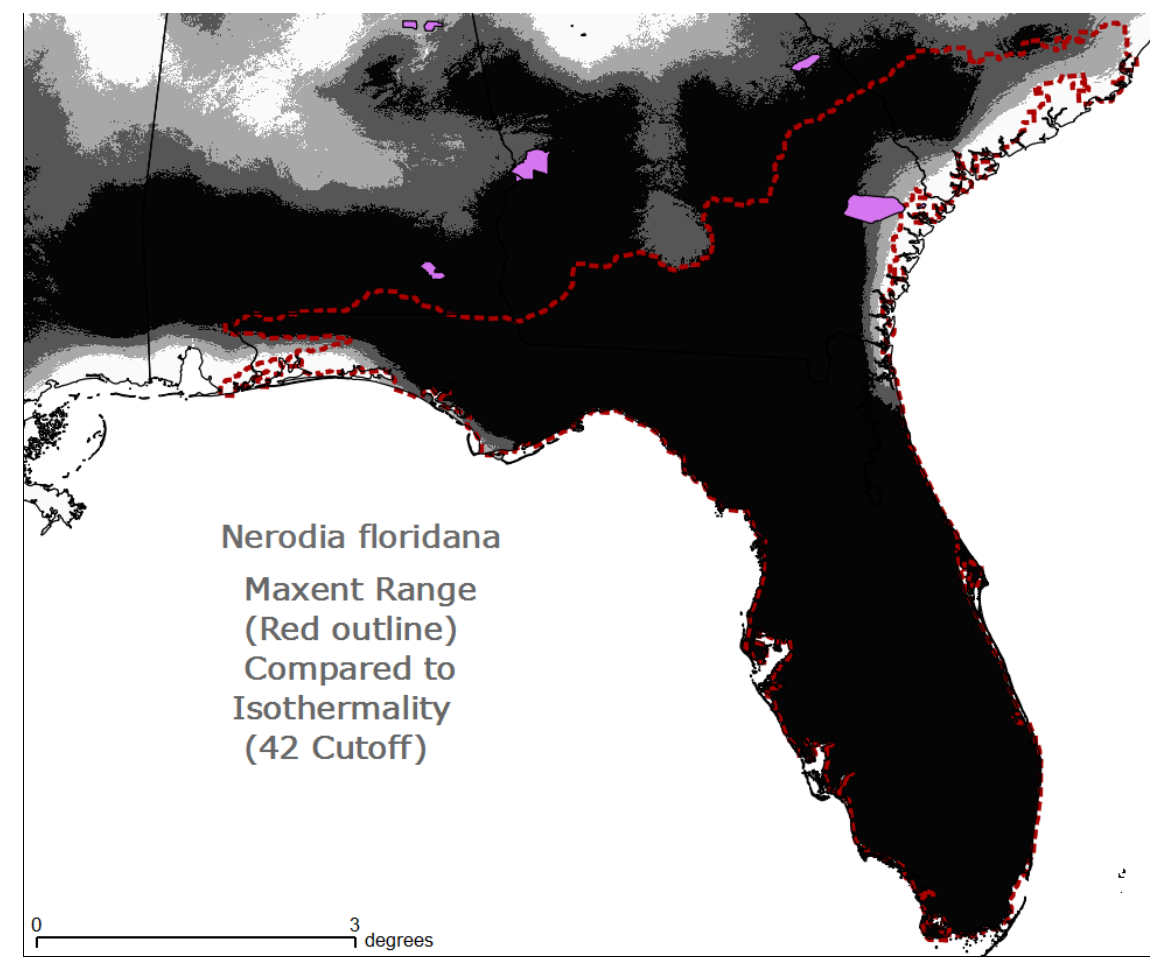

Figure 22. Minimum temperature of coldest month at the 12 degree threshold for $N$. floridana.

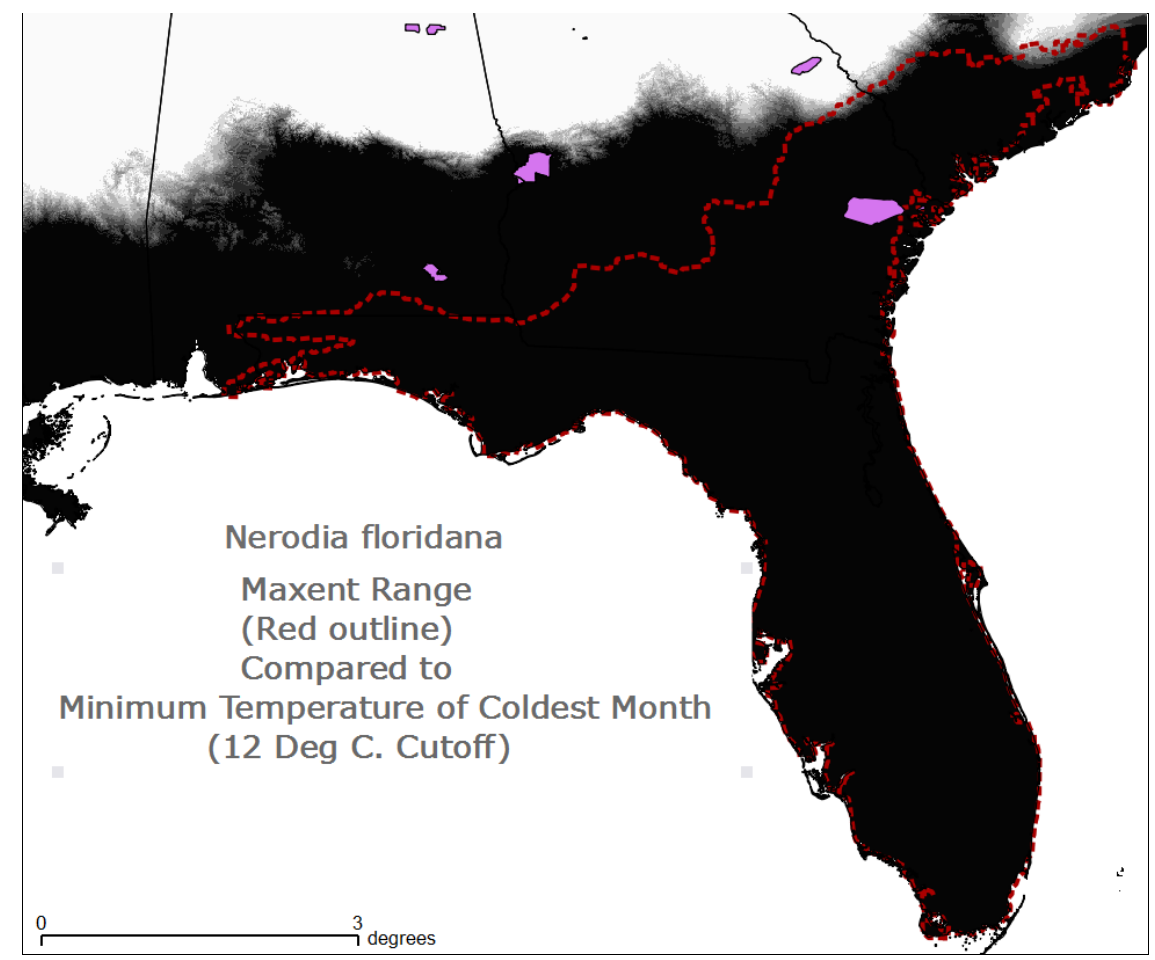




\subsubsection{Spatial conclusions for the Eastern Green Watersnake}

In summary, after this spatial review it is suggested that the four bioclimatic concerns discussed in this section are significant in defining the Eastern Green Watersnake's range. Spatially, from east to west, the controlling threshold factors for the range of this snake are:

- a $12{ }^{\circ} \mathrm{C}$ threshold of minimum temperature of coldest month for the northern limit in South Carolina,

- at least $360 \mathrm{~mm}$ of summer rainfall are critical for the species from east to central Georgia,

- $26^{\circ} \mathrm{C}$ lower threshold mean temperature of wettest quarter for the northern range boundary from central Georgia to central Alabama, and

- isothermality at the value of 42 may modify the northern boundary in central Georgia and southern Alabama.

\subsection{Banded Watersnake (Nerodia fasciata)}

\subsubsection{County data}

A spreadsheet file of sightings of this species from 479 counties was provided by project collaborators at SREL.

\subsubsection{Traditional range map}

The traditional range map (compiled June 2005) was derived from the map presented on the NatureServe website.

\subsubsection{Critical mapping guidance issues}

The Banded Watersnake resides in most wetlands of still or slow-moving water and is unlikely to travel overland. 


\subsubsection{Final 15-run results}

Figure 23. Maxent probability result of the 15 runs; the dotted red/yellow line is the 0.1 probability edge, and yellow dotted line shows the NatureServe traditional boundary.

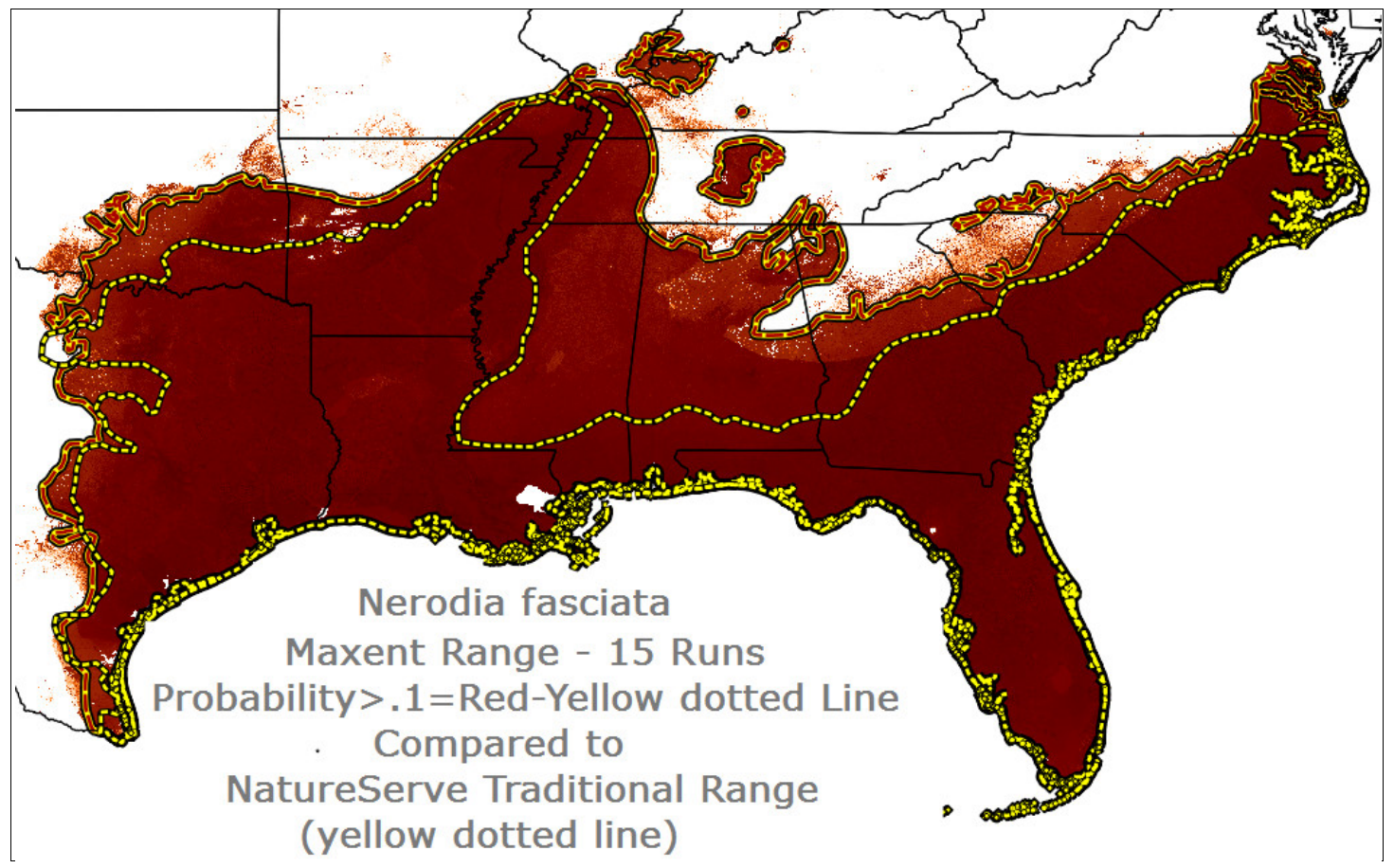

The multi-run probability distribution (Figure 23) is extremely similar to that derived from the single modeling run.

The average omission rate for Nerodia fasciata shows a wide one standard deviation spread (the orange color in Figure 24). The mean omission rate (green line) lies well above the predicted rate (black line). This means that the submitted bioclimatic layers are largely independent of each other. If the mean ommission lies below the black line, then the bioclimatic layers would not be independent. The larger the AUC value is, the better the model is at predicting the presences contained in the test sample of the data. The mean AUC for N. fasciata (0.927) was lower than S. pygaea (.966), $N$. floridana (0.986), and D. reticularia (0.965) but higher than for $K$. subrubrum(0.908). So the value for AUC for Banded Watersnake is considered low, but within the normal range. The Maxent range is well defined and coordinates reasonably with the NatureServe range map; however, it is more extensive in all of Mississippi, Alabama and eastern Oklahoma, mid-south Georgia, the Carolinas, and south-coastal Virginia. Outliers exist in central Tennessee and northwestern Kentucky, where no observations have been reported. Nowhere is the traditional range greater 
than the Maxent range. The Maxent probability map can be considered a "potential" range. All the testing alternatives show a greater range than the NatureServe traditional range in all of Alabama, eastern Arkansas, and mid-south Georgia.

Figure 24. Average omission rate for Banded Watersnake.

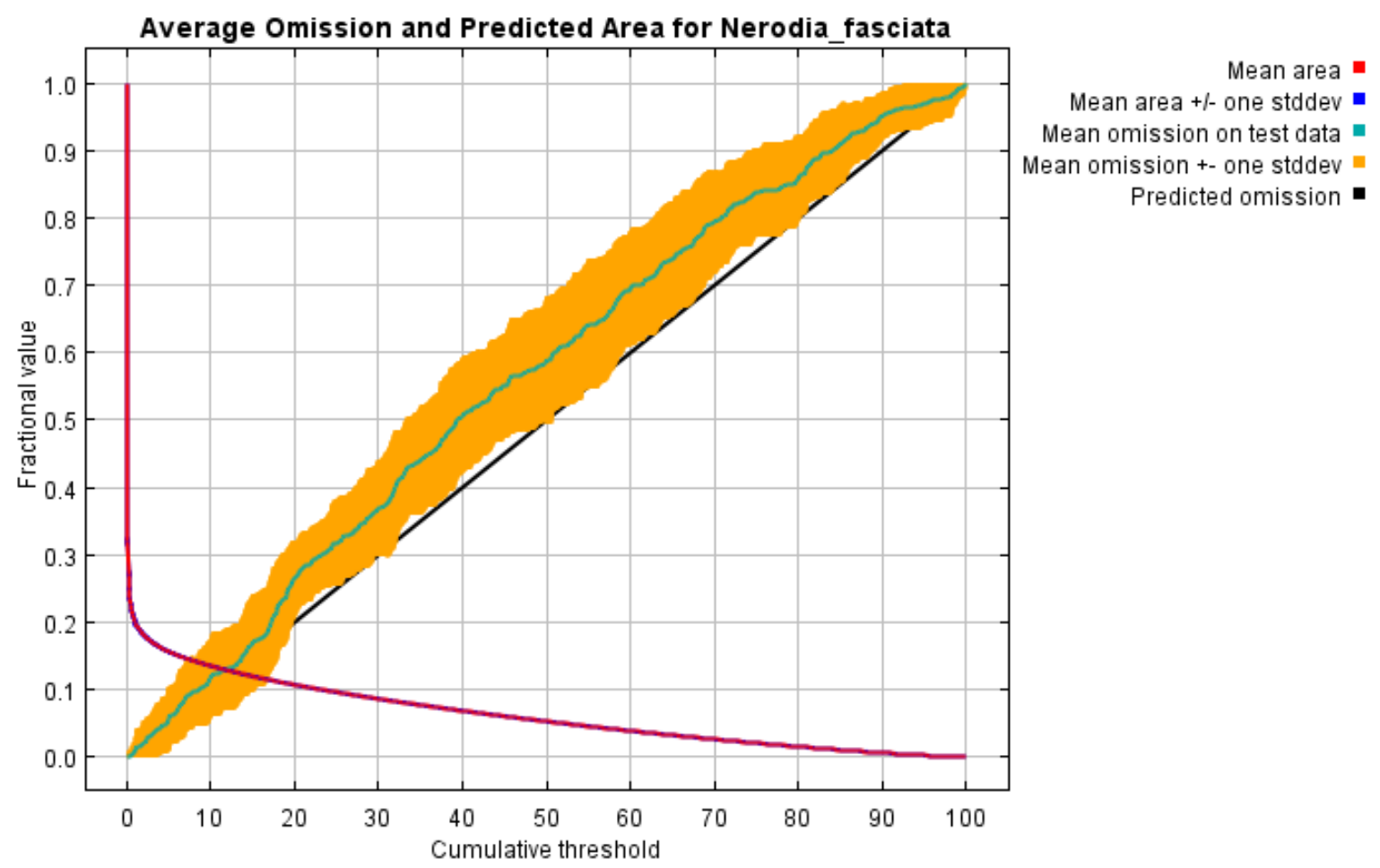

Just as a check, since this range is greater than the traditional in some areas, the Maxent alternative output called the "Minimum Probability" map was examined which shows a smaller possible distribution. There is very little difference between the average map (normally used) and the minimum map. Thus, the Maxent range can be considered stable.

The standard deviation for the 15 model runs is presented in Figure 25. 
Figure 25. The standard deviation for the 15 model runs for Banded Watersnake.

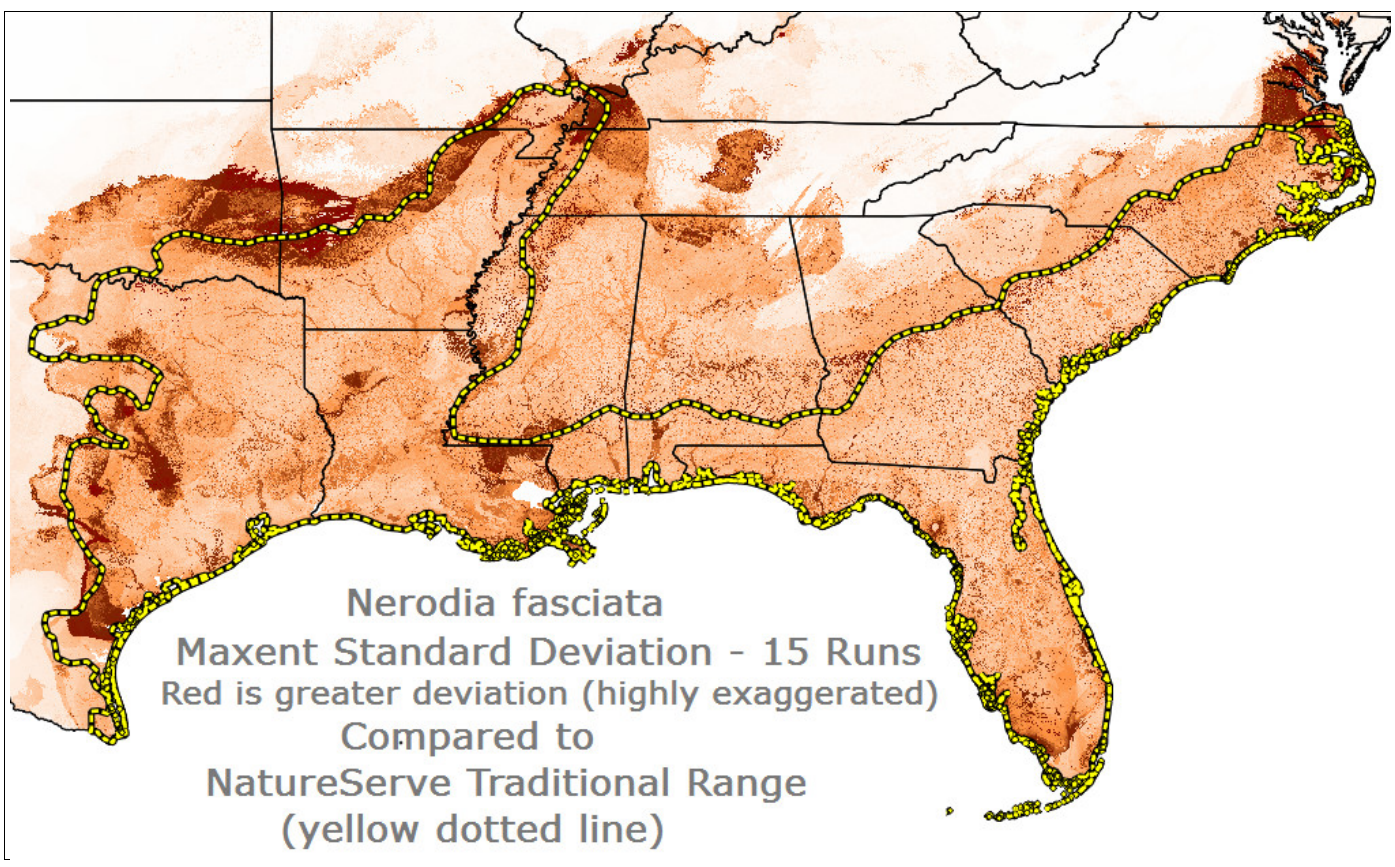

The histogram of the color table in Figure 25 was exaggerated to show the highest deviations (i.e., those locations that varied the most among the 15 models). Figure 25 shows that the greatest variation among the 15 models was not concentrated in those locations that varied most from the traditional range, indicating strongly that all of Alabama, Mississippi, and midsouth Georgia should be within the snake's range. Those areas where Maxent suggests there is the greatest deviation (which might be considered "doubt" in this case) are in the Oklahoma-Arkansas border, in the western tip of Kentucky, and in coastal Virginia. The greatest standard deviation is 0.1 , a low value. The implication is that the model is stable and, even in the areas of greatest standard deviation, it can be considered reliable.

\subsubsection{Variable importance averaged after 15 models}

Table 10 shows there are three or four bioclimatic concerns that are likely important in defining the snake's range. In order of importance the top four are: BIO10 mean temperature of warmest quarter, BIO13 precipitation of wettest month, BIO1 annual mean temperature, and BIO14 precipitation of driest month. These top four account for $77.2 \%$ of the importance of all the bioclimatic factors. The percentages are spread more evenly than for the other snakes examined. It is remotely possible that BIO9 mean temperature of driest quarter could be most important, with BIO13 precip- 
itation of wettest month slipping to third place, followed by BIO19 precipitation of coldest quarter and GAP land cover. No other bioclimatic concerns have the potential to rise above the $9 \%$ importance level. Finally, although the NatureServe descriptions put a high emphasis on the water habitat, the accumulation layer was nearly at the bottom of the list of important factors. Thus, the mean temperature of summer and rainfall in the wettest month of the summer roughly equally share as the two most-likely controlling factors, while the annual average temperature is a close third concern. The minimum amount of rainfall in the driest month (that is usually the winter in the Southeast) may be a limiting factor for the Banded Watersnake.

Table 10. Variable Importance averaged from 15 model runs for $N$. fasciata.

\begin{tabular}{|l|r|r|r|r|}
\hline Variable & $\begin{array}{c}\text { Percent } \\
\text { Contribution }\end{array}$ & $\begin{array}{c}\text { Permutation } \\
\text { Importance }\end{array}$ & $\begin{array}{r}\text { Contribution } \\
\text { Range Low }\end{array}$ & $\begin{array}{r}\text { Contribution } \\
\text { Range High }\end{array}$ \\
\hline Bio10_MeanTempWarmQtr & 25.1 & 11.9 & 13.2 & 37.0 \\
\hline Bio13_PrecipWetMnth & 23.7 & 8.6 & 15.1 & 32.3 \\
\hline Bio1_AnnTemp & 18.4 & 8.0 & 10.4 & 26.4 \\
\hline Bio14_PrecipDryMnth & 10.0 & 11.7 & 0.0 & 21.7 \\
\hline Bio20_ConsecDryMnth & 4.3 & 4.1 & 0.2 & 8.4 \\
\hline gaplc & 3.5 & 7.8 & 0.0 & 11.3 \\
\hline physiographic_regions & 2.2 & 3.5 & 0.0 & 5.7 \\
\hline Bio9_MeanTempDryQtr & 1.8 & 15.7 & 0.0 & 17.5 \\
\hline Bio12_AnnPrecip & 1.8 & 0.5 & 1.3 & 2.3 \\
\hline Bio8_MeanTempWetQtr & 1.7 & 3.6 & 0.0 & 5.3 \\
\hline Bio19_PrecipColdQtr & 1.7 & 9.7 & 0.0 & 11.4 \\
\hline Bio4_TempSeasonality & 1.2 & 1.9 & 0.0 & 3.1 \\
\hline Bio7_AnnTempRange & 1.2 & 0.6 & 0.6 & 1.8 \\
\hline Bio18_PrecipWarmQtr & 0.9 & 1.1 & 0.0 & 2.0 \\
\hline Bio5_MaxTempWarmMnth & 0.8 & 6.7 & 0.0 & 7.5 \\
\hline Bio6_MinTempColdMnth & 0.8 & 2.1 & 0.0 & 2.9 \\
\hline Bio3_Isothermality & 0.3 & 0.0 & 0.3 & 0.3 \\
\hline Bio11_MeanTempColdQtr & 0.2 & 0.6 & 0.0 & 0.8 \\
\hline dem_morph & 0.2 & 0.5 & 0.0 & 0.7 \\
\hline Bio2_DiurnalRange & 0.1 & 0.2 & 0.0 & 0.3 \\
\hline dem_acc & 0.1 & 0.1 & 0.0 & 0.2 \\
\hline Bio15_PrecipSeasonality & 0.0 & 1.2 & 0.0 & 1.2 \\
\hline
\end{tabular}




\subsubsection{Coordinated marginal response curves}

Charts for the four controlling factors are shown in Figure 26.

Figure 26. Coordinated marginal response curves for Banded Watersnake.
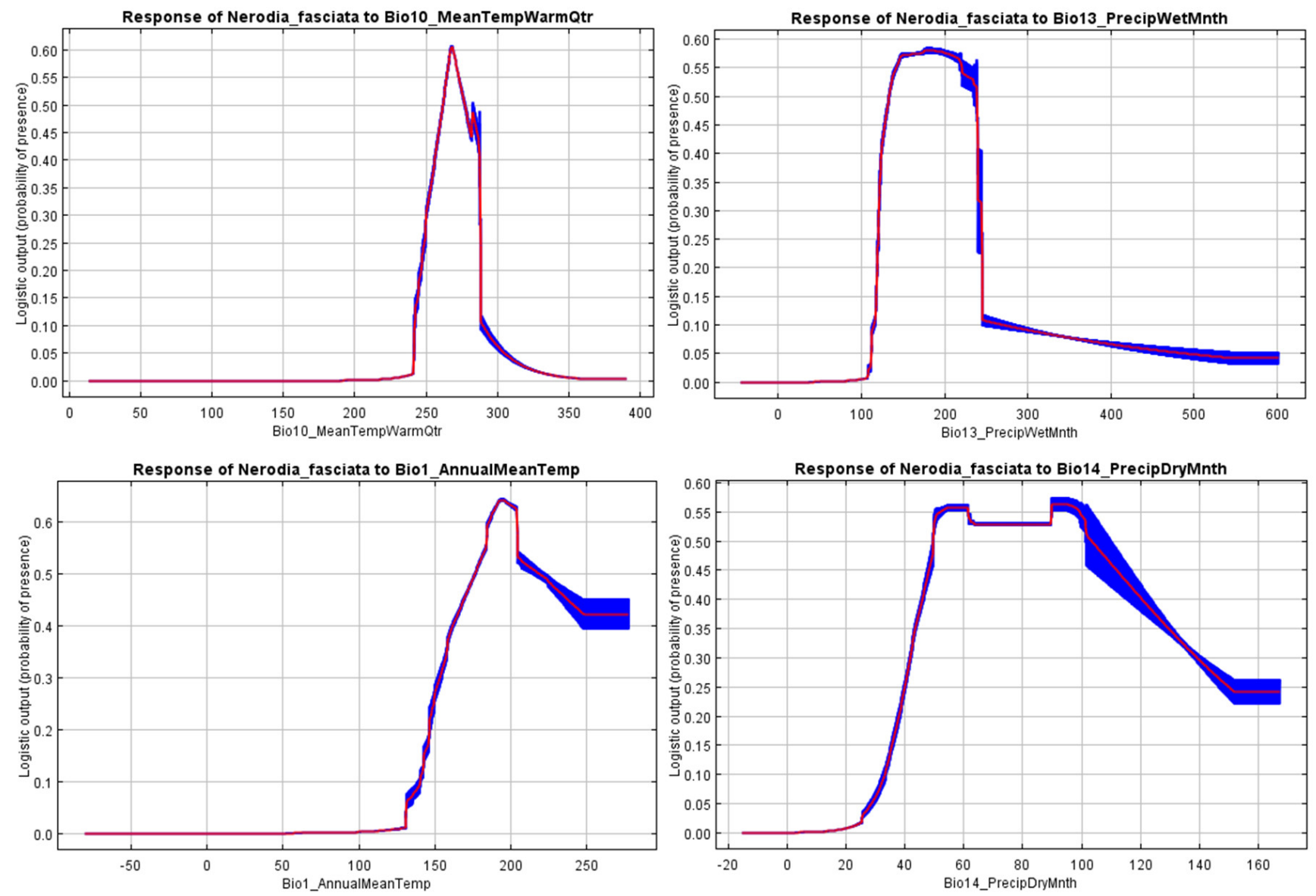

On all the charts in Figure 26, the blue area represents one standard deviation among the 15 models; it is always small. The blue area is only large on the right side, where the bioclimatic input is not a limiting concern. Thus, these charts can be considered stable with regard to the important bioclimatic charactistics of the Banded Watersnake.

\subsubsection{Bioclimatic thresholds of the Banded Watersnake}

The probability level of 0.1 on each of the charts shown in Figure 26 is used for the thresholds presented in Table 11. 
Table 11. Bioclimatic thresholds for the occurrence of the Banded Watersnake.

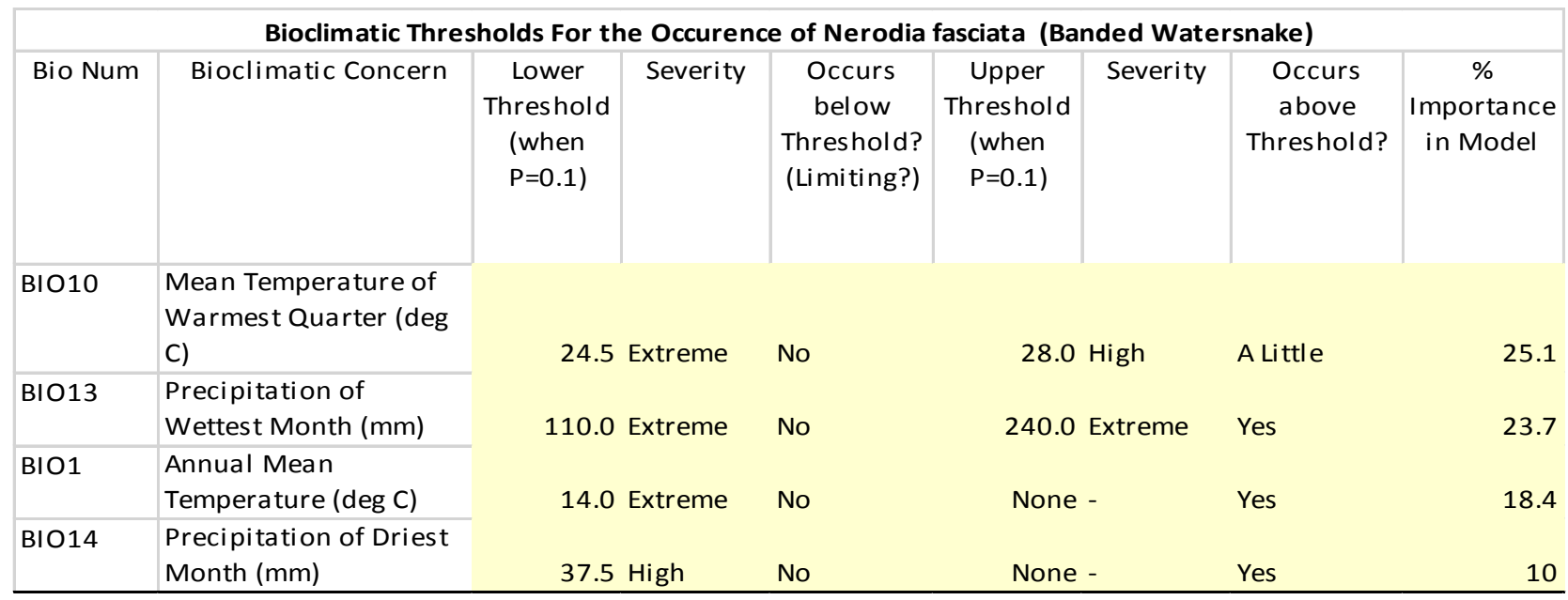

- The lower and upper thresholds for mean temperature of warmest quarter are both significant cut offs for the Banded Watersnake. Since this is the most important variable of any, it suggests that the snake absolutely requires at an average summer temperature range of only 4 degrees between $24.5{ }^{\circ} \mathrm{C}$ and $28.0^{\circ} \mathrm{C}$, with an optimum around $26.0^{\circ} \mathrm{C}$.

- The precipitation of wettest month shows the snake is limited by summer rainfall (usually summer is the wettest time in the Southeast), 110-240 $\mathrm{mm}$. One might expect that a water-limited snake responds to wet-season conditions. Since the importance of this factor is very close to that of the previous factor, these two top concerns are probably determining for the species

- Annual mean temperature is also a defining factor, the lower limit being significant. The Banded Watersnake reacts well to a warm temperature of at least $15{ }^{\circ} \mathrm{C}$ in most years. While the upper limit does inhibit the snake, it will still survive adequately.

- Precipitation of driest month should be about $37.5 \mathrm{~mm}$ on average. In the Southeast, that normally occurs during the winter season. This bioclimatic concern probably contributes about $10 \%$ of the snake's habitat definition. However, taken together with the precipitation of wettest month input, it would seem this snake is sensitive to extremes in rainfall.

- In summary, the critical issues for the Banded Watersnake are a summer mean temperature ranging between $24.0-28.0^{\circ} \mathrm{C}$, a summer rainfall of at least $120 \mathrm{~mm}$ in a month, and maybe a mean annual temperature of at least $14{ }^{\circ} \mathrm{C}$. 


\subsubsection{Spatially explicit thresholds of the Banded Watersnake}

Here it was assumed that the Maxent-defined range at the 0.1 probability level best represented the limits for the Banded Watersnake.

The mean temperature of the warmest quarter at the $24.5{ }^{\circ} \mathrm{C}$ threshold roughly defines much of the northern boundary of the Banded Watersnake. In Figure 27, it is clear that this bioclimatic concern is approximate rather than definitive in that there is a relationship between the two, but it is not an exacting correlation. The edges are also fuzzy rather than sharp. In summary, there is a relationship but not a perfect relationship.

Figure 27. The mean temperature of the warmest quarter at the $24.5^{\circ} \mathrm{C}$. threshold for $N$. fasciata.

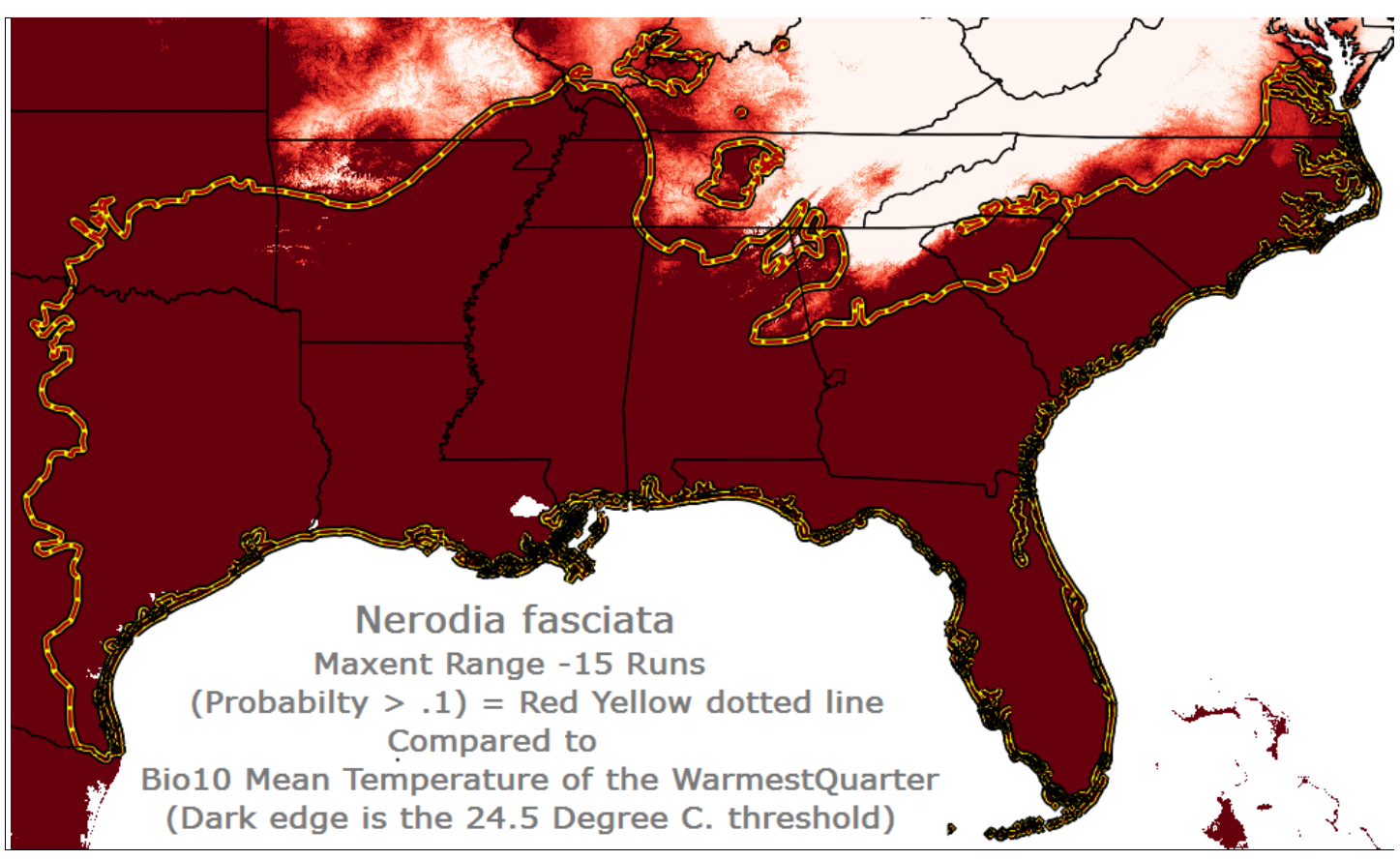


Figure 28. Precipitation of wettest month at the 0.1 probability level.

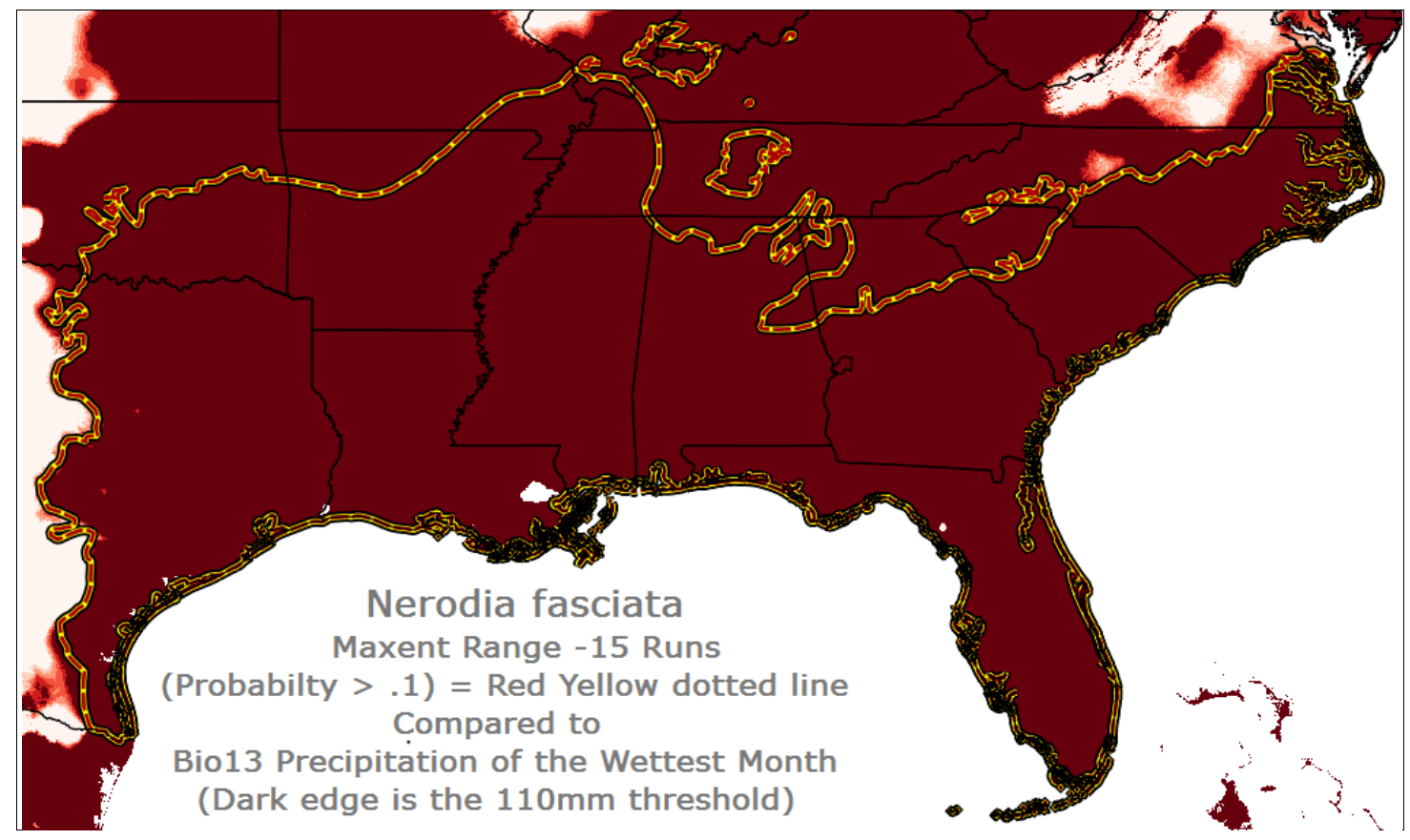

Precipitation of wettest month clearly and precisely controls the Banded Watersnake's western edge (Figure 28). It might have some influence on the northeastern tip of its range in Virginia, but this importance is marginal at best. Precipitation of wettest month is a close second in importance to the mean temperature of warmest quarter.

Figure 29. Annual mean temperature at the $15.0^{\circ} \mathrm{C}$. threshold.

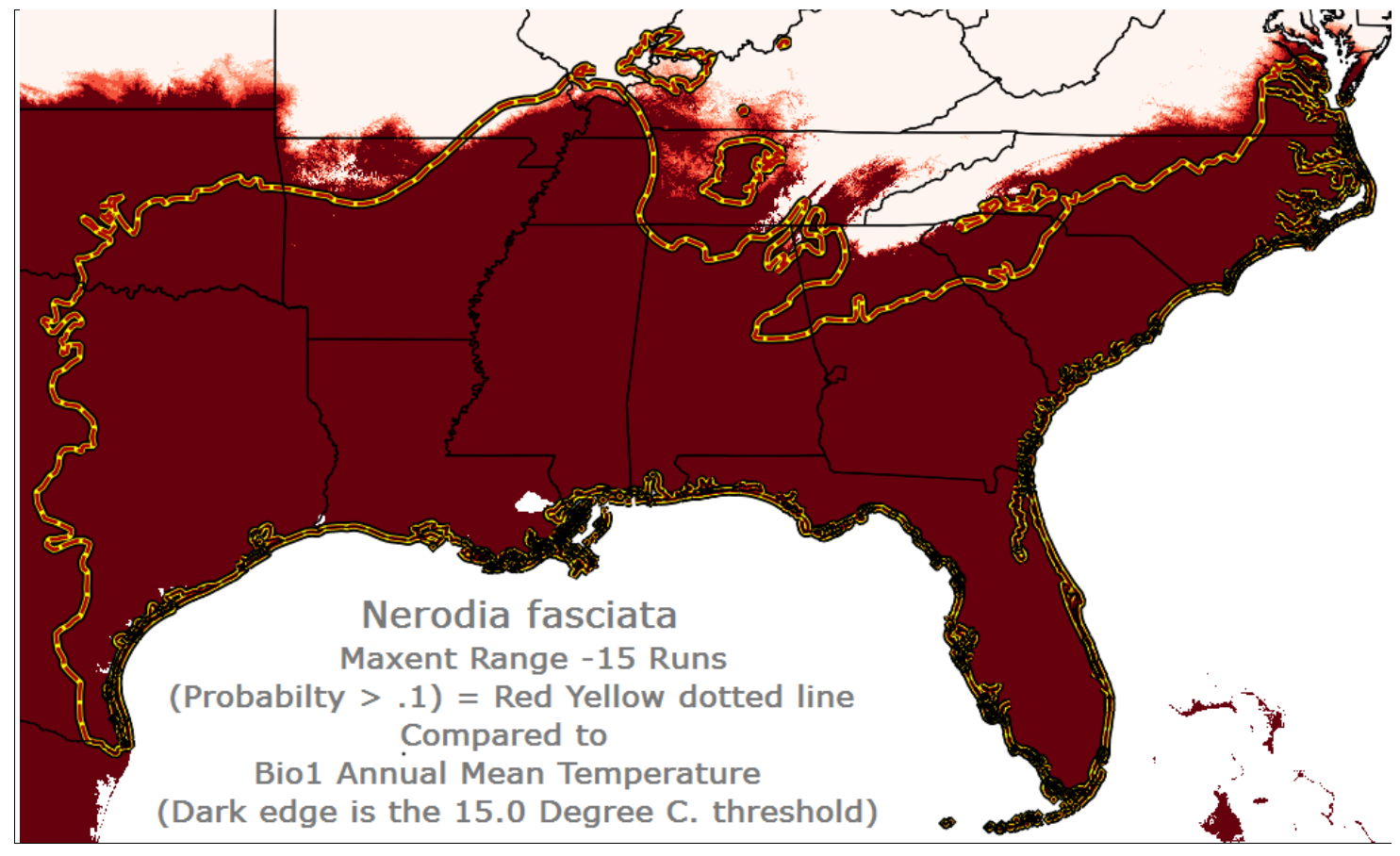


Annual mean temperature at the $15.0^{\circ} \mathrm{C}$ threshold is almost the same as BIO10 mean temperature of warmest quarter. The two are similar concerns, though they address different bioclimatic characteristics. The fact that their northern edges are so similar makes one suspect they are possibility redundant concerns. Together, they represent a combined importance of nearly $40 \%$. Both annual mean temperature at the $15.0^{\circ} \mathrm{C}$ threshold and BIO1O mean temperature of warmest quarter also exhibit similar variation from the 0.1 probability threshold. Clearly, both are making the same statement about limiting factors.

Precipitation of driest month, presented here in Figure 30 at the $37.5 \mathrm{~mm}$ threshold, shows a similar relation to defining the snake's western range edge as did BIO13 precipitation of wettest month, except that the coincidence is not as sharply related. It is also two and one-half times less in importance, so one might expect it to be less definitive.

Figure 30. Precipitation of driest month at the $37.5 \mathrm{~mm}$ threshold.

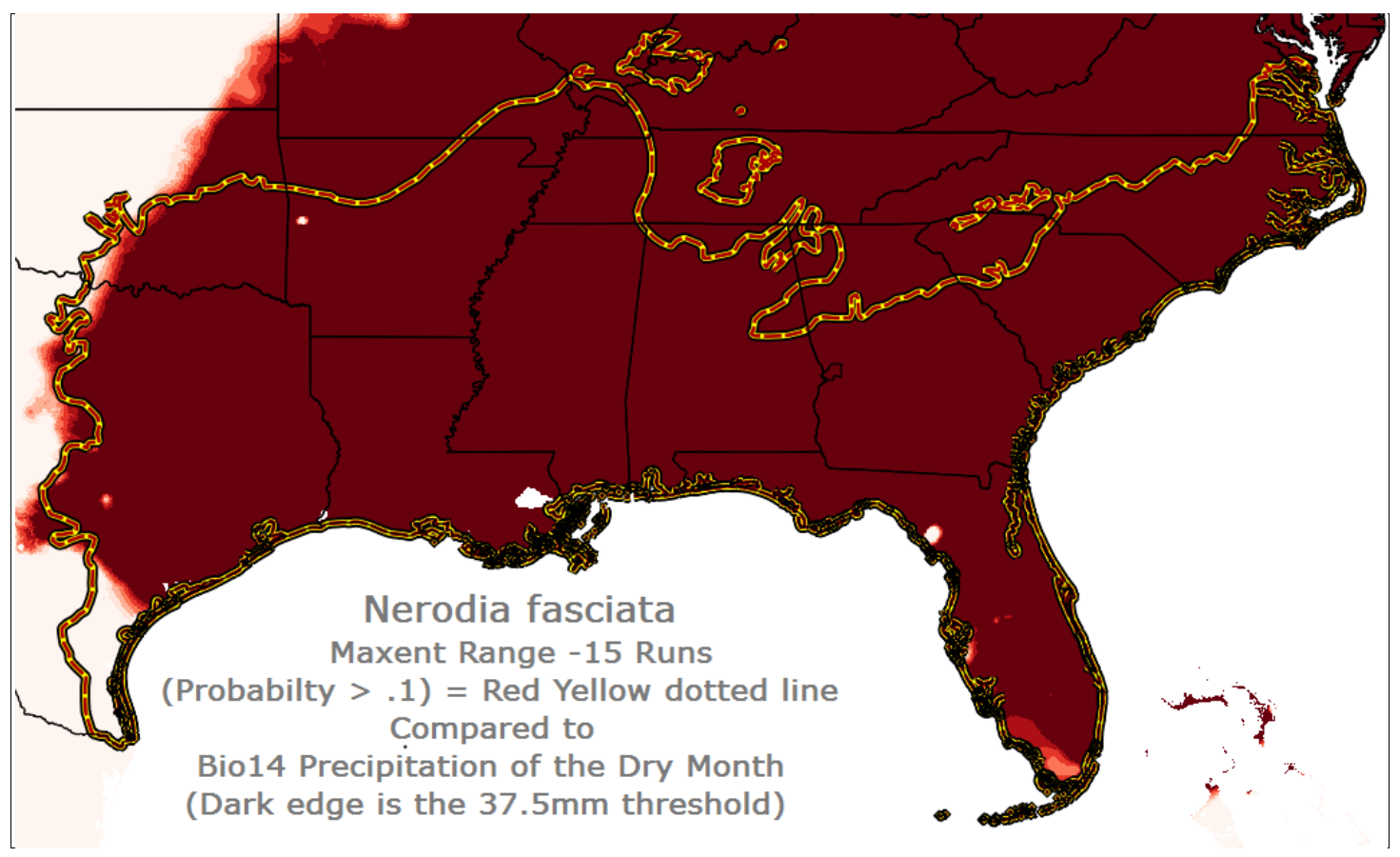

\subsubsection{Spatial conclusions for the Banded Watersnake}

In summary, the conclusion is that two bioclimatic characteristics are significant in defining the Banded Watersnake's range: mean temperature of warmest quarter and precipitation of wettest month. The precipitation of wettest month at the $110 \mathrm{~mm}$ threshold clearly defines the western boundary of the species range. Of more importance but less definitive is the 
mean temperature or warmest quarter at the $24.5{ }^{\circ} \mathrm{C}$ threshold. This bioclimatic concern roughly defines the northern boundary of the snake's habitat. Evidently another concern (not identified) also influences the northern boundary.

\subsection{Glossy Crayfish Snake (Regina rigida)}

\subsubsection{County data}

Sightings from 223 counties were received in a Microsoft Excel file from the project collaborators.

\subsubsection{Traditional range map}

The traditional range map (created June 2005) was derived from the map presented on the NatureServe website.

\subsubsection{Critical mapping guidance issues}

Glossy Crayfish Snake resides in most wetlands with shallow, slow-moving water. It is unlikely to travel overland.

\subsubsection{Final 15-run results}

The multi-run probability distribution (Figure 31) is extremely similar to that derived from the single modeling run.

The average omission rate for Glossy Crayfish Snake shows a wide one standard deviation spread (the orange color in Figure 32). The mean omission rate (green line) lies well above the predicted rate (black line). This means that the submitted bioclimatic layers are largely independent of each other. If it lay below the black line, then the bioclimatic layers would not be independent. The mean AUC for $R$. rigida (0.952) was lower than $S$. pygaea (0.966), N. floridana (0.986), and D. reticularia (0.965), but higher than for K. subrubrum (0.908), so the value for AUC for $R$. rigida is considered low but within the normal range. The Maxent range is welldefined and coordinates reasonably well with the NatureServe range map. However, it is more extensive in all of Alabama and eastern Arkansas, mid-south Georgia, and extends a little farther south to the middle of Florida (although there are no reported sightings in that region). Maxent does not include any of the sightings along the coastal areas of Virginia as part of the Glossy Crayfish Snake's range. 
Figure 31. The multi-run probability distribution for Glossy Crayfish Snake. The dotted red/yellow line is the 15 model run result, and the yellow dotted line shows the NatureServe traditional boundary.

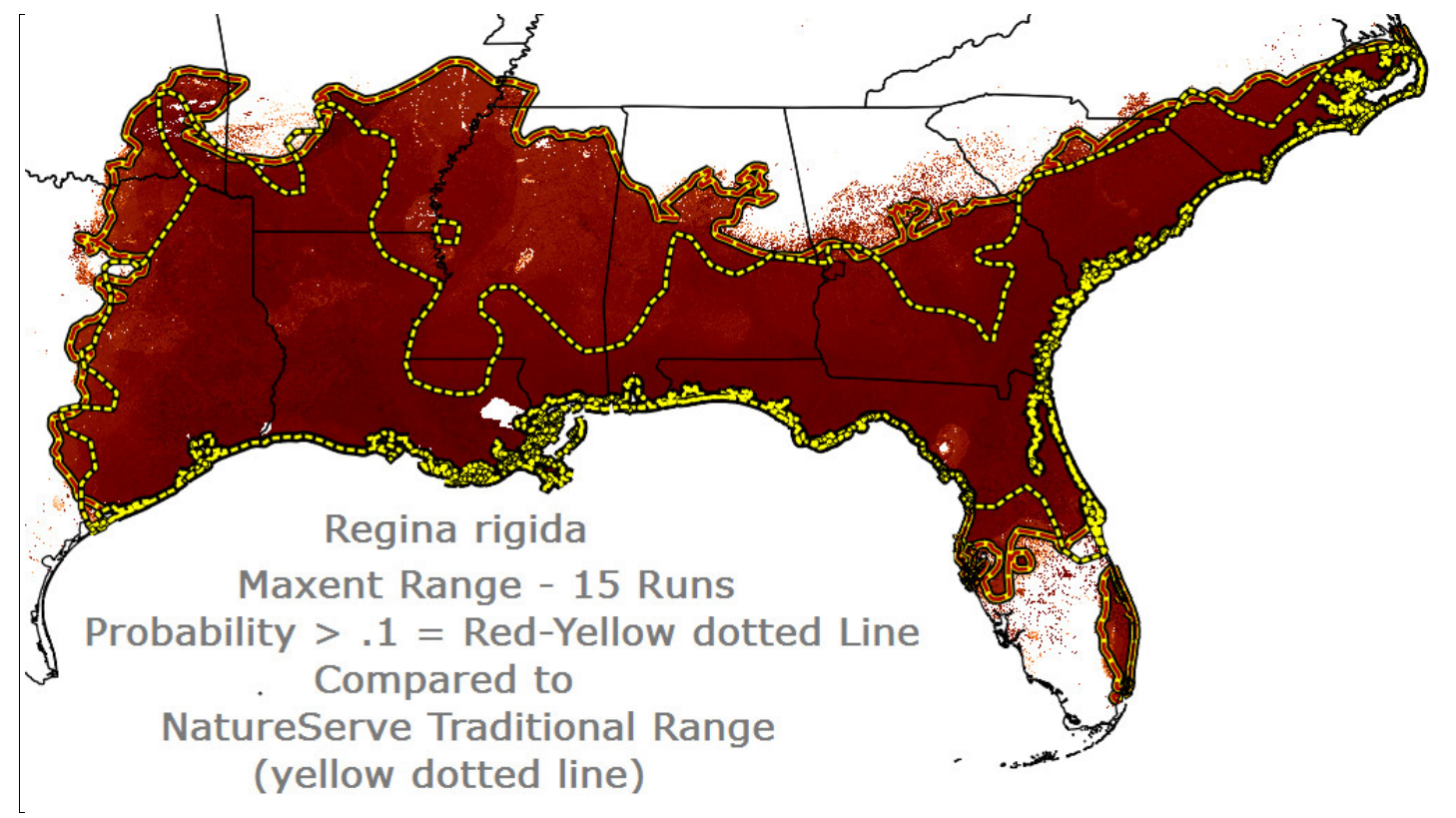

Figure 32. Average omission rate for Glossy Crayfish Snake.

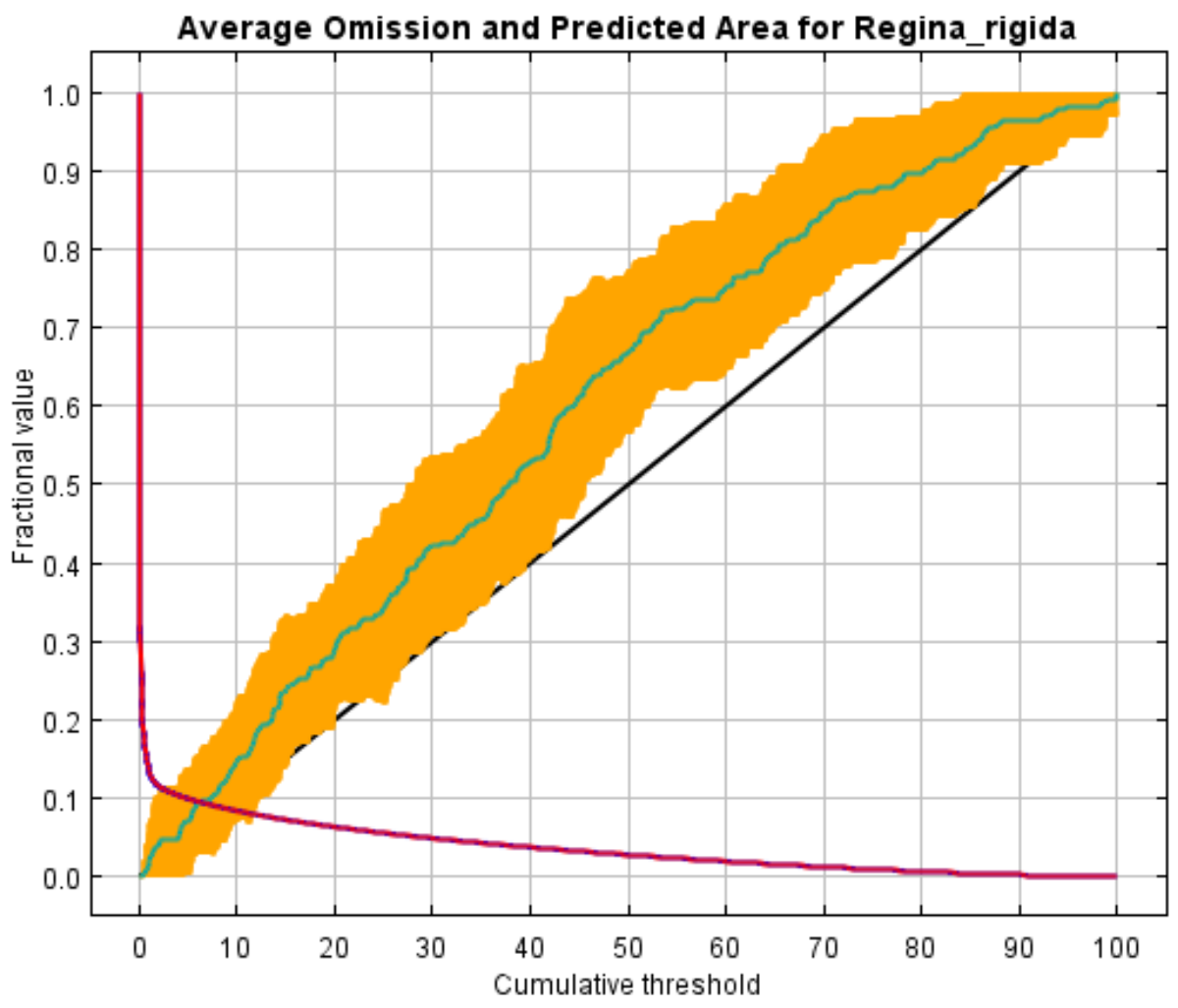


All the testing alternatives show a greater range than the NatureServe traditional range in all of Alabama and eastern Arkansas and mid-south Georgia. The Maxent probability map can be considered a "potential" range.

The standard deviation for the 15 model runs is presented in Figure 33.

Figure 33. The standard deviation for the 15 model runs for $R$. rigida.

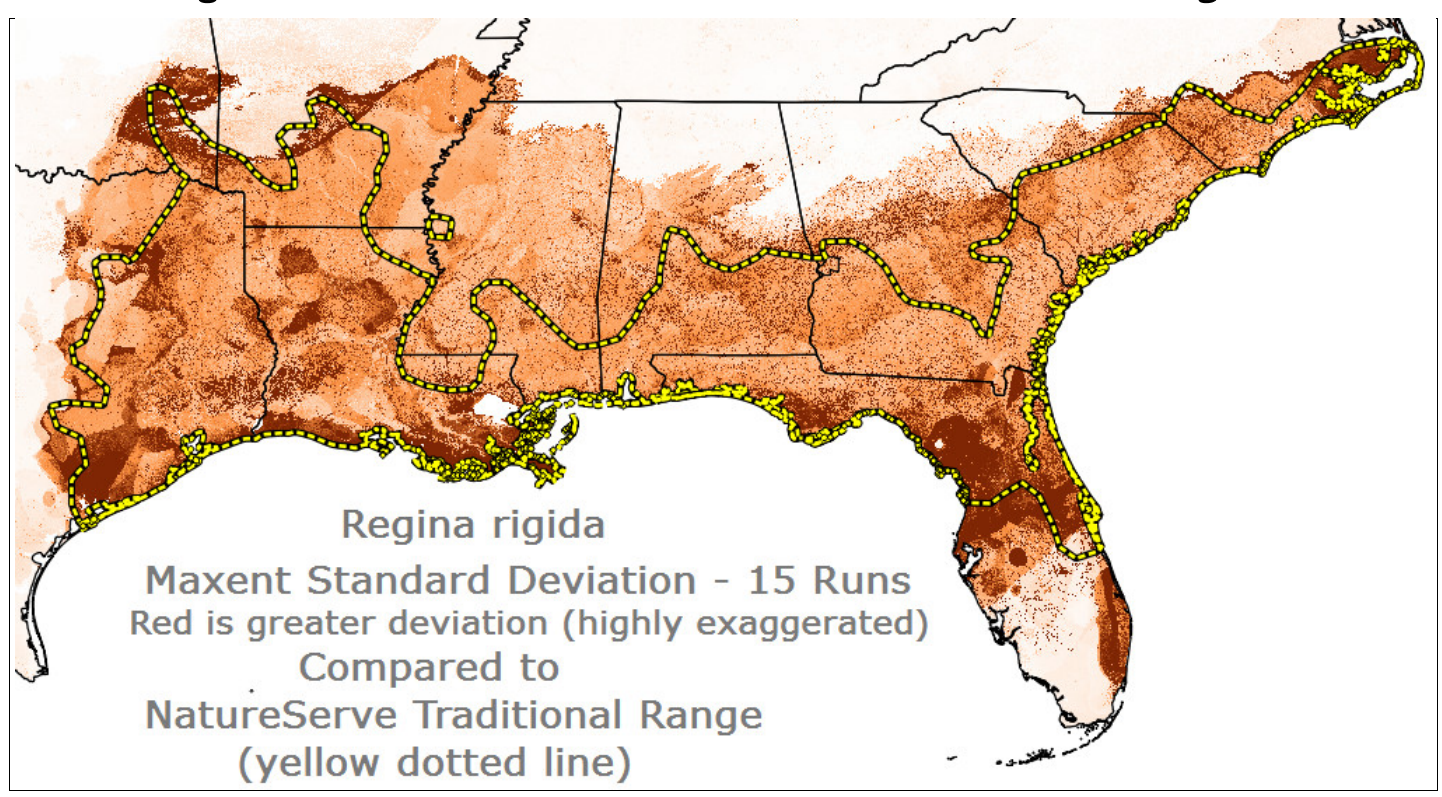

The histogram of the color table in Figure 33 was exaggerated to show the highest deviations (i.e., those locations that varied the most among the 15 model runs). Figure 33 shows that the greatest variation among the 15 models was not concentrated in those locations that varied most from the traditional range. This observation strongly indicates that all of Alabama, all of eastern Arkansas, and mid-south Georgia should be within the snake's range. Those areas that Maxent shows with the greatest deviation (what might be considered doubt in this case) are in Oklahoma, the west coast of Florida (near Cedar Key), and northern coastal North Carolina where sightings existed. The outlier area near Miami is also called into question. Finally, the greatest standard deviation is only 0.04. This is an extremely low value. The implication is that the model is very stable and even in the areas of greatest standard deviation, it is highly reliable.

\subsubsection{Variable importance averaged after 15 models}

Table 12 shows that unlike other species, there are several bioclimatic concerns that have the potential to contribute to defining the Glossy Crayfish 
Snake's range. In order of importance the top six are: $\mathrm{BIO} 1$ annual mean temperature, BIO14 precipitation of driest month, BIO12 annual precipitation, BIO13 precipitation of wettest month, GAP land cover, and BIO19 precipitation of coldest quarter. The top four concerns account for $82.6 \%$ of the importance of all the bioclimatic factors. It is remotely possible that BIO14 precipitation of driest month could be most important, followed by GAP land cover, BIO12 annual precipitation, and then BIO19 precipitation of coldest quarter. At any rate, no other bioclimatic concerns have the potential to rise above the $10 \%$ importance level. It is interesting that in the concerns ranked 2-8, five of those seven are rainfall concerns. Together they represent $41 \%$ of the importance, compared to the $46 \%$ for the top annual precipitation. The implication is that this snake is highly influenced by rainfall character. Finally, although the NatureServe descriptions put a high emphasis on the water habitat, the accumulation layer was nearly at the bottom of the list of important factors. Thus the annual temperature is most likely to be the controlling factor, while the minimum amount of rainfall in driest month (usually the winter in the Southeast) and the amount of yearly rainfall are likely limiting factors for the Glossy Crayfish Snake. 
Table 12. Variable Importance for Glossy Crayfish Snake.

\begin{tabular}{|l|r|r|r|r|}
\hline Variable & $\begin{array}{l}\text { Percent } \\
\text { Contribution }\end{array}$ & $\begin{array}{l}\text { Permutation } \\
\text { Importance }\end{array}$ & $\begin{array}{l}\text { Contribution } \\
\text { Range Low }\end{array}$ & $\begin{array}{l}\text { Contribution } \\
\text { Range High }\end{array}$ \\
\hline Bio1_AnnTemp & 45.7 & 36.0 & 9.7 & 81.7 \\
\hline Bio14_PrecipDryMnth & 17.7 & 6.3 & 11.4 & 24.0 \\
\hline Bio12_AnnPrecip & 12.0 & 1.5 & 10.5 & 13.5 \\
\hline Bio13_PrecipWetMnth & 7.2 & 3.0 & 4.2 & 10.2 \\
\hline gaplc & 5.8 & 11.8 & 0.0 & 17.6 \\
\hline Bio19_PrecipColdQtr & 2.1 & 9.8 & 0.0 & 11.9 \\
\hline physiographic_regions & 2.1 & 4.1 & 0.0 & 6.2 \\
\hline Bio18_PrecipWarmQtr & 2.0 & 6.9 & 0.0 & 8.9 \\
\hline Bio8_MeanTempWetQtr & 1.3 & 3.8 & 0.0 & 5.1 \\
\hline Bio10_MeanTempWarmQtr & 0.7 & 1.7 & 0.0 & 2.4 \\
\hline Bio9_MeanTempDryQtr & 0.6 & 0.5 & 0.1 & 1.1 \\
\hline Bio11_MeanTempColdQtr & 0.4 & 1.8 & 0.0 & 2.2 \\
\hline Bio20_ConsecDryMnth & 0.4 & 2.2 & 0.0 & 2.6 \\
\hline Bio7_AnnTempRange & 0.4 & 0.8 & 0.0 & 1.2 \\
\hline Bio5_MaxTempWarmMnth & 0.3 & 0.3 & 0.0 & 0.6 \\
\hline Bio3_Isothermality & 0.2 & 2.7 & 0.0 & 2.9 \\
\hline Bio15_PrecipSeasonality & 0.2 & 4.5 & 0.0 & 4.7 \\
\hline Bio2_DiurnalRange & 0.2 & 1.2 & 0.0 & 1.4 \\
\hline Bio6_MinTempColdMnth & 0.2 & 0.3 & 0.0 & 0.5 \\
\hline Bio4_TempSeasonality & 0.2 & 0.2 & 0.0 & 0.4 \\
\hline dem_acc & 0.1 & 0.4 & 0.0 & 0.5 \\
\hline dem_morph & 0.1 & 0.1 & 0.0 & 0.2 \\
\hline
\end{tabular}

\subsubsection{Coordinated marginal response curves:}

Charts for the four controlling factors are shown in Figure 34. 
Figure 34. Coordinated marginal response curves for Glossy Crayfish Snake.
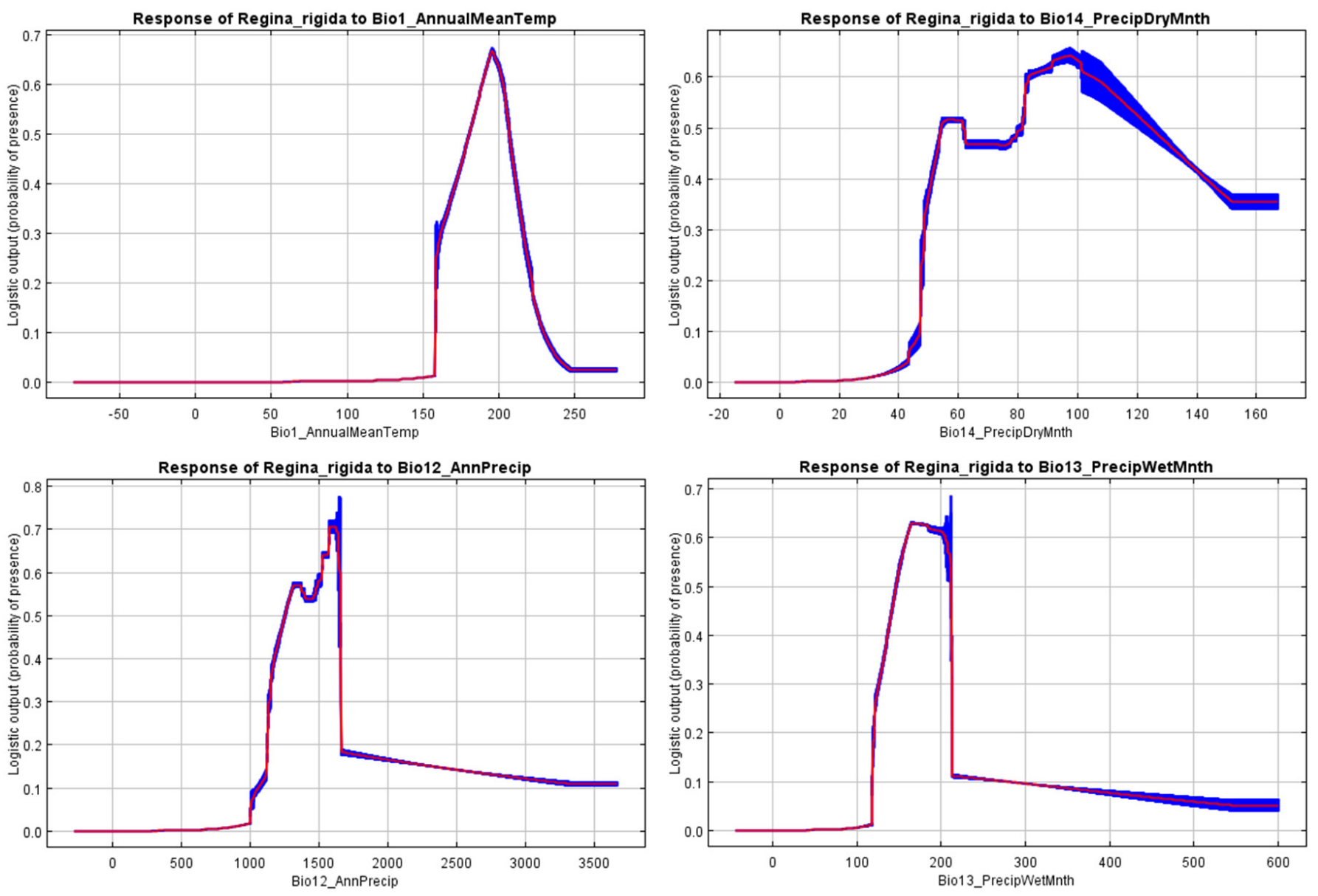

On all of these charts, the blue area representing one standard deviation among the 15 models is small. Thus, these charts can be considered stable with regard to the important bioclimatic charactistics of the Glossy Crayfish Snake.

\subsubsection{Bioclimatic thresholds of the Glossy Crayfish Snake}

Using the probability level of 0.1 on each of these charts as the threshold, (coordinating with the 0.1 threshold used on the $R$. rigida probability map in Figure 31), the threshold results are then defined in the Table 13. 
Table 13. Bioclimatic thresholds for the occurrence of Glossy Crayfish Snake.

\begin{tabular}{|c|c|c|c|c|c|c|c|c|}
\hline \multicolumn{9}{|c|}{ Bioclimatic Thresholds For the Occurence of Regina rigida (Glossy Crayfish Snake) } \\
\hline Bio Num & Bioclimatic Concern & $\begin{array}{l}\text { Lower } \\
\text { Threshold } \\
\text { (when } \\
P=0.1 \text { ) }\end{array}$ & Severity & $\begin{array}{c}\text { Occurs } \\
\text { below } \\
\text { Threshold? } \\
\text { (Limiting?) }\end{array}$ & $\begin{array}{l}\text { Upper } \\
\text { Threshold } \\
\text { (when } \\
\text { P=0.1) }\end{array}$ & Severity & $\begin{array}{c}\text { Occurs } \\
\text { above } \\
\text { Threshold? }\end{array}$ & $\begin{array}{c}\% \\
\text { Importance } \\
\text { in Model }\end{array}$ \\
\hline $\mathrm{BIO} 1$ & $\begin{array}{l}\text { Annual Mean } \\
\text { Temperature (deg C) }\end{array}$ & 16.0 & Extreme & No & 23.0 & \multirow[t]{2}{*}{ High } & \multirow[t]{2}{*}{ A Little } & 45.7 \\
\hline $\mathrm{BlO} 14$ & $\begin{array}{l}\text { Precipitation of Driest } \\
\text { Month (mm) }\end{array}$ & 48.0 & Extreme & No & None & & & 17.7 \\
\hline $\mathrm{BlO} 12$ & $\begin{array}{l}\text { Annual Precipitation } \\
\text { (in centimeters) }\end{array}$ & 110.0 & Extreme & No & 170.0 & Extreme & Yes & 12.0 \\
\hline $\mathrm{BlO} 13$ & $\begin{array}{l}\text { Precipitation of } \\
\text { Wettest Month }(\mathrm{mm})\end{array}$ & 120.0 & Extreme & No & 220.0 & Extreme & Yes & 7.2 \\
\hline
\end{tabular}

- The lower and upper thresholds for the Glossy Crayfish Snake for the annual mean temperature are both sharp cut offs. Since this is the most important variable of any, it suggests that the snake absolutely requires a temperature range of only 11 degrees (between $12.0^{\circ} \mathrm{C}$ and $23.0^{\circ} \mathrm{C}$ ) with an optimum around $19.0^{\circ} \mathrm{C}$. The snake may exist as the average temperature rises to about $24^{\circ} \mathrm{C}$, but it will not tolerate heat above that level over several generations.

- Precipitation of driest month shows the snake is limited by winter rainfall (usually winter is the driest time in the Southeast). One might expect that a water-limited snake responds to dry-season conditions. Since the upper limit of a dry season makes little sense for water species, there is no sense to the upper threshold.

- Annual precipitation is also a defining factor (the lower limit being important), which is similar and somewhat repetitious to the precipitation of driest month above; the upper limit makes little sense, as described above for precipitation of driest month.

- The snake must have at least $120 \mathrm{~mm}$ of rainfall, on average, for the wettest month. In effect, this is similar to a minimum rainfall requirement seen in precipitation of driest month and annual precipitation above. The repetition of this category of concern for the third time reinforces the idea that minimum rainfall is an important bioclimatic concern. These three sum to a combined importance of nearly $37 \%$ of the determining factors, a sizable portion of the Glossy Crayfish's environmental requirements, which added together amount to nearly as high a level of importance as the single top concern of annual mean temperature. 
- In summary, the critical issues for the Glossy Crayfish Snake are an annual temperature between $16.0^{\circ} \mathrm{C}$ and $23.0^{\circ} \mathrm{C}$ and a minimum rainfall of at least $48 \mathrm{~mm}$ that is probably determined most by the driest winter month.

\subsubsection{Spatially explicit thresholds of the Glossy Crayfish Snake}

Figure 35. The annual mean temperature at the $16{ }^{\circ} \mathrm{C}$. threshold for $R$. rigida.

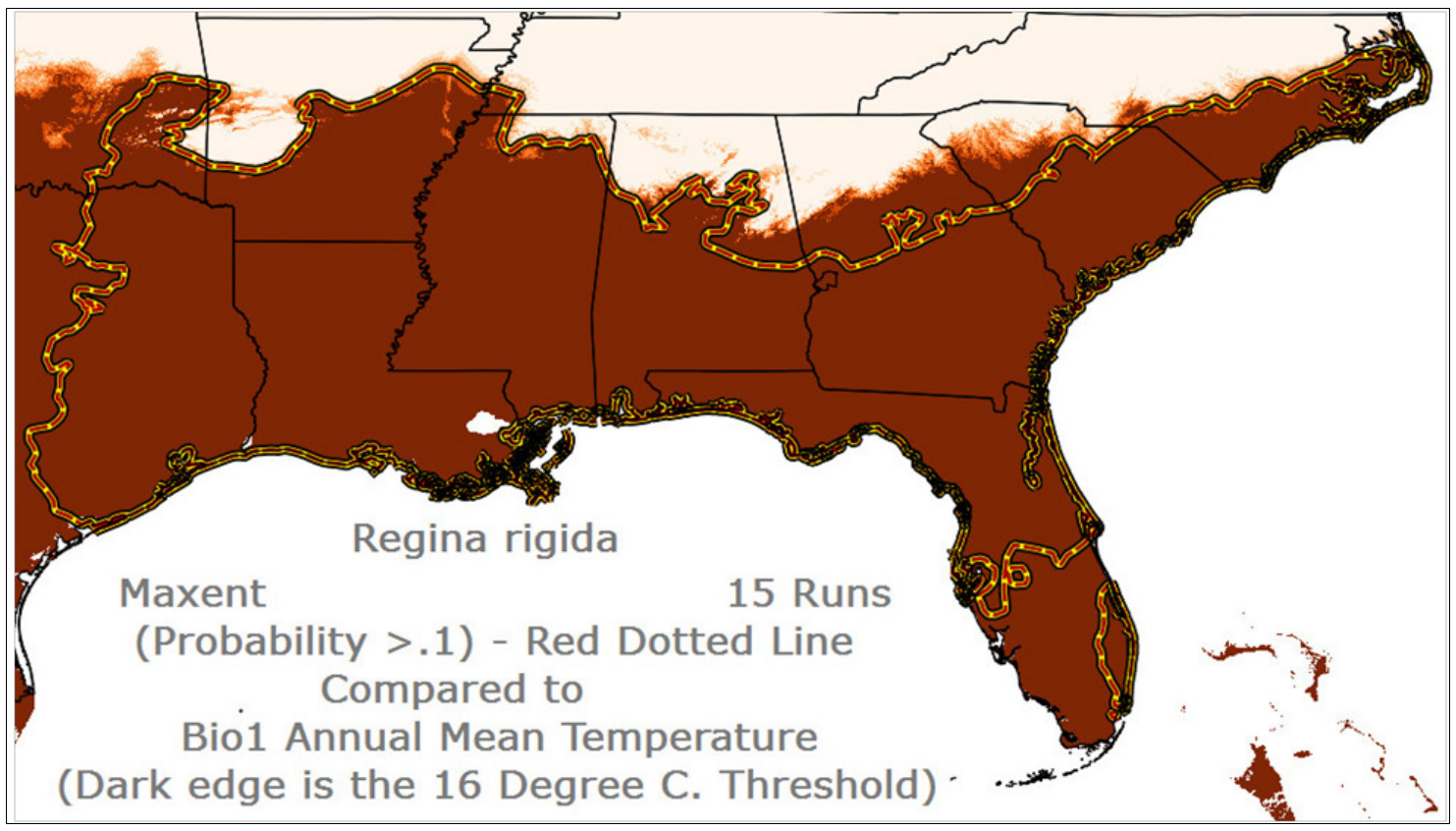

The annual mean temperature at the $16{ }^{\circ} \mathrm{C}$ threshold defines almost the entire northern boundary of the snake, except from the east-central portion of Alabama to the northeastern portion of South Carolina. The coincidence of the two edges on the map is remarkable.

Precipitation of driest month clearly controls the snake's western edge and the two edges that occur in Florida (Figure 36). Thus, between these first two bioclimatic concerns (amounting to $63.4 \%$ of the importance in the Maxent model), the extent of the habitat of the Glossy Crayfish Snake is explained. 
Figure 36. Precipitation of driest month at the $48 \mathrm{~mm}$ threshold for $R$. rigida.

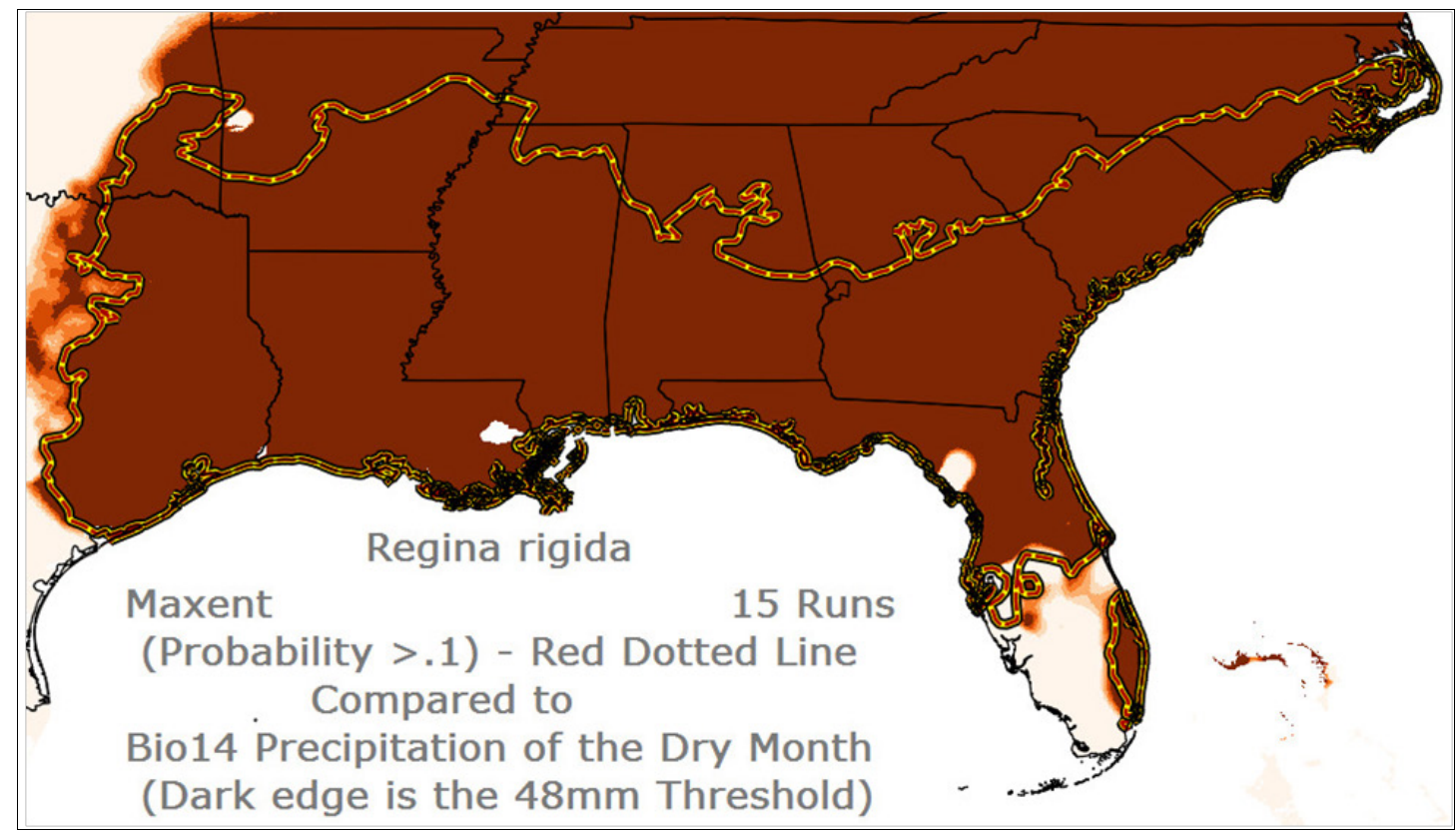

Annual precipitation at the $110 \mathrm{~cm}$ threshold may explain the snake' $\mathrm{s}$ range in eastern Oklahoma, but precipitation of driest month previously did just as well (Figure 36). At 12\% importance, Figure 37 illustrates the redundant nature of this bioclimatic concern.

Figure 37 . Annual precipitation at the $110 \mathrm{~cm}$ threshold for $R$. rigida.

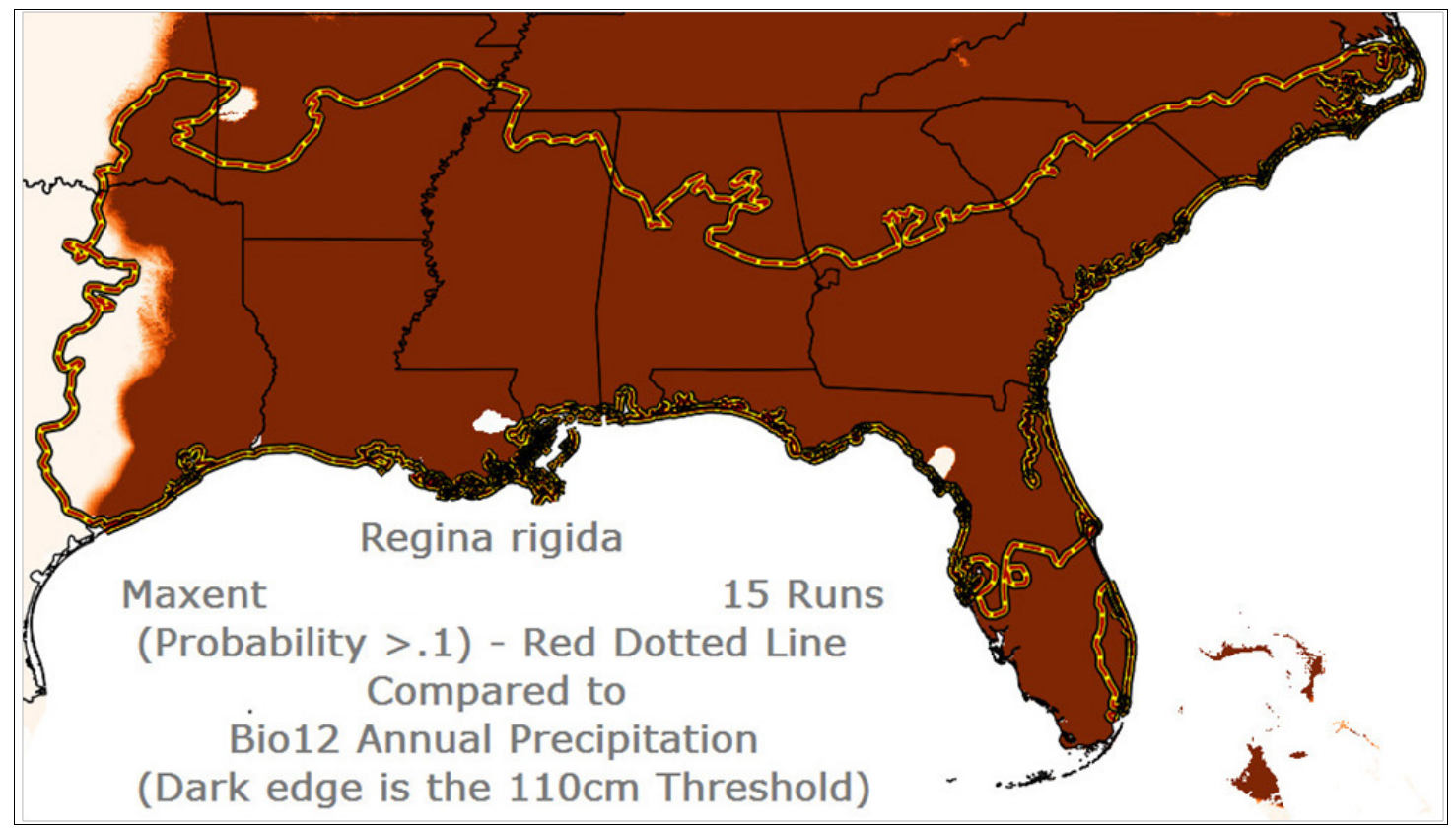


Precipitation of wettest month, presented here at the $120 \mathrm{~mm}$ threshold, shows no relationship to defining the snake's range (Figure 38 ).

Figure 38. Precipitation of the wettest month at the $120 \mathrm{~mm}$ threshold for $R$. rigida.

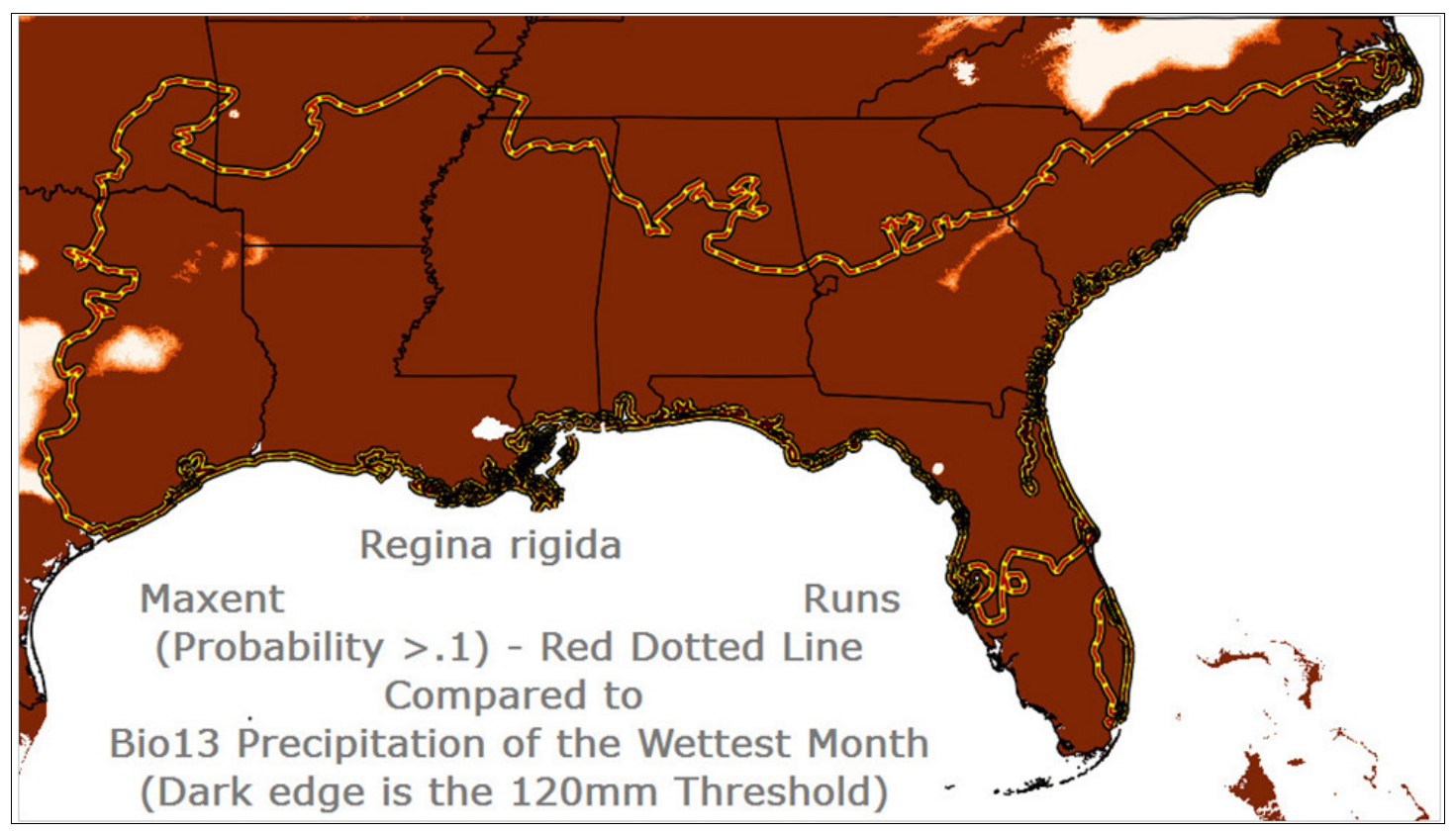

\subsubsection{Spatial conclusions for the Glossy Crayfish Snake}

Two bioclimatic factors are significant in defining the Glossy Crayfish Snake's range: the annual mean temperature and precipitation of driest month. Although the next couple of concerns were reviewed, they seemed to contribute no significant additional information. Of primary importance is the annual mean temperature at the $16^{\circ} \mathrm{C}$ threshold, which defines almost the entire northern boundary of the snake's habitat, and precipitation of driest month at the $48 \mathrm{~mm}$ threshold, which controls the western edge of the snake's habitat and also the two edges that occur in Florida.

\subsection{Black Swampsnake (Seminatix pygaea)}

\subsubsection{County data}

Sighting summaries from 68 counties were received in a Microsoft Excel file format from project collaborators. 


\subsubsection{Traditional range map}

The traditional range map (created 2005) was derived from the map presented on the NatureServe website.

\subsubsection{Critical mapping guidance issues}

The Black Swampsnake resides in most wetlands of any sort and travels overland during wet periods. The species has a high restriction to wet areas.

\subsubsection{Final 15-run results}

The multi-run probability distribution is similar to that derived from the single modeling run, except it is a little more restrictive in Texas. The average omission rate for Black Swampsnake shows a wide one standard deviation spread. On the other hand, the mean AUC for S. pygaea (0.966) was lower than $N$. floridana (0.986), similar to D. reticularia (0.965) and higher than for K. subrubrum (0.908), so the model for S. pygaea is considered within normal variation. The range is well defined and coordinates reasonably with the NatureServe range map, but the range is more extensive in North Carolina and Georgia, and it extends significantly farther to the west in southern Alabama, Mississippi, and eastern Texas. In all of these additional locations, it is likely that either or both of the following are true about the snake:

- existed but is now extirpated, and/or

- never existed because it was out-competed by a similar species.

All of the testing alternatives show a greater range than the NatureServe traditional range, particularly into the west, so this additional extent is likely to be appropriate. It is also possible there exists an input layer(s) not used in this analysis that controls the snake's range in those areas. 
Figure 39. The 15 run probability distribution Maxent output for S. pygaea. The dotted red/yellow line is the 15 model run result, and the yellow dotted line shows the NatureServe traditional boundary.

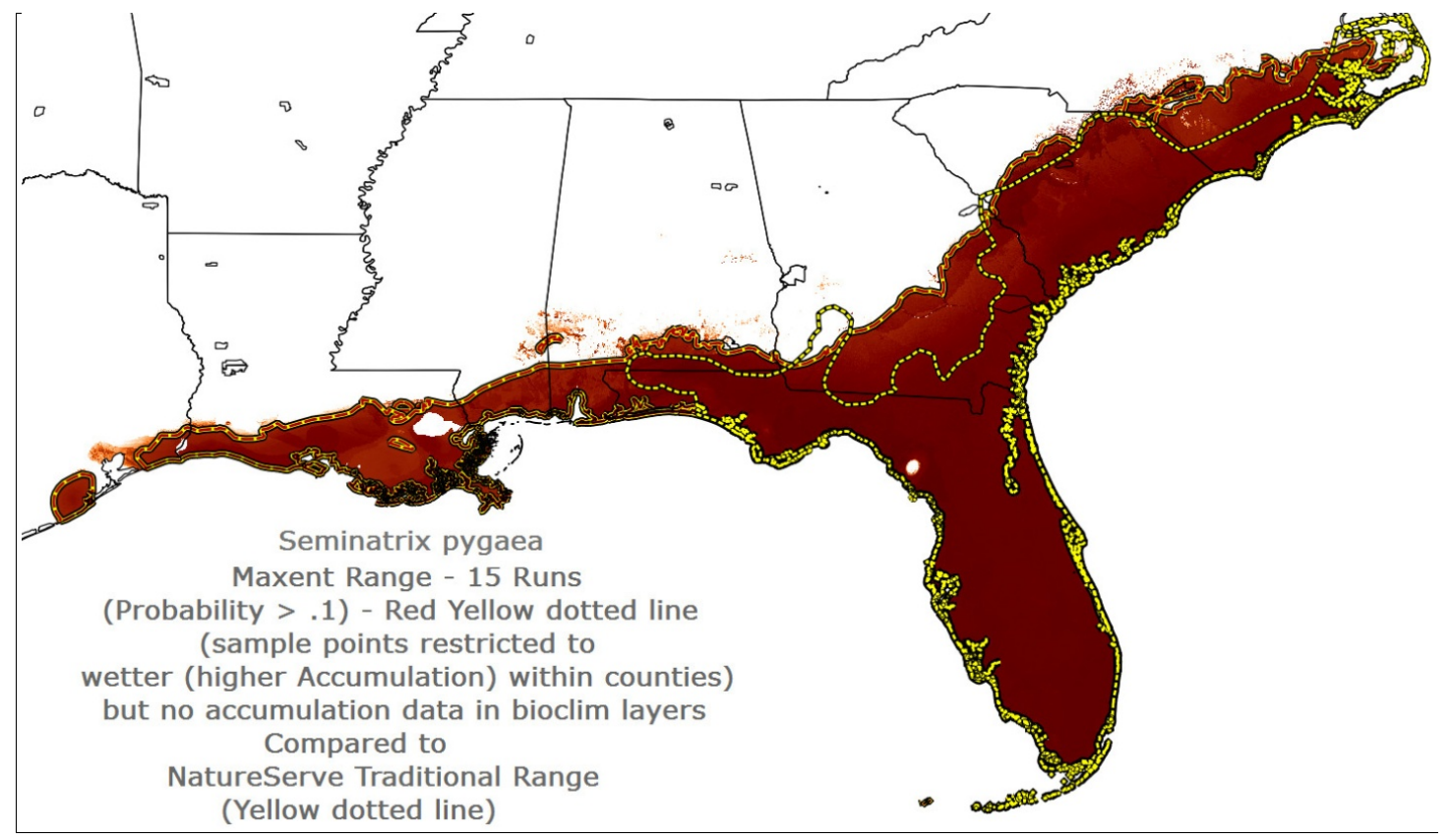

The standard deviation for the model's 15 runs is presented in Figure 40.

Figure 40. The standard deviation for the model 15 runs for $S$. pygaea. Blue dots are county sightings.

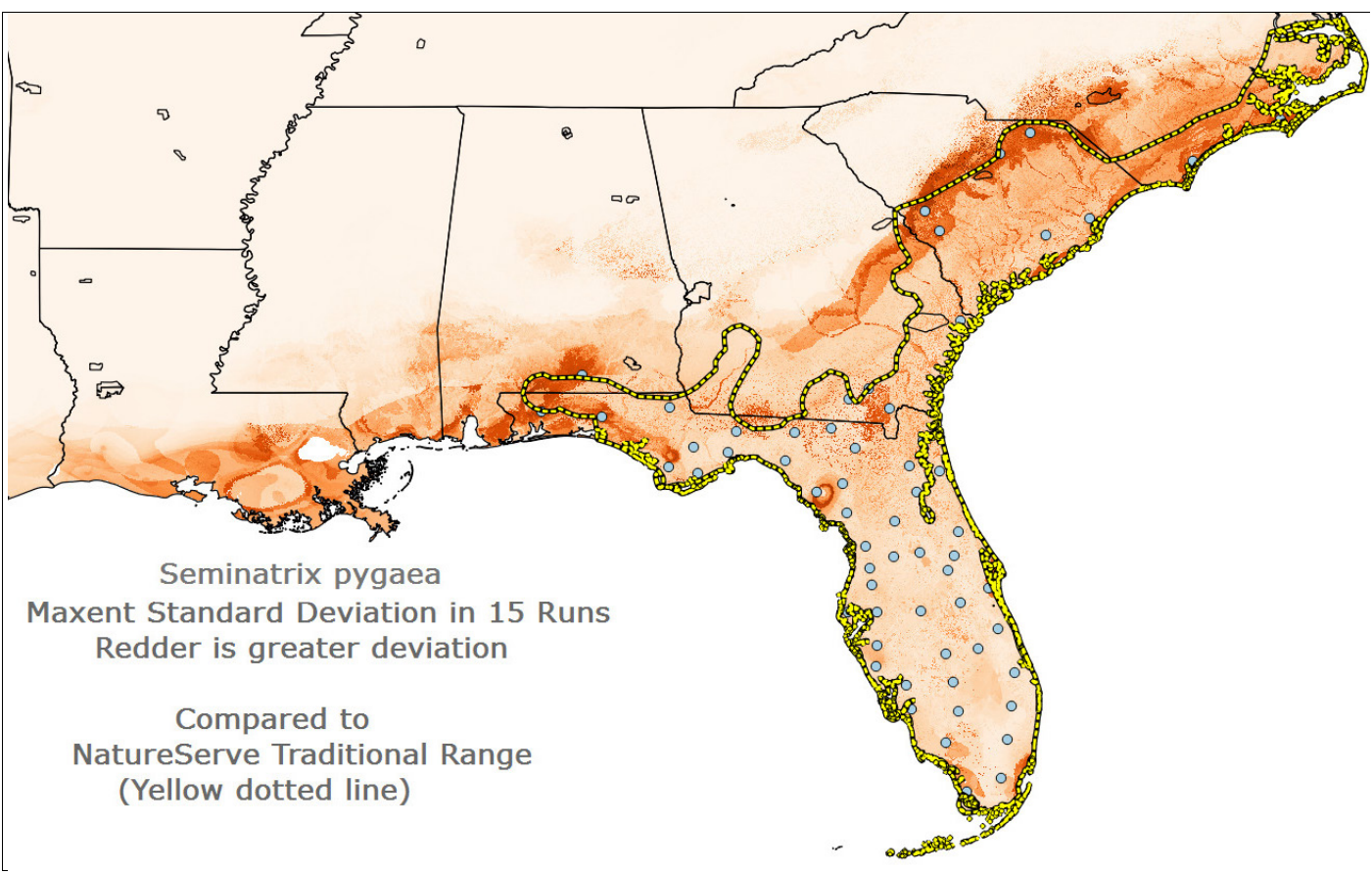


The histogram of the color table was exaggerated to show the highest deviations (i.e., those locations that varied the most among the 15 models). Figure 40 shows that the greatest variation among the 15 models was concentrated at the interior county sighting (light blue dots) in the mid-South Carolina area. There is a similar dark red area near the west end of the Florida panhandle. It is significant that within the western coastal area (that is not included in the traditional range for the Black Swampsnake), Maxent suggests there is little variation in the combination of conditions that make that area appropriate for the species. Finally, the greatest standard deviation is only 0.12; this is an intrinsically low value. The implication is that the model is very stable.

\subsubsection{Variable importance, averaged from 15 model runs}

Table 14 shows that precipitation of warmest quarter and mean temperature of wettest quarter are by far the most important concerns for the Black Swampsnake; they account for $86 \%$ of the Maxent model. No matter what, mean temperature of the wettest quarter will always be in the top two concerns. Precipitation of warmest quarter is likely to be among the most important concerns. No other concerns have the potential to contribute more than $2.5 \%$. Thus, the temperature during the summer is highly likely to be a controlling factor for the Black Swampsnake, and the summer rain certainly is also. 
Table 14. Variable importance averaged from 15 model runs for Black Swampsnake.

\begin{tabular}{|l|r|r|r|r|}
\hline Variable & $\begin{array}{c}\text { Percent } \\
\text { Contribution }\end{array}$ & $\begin{array}{c}\text { Permutation } \\
\text { Importance }\end{array}$ & $\begin{array}{c}\text { Contribution } \\
\text { Range Low }\end{array}$ & $\begin{array}{c}\text { Contribution } \\
\text { Range High }\end{array}$ \\
\hline Bio18_PrecipWarmQtr & 64.0 & 92.1 & 0.0 & 100.0 \\
\hline Bio8_MeanTempWetQtr & 24.2 & 0.9 & 23.3 & 25.1 \\
\hline Bio1_AnnTemp & 1.6 & 0.9 & 0.7 & 2.5 \\
\hline Bio10_MeanTempWarmQtr & 1.2 & 0.8 & 0.4 & 2.0 \\
\hline Bio11_MeanTempColdQtr & 1.1 & 0.3 & 0.8 & 1.4 \\
\hline Bio6_MinTempColdMnth & 0.9 & 0.1 & 0.8 & 1.0 \\
\hline Bio7_AnnTempRange & 0.9 & 0.2 & 0.7 & 1.1 \\
\hline Bio12_AnnPrecip & 0.7 & 0.6 & 0.1 & 1.3 \\
\hline Bio14_PrecipDryMnth & 0.7 & 0.1 & 0.6 & 0.8 \\
\hline Bio13_PrecipWetMnth & 0.6 & 0.6 & 0.0 & 1.2 \\
\hline Bio3_Isothermality & 0.6 & 0.6 & 0.0 & 1.2 \\
\hline Bio5_MaxTempWarmMnth & 0.5 & 0.2 & 0.3 & 0.7 \\
\hline Bio20_ConsecDryMnth & 0.5 & 0.5 & 0.0 & 1.0 \\
\hline gaplc & 0.5 & 0.6 & 0.0 & 1.1 \\
\hline natgaplu_mod & 0.5 & 0.5 & 0.0 & 1.0 \\
\hline Bio9_MeanTempDryQtr & 0.4 & 0.6 & 0.0 & 1.0 \\
\hline Bio4_TempSeasonality & 0.4 & 0.6 & 0.0 & 1.0 \\
\hline Bio15_PrecipSeasonality & 0.4 & 0.4 & 0.0 & 0.8 \\
\hline Bio2_DiurnalRange & 0.2 & 0.5 & 0.0 & 0.7 \\
\hline Bio19_PrecipColdQtr & 0.1 & 0.1 & 0.0 & 0.2 \\
\hline
\end{tabular}

\subsubsection{Coordinated marginal response curves:}

The charts for the two controlling factors are shown in Figure 41.

Figure 41. Coordinated marginal response curves for Black Swampsnake.
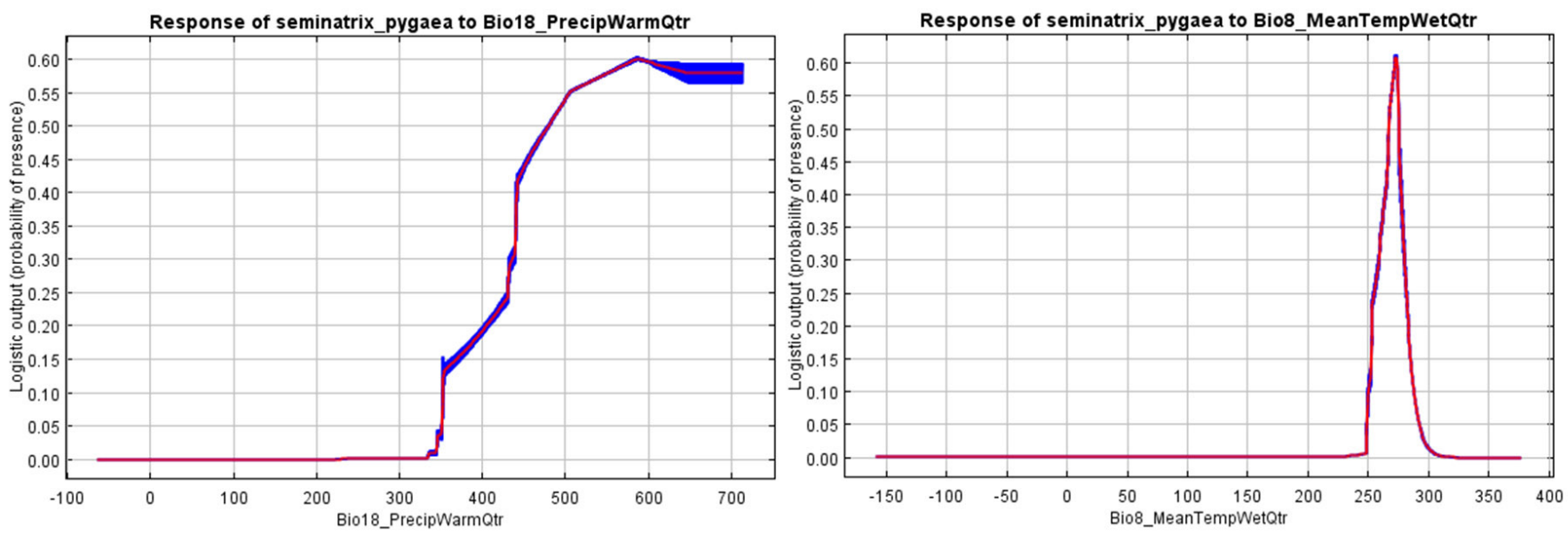

\subsubsection{Bioclimatic thresholds of the Black Swampsnake}

The probability level of 0.1 on each of the charts in Figure 41 is used as the threshold (coordinating with the 0.1 threshold used in Figure 39 for the $S$. 
pygaea probability map above) to define the species thresholds, as shown in Table 15.

Table 15. Bioclimatic thresholds for the occurrence of Black Swampsnake.

\begin{tabular}{|c|c|c|c|c|c|c|c|c|}
\hline Bio Num & Bioclimatic Concern & $\begin{array}{c}\text { Lower } \\
\text { Threshold } \\
\text { (when } \\
\text { P=0.1) }\end{array}$ & Severity & $\begin{array}{l}\text { Occurs below } \\
\text { Threshold? } \\
\text { (Limiting?) }\end{array}$ & $\begin{array}{c}\text { Upper } \\
\text { Threshold } \\
\text { (when } \\
\text { P=0.1) }\end{array}$ & Severity & $\begin{array}{c}\text { Occurs } \\
\text { above } \\
\text { Threshold? }\end{array}$ & $\begin{array}{c}\% \\
\text { Importance } \\
\text { in Model }\end{array}$ \\
\hline $\mathrm{BlO18}$ & $\begin{array}{l}\text { Precipitation of } \\
\text { Warmest Quarter }(\mathrm{mm})\end{array}$ & 350.0 & Extreme & No & None & & Yes & 64.0 \\
\hline $\mathrm{BIO}$ & $\begin{array}{l}\text { Mean Temperature of } \\
\text { Wettest Quarter (deg C) }\end{array}$ & 25.0 & Extreme & No & 28.5 & Extreme & No & 24.2 \\
\hline
\end{tabular}

- The lower threshold for the Black Swampsnake for the precipitation of warmest quarter is a sharp cut off. Since this is the most important variable of any, it suggests that the snake absolutely requires at least $35^{\circ}$ $\mathrm{mm}$ of rain in the summer. It will continue to flourish as the amount increases to an optimum of about $600 \mathrm{~mm}$ and continue to exist with more precipitation, so no upper limit is observed. Since it is called a swamp snake, this finding is not surprising.

- The mean temperature of the wettest quarter shows the snake has a very limited range for summer temperatures (usually summer is the wettest time in the Southeast). It is expected that a cold-blooded reptile responds to temperature concerns. Its range for the three-month period is only $3.5^{\circ} \mathrm{C}$ centered on optimum near $27.0^{\circ} \mathrm{C}$. Since this is the second most important concern, this temperature range has to be significant. Both the precipitation of warmest quarter and mean temperature of wettest quarter are summer-centered concerns, so the summer in the Southeast is critical to the Black Swampsnake.

In summary, the critical issues for the Black Swampsnake are the summer rainfall of at least $350 \mathrm{~mm}$ and a summer temperature between $25{ }^{\circ} \mathrm{C}$ and $28.5^{\circ} \mathrm{C}$.

\subsubsection{Spatially explicit thresholds of the Black Swampsnake}

In this section, it was determined at what level the bioclimatic concern best matched that of the 0.1 probability level. 
Precipitation of warmest quarter at the $350 \mathrm{~mm}$ threshold defines the northern boundary through the east central portion of Georgia and all of South Carolina (Figure 42). It may seem that it has influence elsewhere, but investigation shows that elsewhere there is a range of values from 350 $\mathrm{mm}$ to about $440 \mathrm{~mm}$.

Figure 42.Spatial distribution of precipitation of warmest quarter at the $350 \mathrm{~mm}$ threshold for $S$. pygaea.

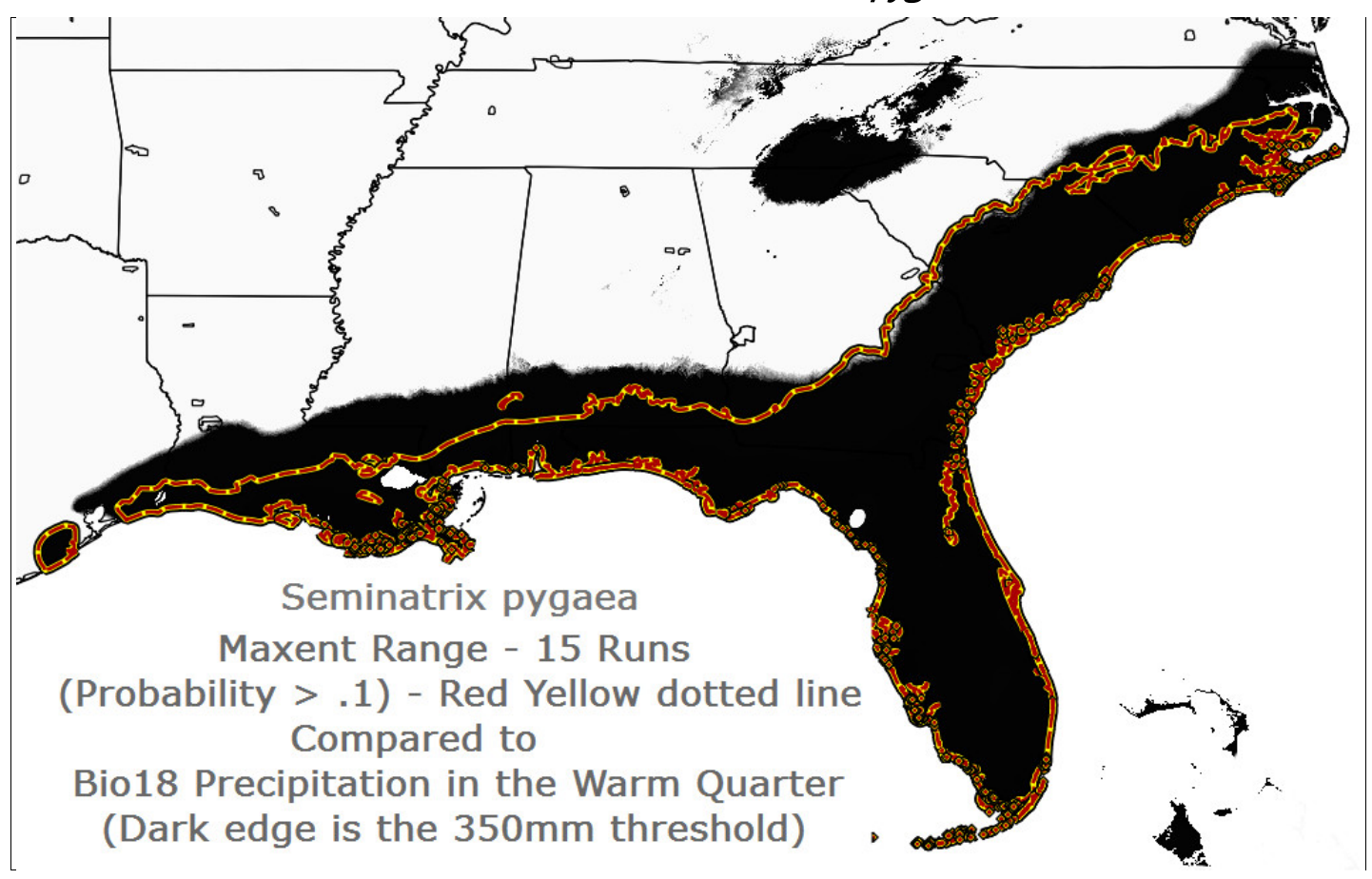

Much of the northern edge of the swamp snake's range from mid-South Carolina to the middle of Louisiana is controlled by the mean temperature of wettest quarter at the $25{ }^{\circ} \mathrm{C}$ level (Figure 43). 
Figure 43. Mean temperature of the wettest quarter at the $25^{\circ} \mathrm{C}$ level for $S$. pygaea.

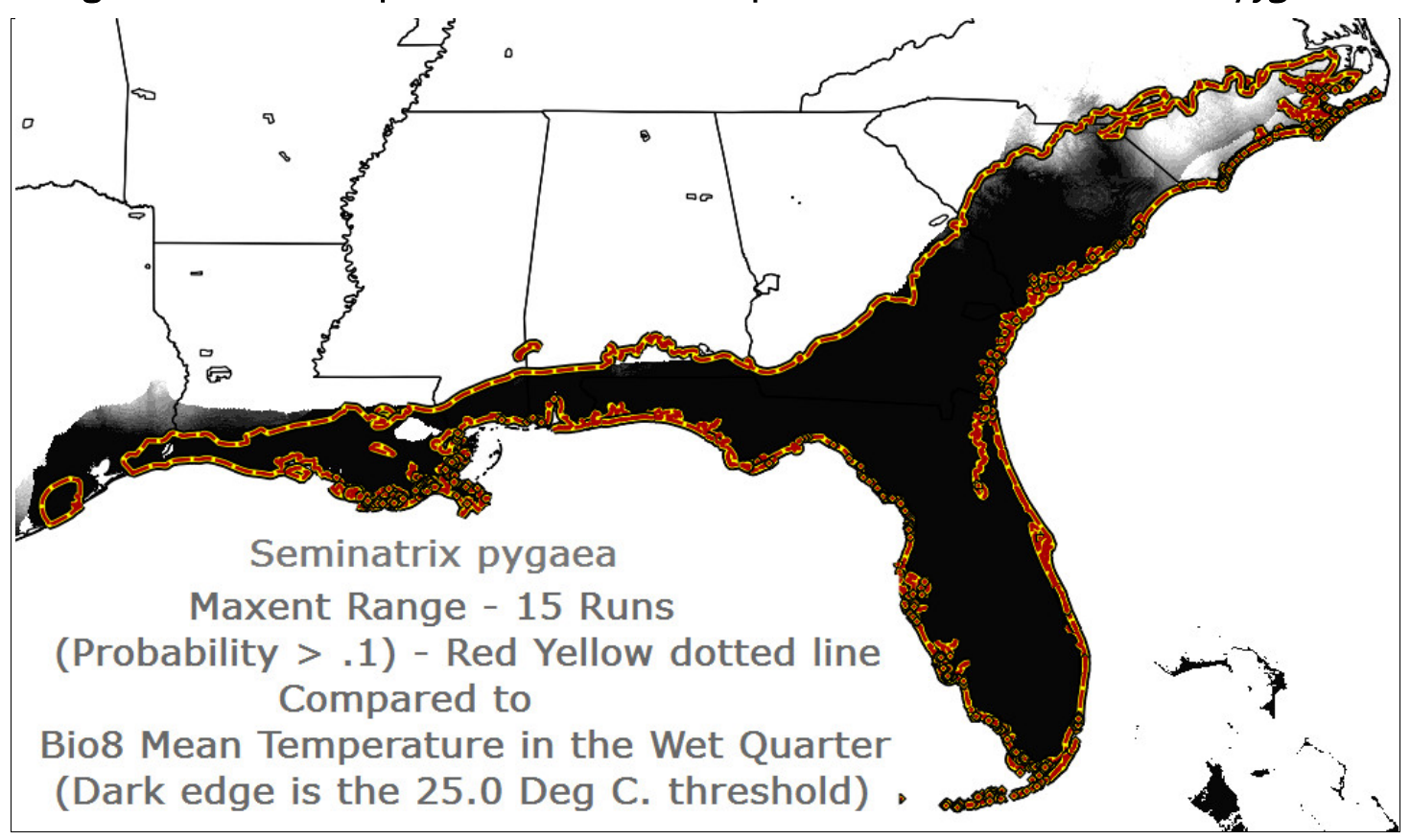

\subsubsection{Spatial conclusions for the Black Swampsnake}

In summary, it is suggested that both the two bioclimatic concerns discussed in this section are significant in defining the Black Swampsnake's range. In addition, the mean temperature of wettest quarter will certainly be a controlling bioclimatic factor (even though Maxent assigned it to be second in importance). At the $25{ }^{\circ} \mathrm{C}$ level, this temperature defines the range of the Black Swampsnake over several states and only begins to fail at limiting the snake at its western extent, where museum observations did not occur. Although primary in importance, it is possible that the precipitation of warmest quarter may have no importance in defining the snake's range. At the $350 \mathrm{~mm}$ level of summer rainfall, it defines the northern boundary exclusively in northern South Carolina. From central Georgia to mid-South Carolina, both concerns seem to limit the northern range of the Black Swampsnake.

\subsection{Common Musk Turtle (Sternotherus odoratus)}

\subsubsection{County data}

County names which were based on a recent study (Buhlmann 2009) were received in a Microsoft Excel file. 


\subsubsection{Traditional range map}

The traditional range map (created in 2008) was derived from the map presented on the NatureServe website.

\subsubsection{Critical mapping guidance issues}

Common Musk Turtle resides near fresh water, not salt water. The turtle travels overland beyond its home watershed, but these areas are not considered habitats. Distances from small streams and small water bodies are important.

\subsubsection{Final run results}

Figure 44 shows that, in general, the Maxent distribution at the 0.1 probability and the traditional range is not great. In the west and north, Maxent tends to include a little more land, and it is also more inclusive north of Lakes Erie and Ontario and along the Appalachian region. Evidently, concerns that slightly limit the Musk Turtle range are not among those used in this analysis.

Figure 44. The difference between the Maxent distributions at the 0.1 probability (red-yellow dotted line) to the traditional range (yellow dotted line) for $S$. odoratus.

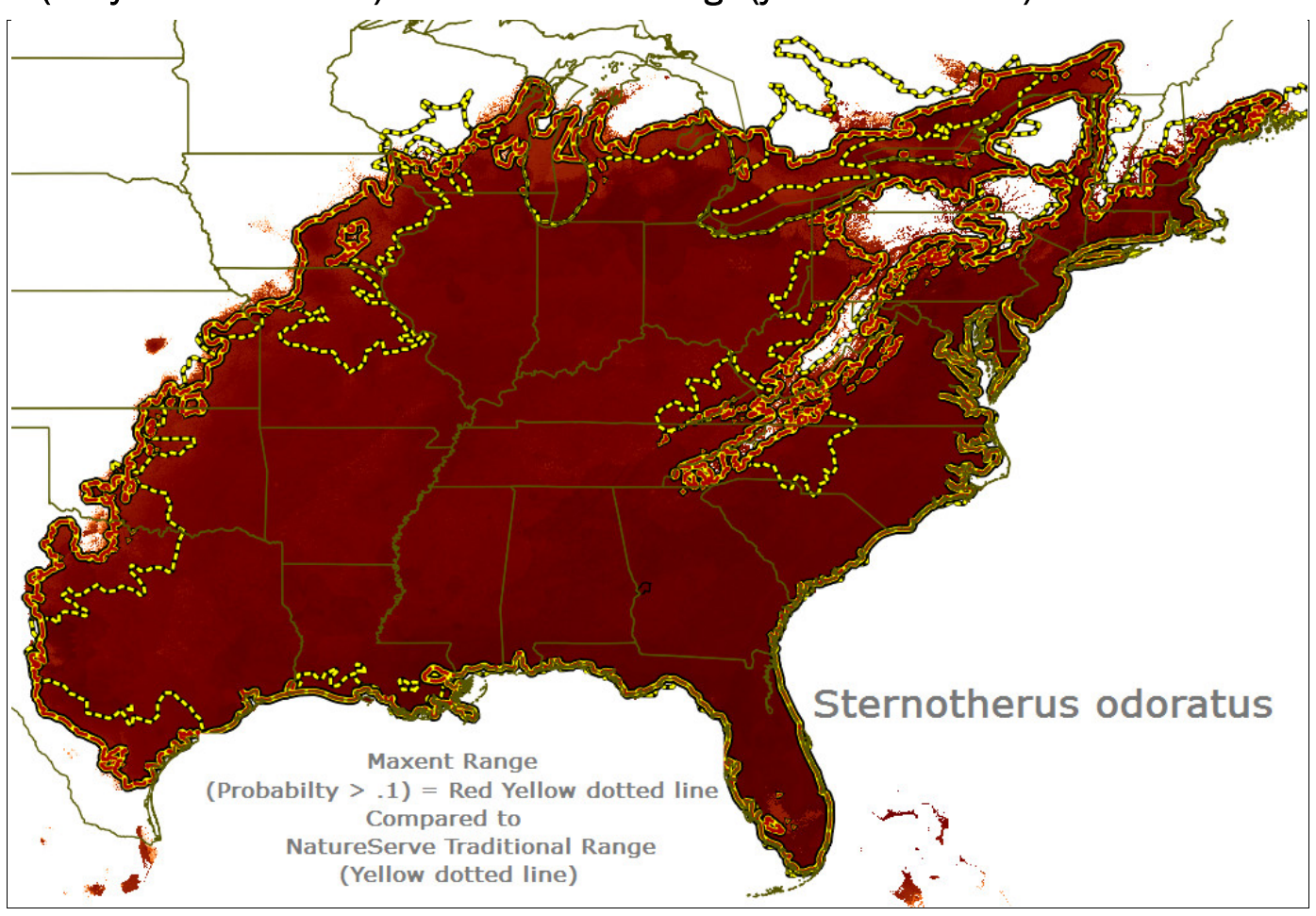


Statistical tests of the Musk Turtle model's viability show the model as reliable. The fraction of the test localities is low that falls into pixels not predicted as suitable. The larger the AUC, the better the model has done. The Musk Turtle value of 0.914 is very high. All of the 11 null statistical tests were carried out, testing the statement that says "points are predicted no better than by a random prediction" to indicate the probability that the distribution is random is vanishingly small. The model appears to have passed its own viability tests.

\subsubsection{Variable importance averaged from 15 model runs}

Table 16 shows that mean temperature of warmest quarter, precipitation of driest month, and precipitation of the driest quarter are the most important concerns for the Musk Turtle. They account for $87.2 \%$ of the importance in the Maxent model. No matter what, precipitation of driest month and precipitation of driest quarter will always be among the top three concerns. It should be noted that those two bioclimatic concerns are probably redundant. If counted as a single input to the model, their combined contribution would be $49.3 \%$, which is significantly greater than the value for any single concern alone.

The issue of precipitation in driest period is critical. Dry period precipitation takes on an even greater importance when considering the top concern (mean temperature of warmest quarter) may provide as little as 3.8\% contribution in the worst case, making it potentially of minor concern. No other bioclimatic factors have the possibility of rising in importance to as great as $17.2 \%$, the value for precipitation of driest quarter. Thus, potential lack of precipitation in driest period (usually meaning winter over much of this area) is certainly the controlling factor for the Musk Turtle. 
Table 16. Variable importance, averaged from 15 model runs for Musk Turtle.

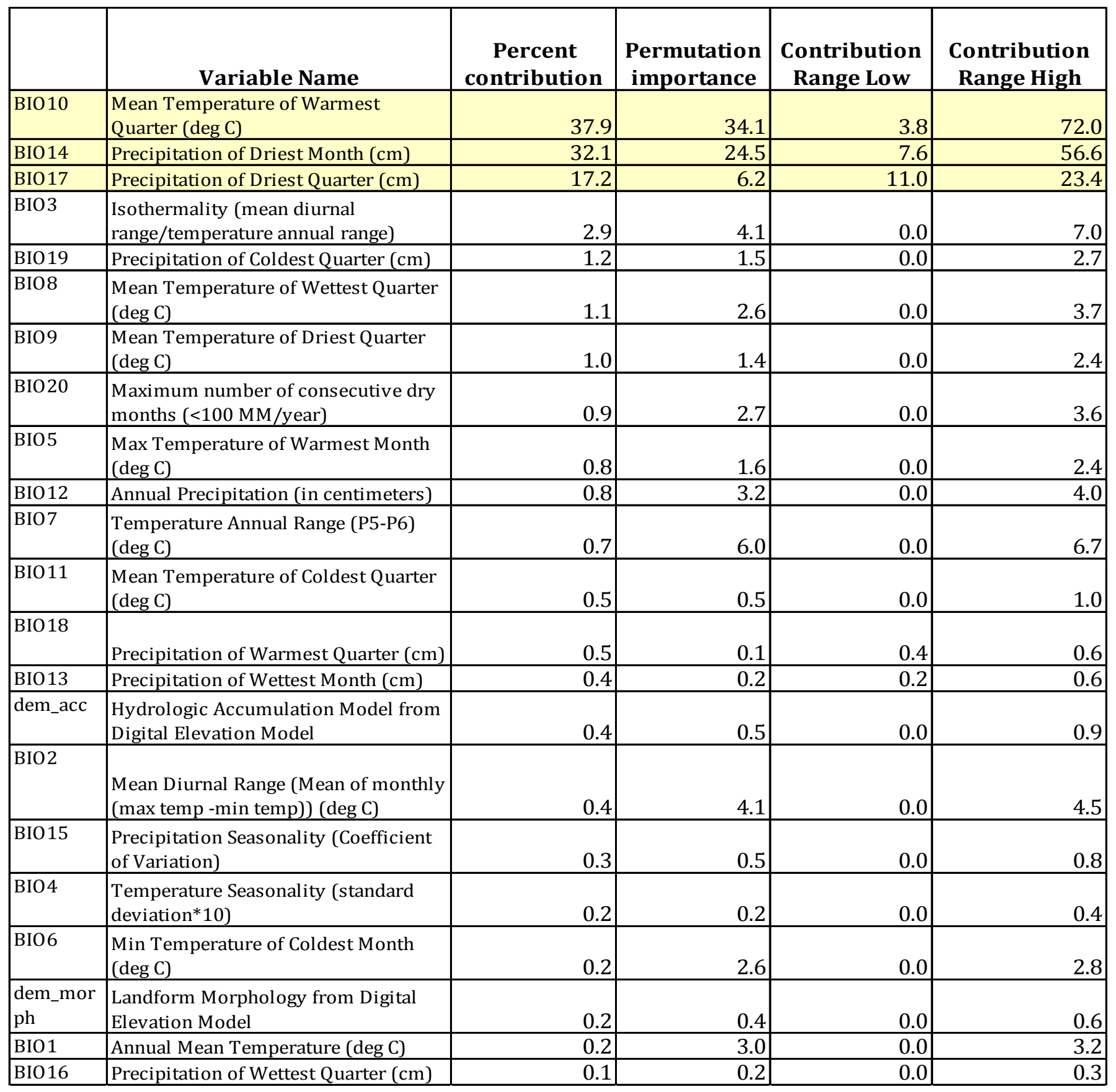

\subsubsection{Coordinated marginal response curves}

The charts for the three controlling factors are shown in Figure 45. 
Figure 45. Coordinated marginal response curves for Musk Turtle.
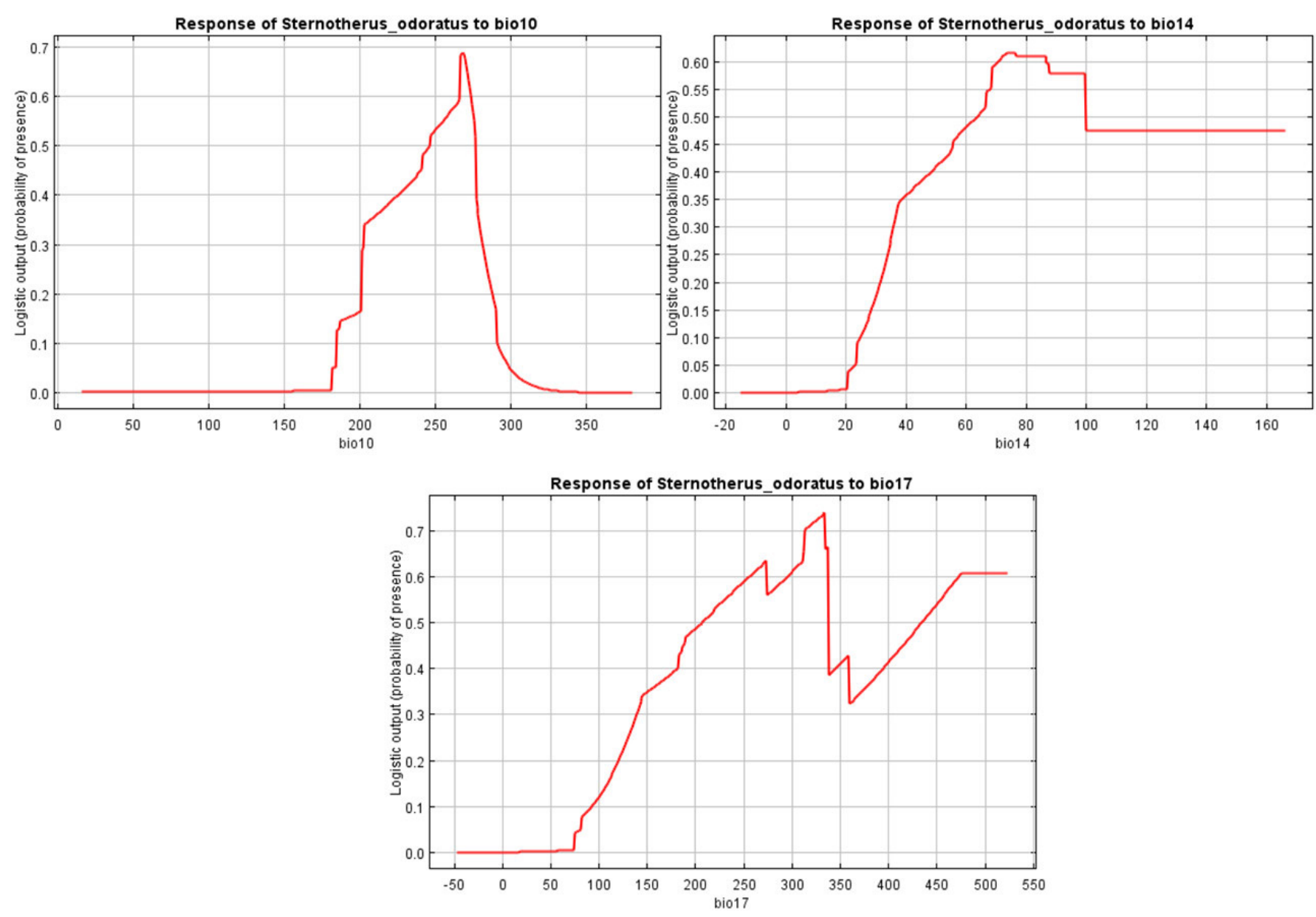

\subsubsection{Bioclimatic thresholds of the Musk Turtle}

For Table 17, the probability level of 0.1 was used as the threshold on each of the charts in Figure 45 (coordinating with the 0.1 threshold used on the S. odoratus probability map in Figure 44).

Table 17. Bioclimatic thresholds of the Musk Turtle.

\begin{tabular}{|c|c|c|c|c|c|c|c|c|}
\hline $\begin{array}{l}\text { Bio } \\
\text { Num }\end{array}$ & Bioclimatic Concern & $\begin{array}{l}\text { Lower } \\
\text { Threshold } \\
\text { (when } \\
\mathrm{P}=0.1 \text { ) }\end{array}$ & Severity & $\begin{array}{l}\text { Occurs } \\
\text { below } \\
\text { Threshold? } \\
\text { (Limiting?) }\end{array}$ & $\begin{array}{c}\text { Upper } \\
\text { Threshold } \\
\text { (when } \mathrm{P}=0.1 \text { ) }\end{array}$ & Severity & $\begin{array}{c}\text { Occurs } \\
\text { above } \\
\text { Threshold? }\end{array}$ & $\begin{array}{c}\% \\
\text { Importance } \\
\text { in Model }\end{array}$ \\
\hline $\mathrm{BlO10}$ & $\begin{array}{l}\text { Mean Temperature of } \\
\text { Warmest Quarter (deg C) }\end{array}$ & 19.0 & Extreme & No & 28.5 & Extreme & A little & 37.9 \\
\hline $\mathrm{BlO} 14$ & $\begin{array}{l}\text { Precipitation of Driest Month } \\
(\mathrm{mm})\end{array}$ & 23 & High & No & None - & & - & 32.1 \\
\hline $\mathrm{BlO} 17$ & $\begin{array}{l}\text { Precipitation of Driest } \\
\text { Quarter }(\mathrm{mm})\end{array}$ & 90 & Moderate & A little & None - & & - & 17.2 \\
\hline
\end{tabular}


The concern of the mean temperature of warmest quarter suggests that, over a long period, the turtle can survive only at the $19{ }^{\circ} \mathrm{C}$ threshold, suggesting that the summer must normally reach this temperature.

- Precipitation of driest month shows the Musk Turtle must have at least some rainfall (23.0 $\mathrm{mm}$ threshold) in the driest winter month (in the Southeast). The turtles welcome greater amounts.

- Precipitation of driest quarter is a similar bioclimatic concern, although only half as important as the previous concern. A threshold of about $23.0 \mathrm{~mm}$ is expected during the driest month quarter. This concern suggests that winters are important, and a minimum rainfall is required during the entire period.

In summary, the Musk Turtle's critical concerns are at least a summer average temperature of $19{ }^{\circ} \mathrm{C}$ and winter rainfall of at least $23.0 \mathrm{~mm}$ in the shorter time frame and at least $90.0 \mathrm{~mm}$ for the season.

\subsubsection{Spatially explicit thresholds for the Musk Turtle}

In this section, it is assumed that the Maxent range defined at the o.1 probability level represented the limits for the species.

The mean temperature of the warmest quarter at the $19{ }^{\circ} \mathrm{C}$ threshold defines the northern boundary, which even dips downward along the Appalachian Mountain range (Figure 46). 
Figure 46. Mean temperature of warmest quarter at the $19^{\circ} \mathrm{C}$ threshold defines the northern edge of the Musk Turtle's range.

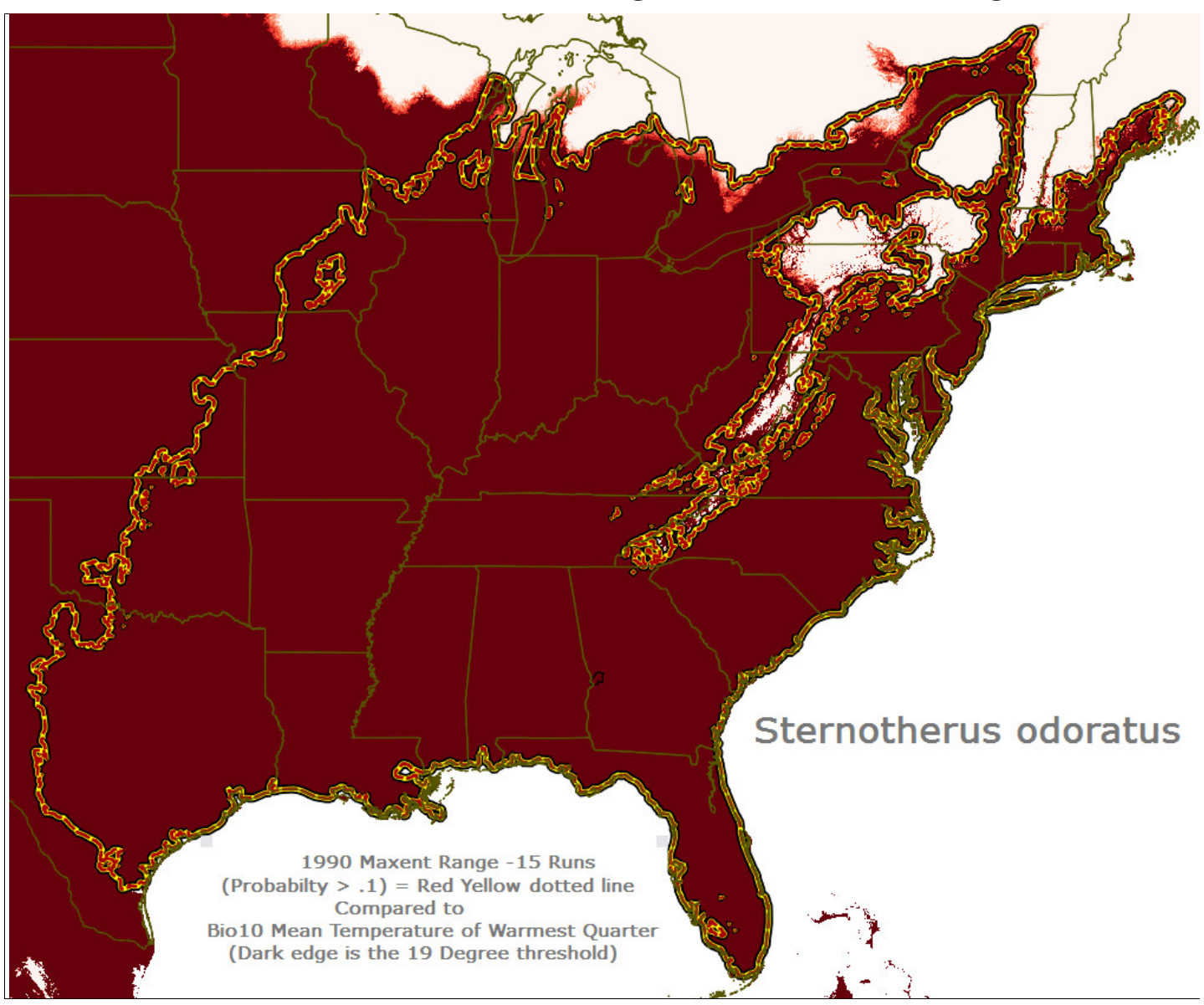

Clearly the second most important concern, precipitation of driest month, controls the Musk Turtle's entire western range edge from Texas through Iowa at the $23.0 \mathrm{~mm}$ threshold level (Figure 47).

The third most important concern, again precipitation of driest month but at the $90.0 \mathrm{~mm}$ threshold, exactly controls the western limit of the Musk Turtle, defined in Table 17 at the 0.1 probability level (Figure 48). As mentioned above, these last two concerns are probably redundant since they measure the same concern over slightly different temporal horizons. They do demonstrate the importance of rainfall during the driest period. Because the range of $S$. odoratus extends well beyond the southeastern section of the United States, it is less clear that the dry season occurs in the winter. On balance, it is still a correct observation, even when considering the greater range of the Musk Turtle. Both of these last bioclimatic concerns closely define the western edge of the turtle's range. Since the month's time horizon is temporally more restrictive and also twice as im- 
portant as the season-long concern, the indication is that the shorter dry period is the critical issue for the Musk Turtle.

Figure 47. Precipitation of driest month at the $23.0 \mathrm{~mm}$ threshold level for $S$. odoratus.

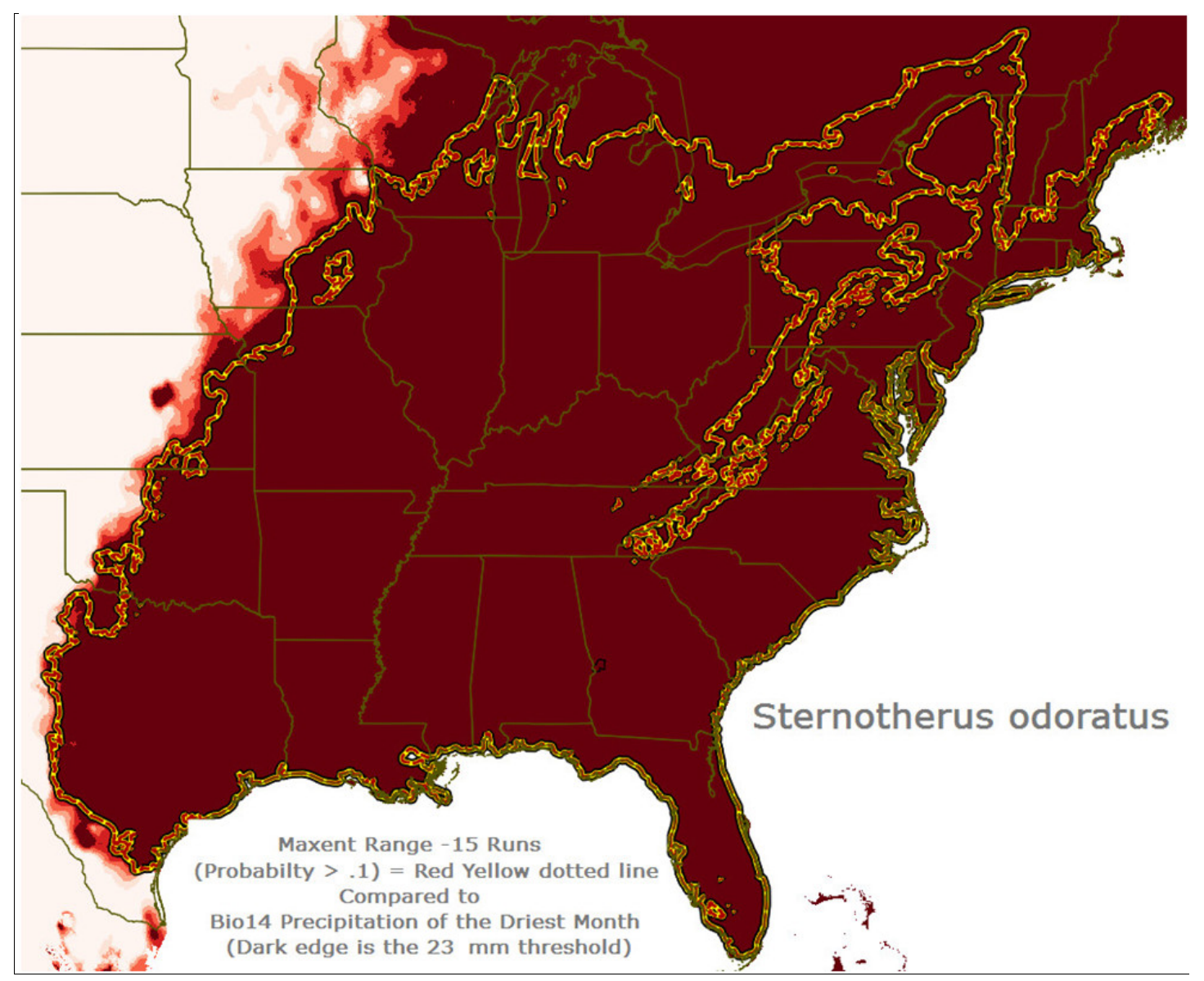


Figure 48. Precipitation of driest month for the Musk Turtle at the $90.0 \mathrm{~mm}$ threshold.

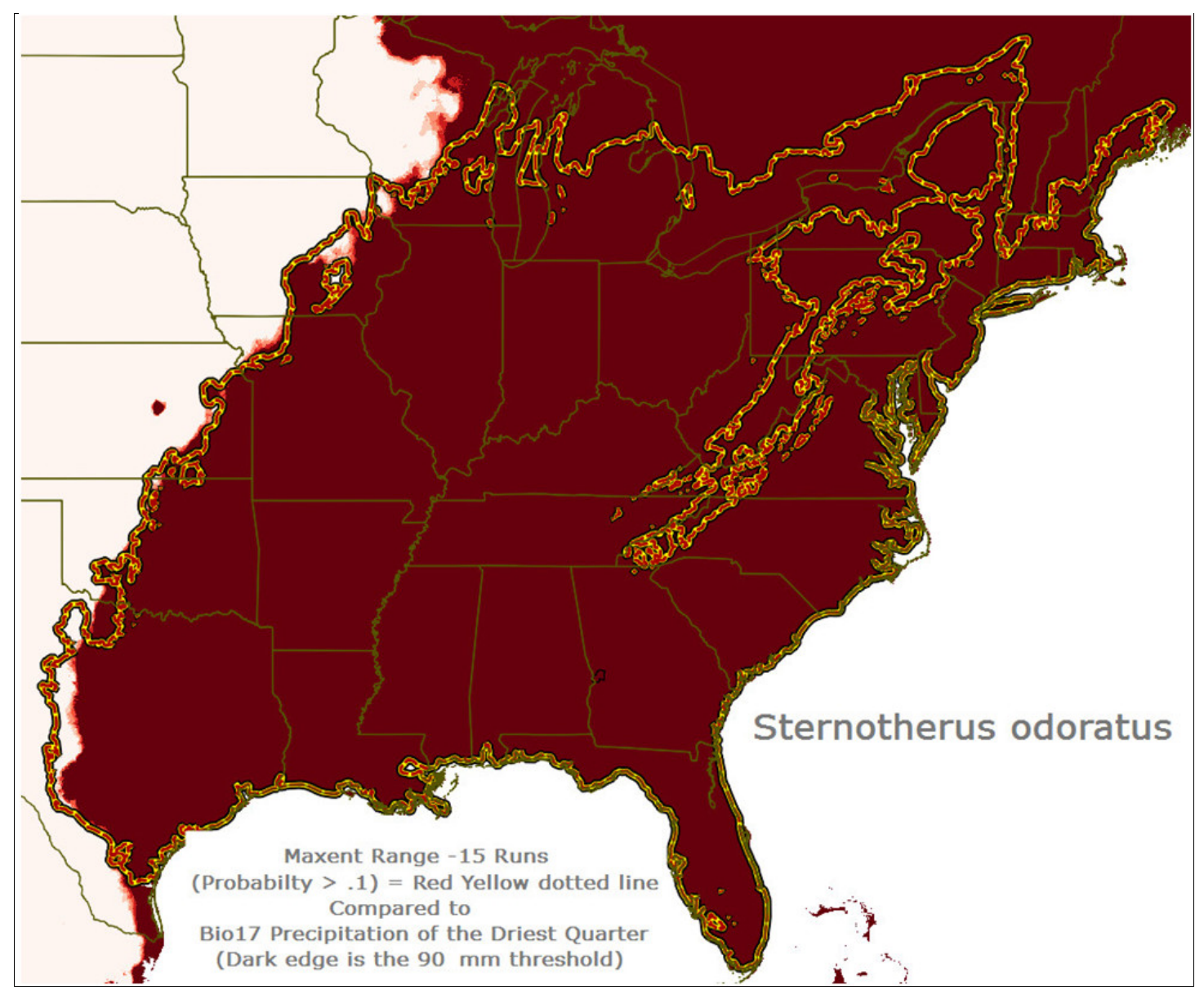

\subsubsection{Spatial conclusions for the Musk Turtle}

Spatially, the controlling threshold factor for the Musk Turtle's northern boundary is the most important bioclimatic concern, that is the mean temperature of the warmest (summer) quarter at $19{ }^{\circ} \mathrm{C}$ threshold. The western range's edge is a $23.0 \mathrm{~mm}$ threshold of precipitation of driest month, normally occurring in the winter period. 


\section{Comparisons Among the Different Models and Thresholds}

Table 18 presents a summary comparison of the occurrence of controlling bioclimatic concerns on the seven species researched for this work.

Table 18. Comparison of the occurrence of controlling bioclimatic concerns on all the species researched.

\begin{tabular}{|c|c|c|c|c|c|c|}
\hline \multirow[t]{2}{*}{ Bioclimatic Concern } & \multirow[t]{2}{*}{ Top Importance for: } & \multirow[t]{2}{*}{\begin{tabular}{c|} 
Model \\
Importance \\
Percent
\end{tabular}} & \multirow[t]{2}{*}{\begin{tabular}{|c|} 
Spatially \\
Important \\
Threshold?
\end{tabular}} & \multirow[t]{2}{*}{$\begin{array}{c}\text { Threshold } \\
\text { Value }\end{array}$} & \multicolumn{2}{|c|}{$\begin{array}{c}\text { Rough Percent of } \\
\text { Boundary Defined } \\
\text { (excluding coastal areas } \\
\text { i.e. east and south) }\end{array}$} \\
\hline & & & & & North & West \\
\hline \multirow[t]{3}{*}{ BI01 Annual Mean Temperature } & Deirochelys reticularia & 11.9 & Roughly & 15 & 10 & \\
\hline & Nerodia fasciata & 18.4 & Roughly & 15 & 15 & \\
\hline & Regina rigida & 45.7 & Yes & 16 & 75 & \\
\hline \multicolumn{7}{|l|}{ BIO2 Mean Diurnal Range } \\
\hline BI03 Isothermality & Nerodia floridana & 6.2 & Maybe & 42 & 5 & \\
\hline \multicolumn{7}{|l|}{\begin{tabular}{|l} 
BIO4 Temperature Seasonality \\
\end{tabular}} \\
\hline \multicolumn{7}{|l|}{ BI05 Max Temperature of Warmest Month } \\
\hline BI06 Min Temperature of Coldest Month & Kinosternon subrubrum & 20 & Yes & -6 & 60 & \\
\hline \multicolumn{7}{|l|}{\begin{tabular}{|l|} 
BIO7 Temperature Annual Range \\
\end{tabular}} \\
\hline \multirow{2}{*}{ BI08 Mean Temperature of Wettest Quarter } & Nerodia floridana & 27.4 & Yes & 26 & 40 & \\
\hline & Seminatrix pygaea & 64 & Yes & 25 & 60 & \\
\hline \multicolumn{7}{|l|}{ BI09 Mean Temperature of Driest Quarter } \\
\hline \multirow{4}{*}{ BI010 Mean Temperature of Warmest Quarter } & Deirochelys reticularia & 33.2 & Yes & 25.5 & 80 & \\
\hline & Kinosternon subrubrum & 33.2 & Yes & 22 & 25 & \\
\hline & Nerodia fasciata & 25.1 & Roughly & 24.5 & 20 & \\
\hline & Sternotherus odoratus & 37.9 & Yes & 19 & 85 & \\
\hline BI012 Annual Precipitation & Kinosternon subrubrum & 7.5 & Maybe & 700 & & 20 \\
\hline \multirow[t]{2}{*}{ BI013 Precipitation of Wettest Month } & Deirochelys reticularia & 8.9 & Maybe & 129 & 5 & \\
\hline & Nerodia fasciata & 23.7 & Yes & 110 & & 80 \\
\hline \multirow[t]{3}{*}{ BI014 Precipitation of Driest Month } & Nerodia fasciata & 10 & Maybe & 375 & & 5 \\
\hline & Sternotherus odoratus & 32.1 & Yes & 23 & & 85 \\
\hline & Rigina rigida & 17.7 & Yes & 48 & & 55 \\
\hline \multicolumn{7}{|l|}{ BI015 Precipitation Seasonality } \\
\hline \multicolumn{7}{|l|}{ BI016 Precipitation of Wettest Quarter } \\
\hline \multirow{3}{*}{ BI017 Precipitation of Driest Quarter } & Deirochelys reticularia & 21.9 & Yes & 120 & & 90 \\
\hline & Kinosternon subrubrum & 33.5 & Yes & 106 & & 90 \\
\hline & Sternotherus odoratus & 17.2 & Yes & 90 & & 75 \\
\hline \multirow[t]{3}{*}{ BIO18 Precipitation of Warmest Quarter } & Deirochelys reticularia & 10.6 & Maybe & 330 & 5 & \\
\hline & Nerodia floridana & 50.4 & Yes & 360 & 15 & \\
\hline & Seminatrix pygaea & 24.2 & Yes & 350 & 20 & \\
\hline \multicolumn{7}{|l|}{ BI019 Precipitation of Coldest Quarter } \\
\hline BIO20 Consecutive Months & & & & & & \\
\hline
\end{tabular}

The concern that showed the greatest frequency, for four times or $57 \%$ of the species, was BIO10 mean temperature of warmest quarter. For all four of those species, summer temperature was also spatially controlling.

The concerns that showed a high frequency, for three times or $43 \%$ of the species, were BIO1 annual mean temperature, BIO14 precipitation of dri- 
est month, BIO17 precipitation of driest quarter, and BIO18 precipitation of warmest quarter. BIO17 precipitation of driest quarter definitely spatially controlled the range of three species; BIO14 precipitation of driest month definitely spatially controlled the range of two species; $\mathrm{BIO} 1$ annual mean temperature definitely spatially controlled the range of one species; and BIO18 precipitation of warmest quarter probably controlled the spatial extent of three species. Most of these concerns are rainfall related.

Those concerns that showed moderate frequency, for two times or $29 \%$ of the species, were BIO8 mean temperature of wettest quarter and BIO13 precipitation of wettest month. Of those, BIO8 mean temperature of wettest quarter definitely controlled the ranges, and BIO13 precipitation of wettest month was likely controlling the ranges.

Those concerns that showed some importance, for one time or about $14 \%$ of the species, were $\mathrm{BIO}_{3}$ isothermality, $\mathrm{BIO} 6$ minimum temperature of coldest month, and BIO12 annual precipitation. BIO6 minimum temperature of coldest month definitely controlled the range, while $\mathrm{BIO}_{3}$ Isothermality and BIO12 annual precipitation likely controlled the range.

Those concerns that seemed not to contribute to spatially controlling any species range were $\mathrm{BIO}_{2}$ mean diurnal range, $\mathrm{BIO}_{4}$ temperature seasonality, $\mathrm{BIO}_{7}$ temperature annual range, $\mathrm{BIO} 15$ precipitation seasonality (all long temporal concerns), $\mathrm{BIO}_{5}$ maximum temperature of warmest month, BIO9 mean temperature of driest quarter, $\mathrm{BIO} 16$ precipitation of wettest quarter, BIO19 precipitation of coldest quarter, and BIO2O consecutive dry months. One would think that $\mathrm{BIO} 20$ consecutive dry months is a concern that would show stress on species. It is surprising that it never showed up as an important concern for these reptiles. At least for reptiles, it appears that only half of the bioclimatic factors need to be used to effectively delineate the ranges.

It might be expected that those concerns noted as long-term concerns do not have greater importance. However, it is likely $\mathrm{BIO}_{3}$ isothermality and BIO12 annual precipitation are spatially controlling concerns and can certainly be considered long-term factors. So the issue of the effect of temporal length on a species habitat is muddy at best.

If the temporal length that a bioclimatic concern represents is examined versus how well-defined the spatially important thresholds are, it becomes 
noticeable that shorter time frames tend to better define a boundary. Periods of a month tend to better define boundaries, seasons (quarters) a little less so, and annual time frames are more often in the "maybe" category. One might expect that the more immediately expressed a concern is, the more likely it is that an organism will respond to it.

So for these seven reptiles, was temperature or precipitation more important in controlling their range? The bioclimatic inputs which were spatially controlling temperature concerns were:

- BIO10 mean temperature of warmest quarter,

- BIO1 annual mean temperature,

- $\mathrm{BIO}_{3}$ isothermality, and

- BIO6 minimum temperature of coldest month.

Those items which were spatially controlling precipitation concerns were:

- BIO12 annual precipitation,

- BIO17 precipitation of driest quarter,

- BIO13 precipitation of wettest month, and

- BIO14 precipitation of driest month.

Those items which were spatially controlling concerns that are both temperature-related and precipitation-related were:

- BIO18 precipitation of warmest quarter, and

- BIO8 mean temperature of wettest quarter.

Of those concerns that definitely were spatially controlling factors, four are related to temperature, four are related to precipitation, and two are related to both. So for the reptiles in this study, the question of spatially controlling factors could not be more evenly matched statistically.

Since all of the species examined are native to the eastern or southeastern United States, with the Gulf of Mexico and the Atlantic Ocean as the eastern and southern boundaries, it is possible to evaluate influences only on the northern and western limits to their ranges. Table 18 shows the amounts that these boundaries are defined by bioclimatic factors. It is very striking that temperature is always the controlling factor for the northern boundaries, and precipitation is always the controlling factor for the west- 
ern boundaries (BIO18 precipitation of warmest quarter is a combination of both). It is interesting to note that, in Table 18, it is often true that the greater the importance that Maxent assigns to a bioclimatic concern in a model, the more extent it defines with greater definitiveness. In general, for importance values above 30\%, the definition of a boundary is definitive. For importance values from $20 \%-30 \%$, the definition of the boundary is definitive or roughly defined. For importance values from 10\%-20\%, the designation of the boundary is roughly defined. For an importance level below $10 \%$, the definition of the boundary may be defined. This conclusion was expected, but it is also good to see it reinforced in the data.

Table 19 attempts to determine how much of the range edges were set by each species from the bioclimatic concerns that were identified as possible determining factors.

Table 19. Amount of the range edges determined for each of the species from the bioclimatic concerns.

\begin{tabular}{|c|c|c|c|c|c|}
\hline $\begin{array}{l}\text { Species Scientific } \\
\text { Name }\end{array}$ & Common Name & $\begin{array}{l}\text { Rough Perce } \\
\text { entire Land } \\
\text { Defined by } \\
\text { Concerns (n } \\
\text { reduntant) }\end{array}$ & $\begin{array}{l}\text { ent of the } \\
\text { Boundary } \\
\text { Bioclimatic } \\
\text { one }\end{array}$ & \begin{tabular}{|l|} 
Total \\
boundary \\
Identified with \\
bioclimatic \\
thresholds \\
\end{tabular} & $\begin{array}{l}\text { Level of } \\
\text { Surety }\end{array}$ \\
\hline & & North & West & & \\
\hline Deirochelys reticularia & Chicken Turtle & $50+10$ & 30 & 90 & High \\
\hline Kinosternon subrubrum & Eastern Mud Turtle & 70 & 30 & 100 & High \\
\hline Nerodia floridana & Eastern Green Watersnake & $15+35+10$ & & 60 & Moderate \\
\hline Nerodia fasciata & Banded Watersnake & 15 & 25 & 40 & High \\
\hline Regina rigida & Glossy Crayfish Snake & 45 & 20 & 65 & High \\
\hline Seminatrix pygaea & Black Swampsnake & 55 & & 55 & High \\
\hline Sternotherus odoratus & Common Musk Turtle & 40 & 55 & 95 & High \\
\hline
\end{tabular}

From Table 19, it is easy to demonstrate that the few most important bioclimatic input layers almost always define the majority of the species' ranges. On average, the top importance bioclimatic concerns explain roughly $72 \%$ of the entire range boundary, $50 \%$ on the northern boundary, and another $22 \%$ on the western boundary. Note that in this study, northern boundaries were almost always longer than western boundaries, so the value for the northern boundary would be expected to be greater than that for the western. To be able to state that the majority of a reptile's range can be delineated with just a few bioclimatic concerns specific to that species is rather impressive. It says that most of the habitat is controlled by a very few very specific factors for which the reptile is innately suited. This 
statement can normally be made with a high level of surety (see Table 19, last column).

Turtles had a greater amount of their boundaries defined (average 95\%), with higher levels of certainty, than did snakes (average 55\%). This finding is a significant difference based on subgroup membership - Testudines for the turtles and Squamata for the snakes. Evidently turtles are more sensitive to bioclimatic factors than snakes. 


\section{Application of Findings to Climate Change Modeling}

In the introduction, the hypothesis was posed that "if you know the distributions of the controlling bioclimatic factors for a species, then as climate changes you need not remodel a species habitat; rather you need only identify how the single bioclimatic concern will reposition itself due to climatic change." This research was a means of testing this hypothesis. As part of the original test, the habitat for $S$. odoratus was modeled with the bioclimatic data for both the current situation and for the period centered on 2025 (Lozar and Westervelt 2014). The following discussion builds on that research as it relates to the proposed hypothesis.

For Common Musk Turtle, $85 \%$ of the northern boundary was defined with a high degree of confidence by BIO 10 mean temperature of warmest quarter. On the left panel in Figure 49, the range for 1990 shows at the 0.1 probability level as the red-yellow dotted line and the comparable Maxent predicted range for 2025 for the turtle at the 0.1 probability level as the red area. It can be seen on the northern edge the range increases in Canada east of Lake Huron and from Toronto to Georgian Bay. In the top right panel of Figure 49 the Maxent derived range for the Common Musk Turtle for 1990 at the 0.1 probability level is again shown as the red-yellow dotted line and the 2025 prediction for $\mathrm{BIO} 10$ mean temperature of warmest quarter as the dark edge at the $19{ }^{\circ} \mathrm{C}$ threshold. The temperature for the summer also increased in those areas in some places in a strikingly similar pattern. However in other areas it increased but the turtle's range did not comparably increase. So as an examination for the northern boundary, there seems to be some relationship but it is not exact and dependable.

Also, $85 \%$ of the western boundary was defined with a high degree of surety by BIO 14 precipitation of driest month. In the bottom right panel in Figure 49, the Maxent predicted range for 2025 for the western edge shrinks in Texas, Oklahoma and Iowa. In the bottom right panel of Figure 49 the range for 1990 at the 0.1 probability level is again shown as the redyellow dotted line, and the 2025 prediction for BIO 14 precipitation of the driest month as the dark edge at the $23 \mathrm{~mm}$ level. It can be seen that in Texas the range shrank, but it did not in Oklahoma or Iowa. Again, as an 
examination for the western boundary, there seems to be some relationship but it is not exact and dependable..

Figure 49. Climate change test for S. odoratus. Left: Range for 1990 (red-yellow dotted line) and the comparable range for 2025 as the red area. Top right: the range for 1990 at the 0.1 probability level (red-yellow dotted line) and the 2025 prediction for BIO 10 mean temperature of warmest quarter as the dark edge at the $19^{\circ} \mathrm{C}$ threshold. Bottom right: Turtle range for 1990 at the 0.1 probability level (red-yellow dotted line) and the 2025 prediction for BIO 14 precipitation of the driest month at the $23 \mathrm{~mm}$ level (dark edge).

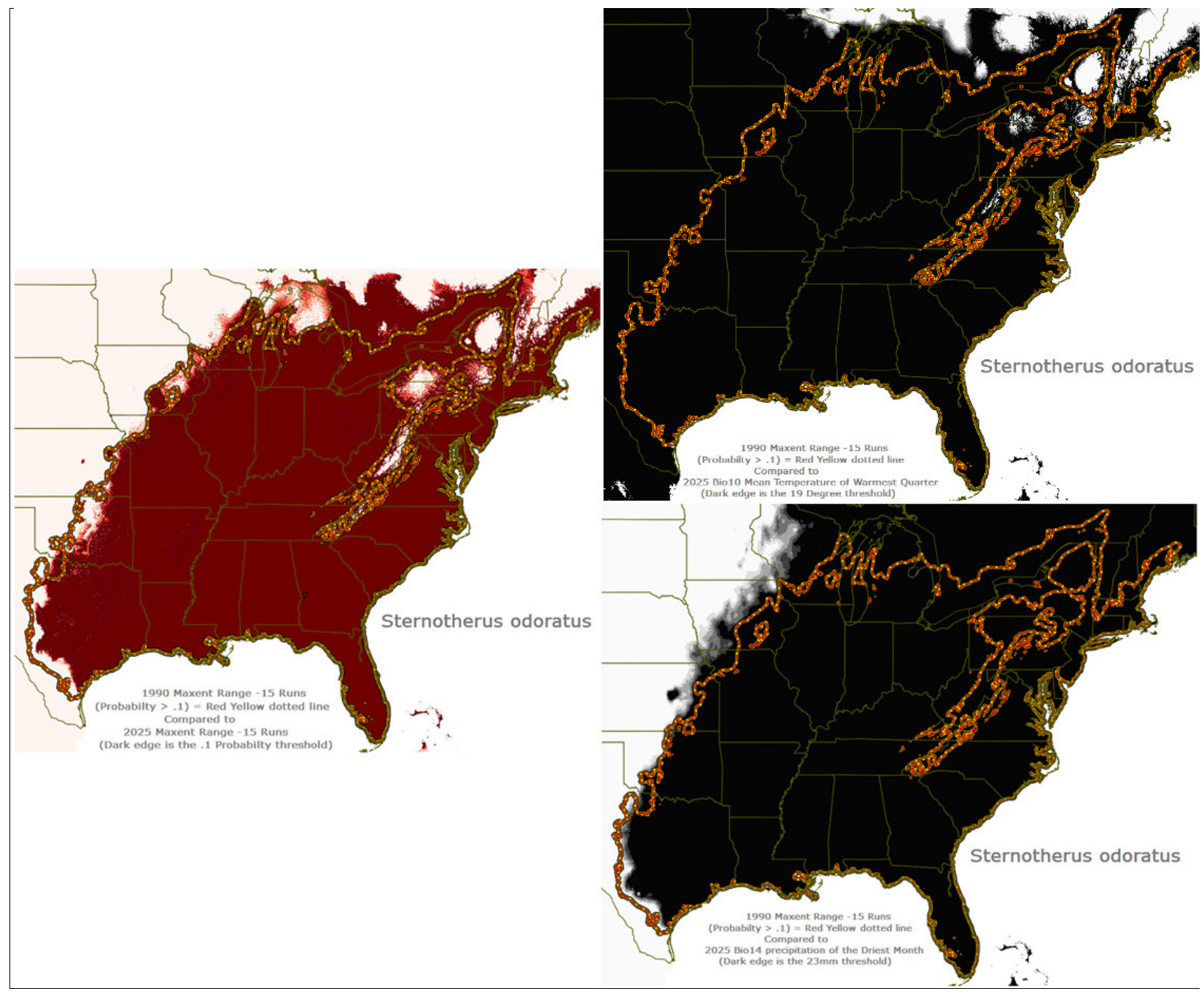

For this single test of the hypothesis, mixed results occurred for both the northern and western boundaries; therefore, the hypothesis is not proven. Among the species examined, $S$. odoratus is the most robust, and its habitat may actually expand due to climate change. Perhaps using a less-robust species could have been more telling. Additional, similar comparisons would be useful in determining if the hypothesis has merit. 


\section{Conclusions and Recommendations}

\subsection{Conclusions}

The traditional means of defining the distribution of a species is not useful for analysis of species range change over time. The objective of this work was to determine whether maximum entropy analysis could be applied to the projection of species range change with input on key climate parameters as they relate to survival probabilities. The following conclusions are offered.

\subsubsection{Conclusions regarding Maxent}

- The analyses and tests presented show that Maxent is an effective tool for delineating the probability distribution of a species, based on a series of inputs.

- The statistical evaluations generated by the Maxent software for the viability of each of the models provide consistent, objective appraisals of the quality of the models generated.

- Little variation was found between running the model many times or just once. The outputs were all stable.

Seven reptile species of the Southeast region of the United States (three turtles and four snakes) were investigated. Using the county level data with the downscaled bioclimatic parameters worked out well. Surprisingly, the level of detail at the "county size" is in the same range as that used for the environmental parameters (30 arc-seconds [ $\sim 0.8 \mathrm{~km}]$ on an edge). Increasing the accuracy of the within-county locations of the species provided no additional information on the range of a species (although it would increase the detail within the range). Using 20 bioclimatic concerns seemed to represent well those types of issues that would matter to a species distribution.

\subsubsection{Conclusions regarding the testing of alternative inputs for the Maxent program}

- Maxent generates a stable basic model with only a few county-level sample points.

- Increasing the locational accuracy of the input points (e.g., for a watersnake using only locations within a county that are likely to be wetter 
areas) results in a similar extent distribution when compared to that resulting from just using the simple county centroids.

- The addition of concerns that do not vary as a slow gradient over the country (e.g., wet areas) provides no regional information, only local detail.

The testing effort is likely not necessary. During a Maxent run, the output statistics will determine which input layers are the most important. Input parameter layers other than the bioclimatic inputs never appeared to be important or spatially determining for the range extent. Non-bioclimatic layers had little influence in modifying the extent of a reptile's habitat.

\subsubsection{Conclusions regarding the individual species}

- The marginal response curves provided thresholds for a species survival. Defining species thresholds objectively was a major advantage in carrying out this research.

- The thresholds, in combination with the ranking of input layer importance, afforded the ability to objectively categorize which bioclimatic concerns will make the biggest difference for a species' survival.

Maxent generates a "potential" range, so it can be expected to be more extensive than an observed range. In some cases, the Maxent range was well matched to the known range in part of the habitat and was more inclusive in others. This observation suggests one or a combination of possibilities:

- Important bioclimatic parameters necessary in defining a species range were not available (and during testing several new parameters were created to try to find those, without success).

- Another similar species was out-competing the subject reptile in those areas.

- The species once existed in those areas but were extirpated.

It was surprising to see how closely the edge of the range maps were coordinated with the bioclimatic threshold values. Often a large portion of the edges coincided with the few bioclimatic parameters that Maxent identified to be of highest importance. This observation allows an individual to objectively identify which bioclimatic factor (and at what level) will make a difference in the likely survivability of a species. The bioclimatic concerns used here represent average values over many years and over a large temporal horizon (e.g. a month or a quarter of a year). These thresholds define 
a species population range over a lifetime or several generations. The thresholds are different levels than would be expected for a single entity over the short term.

\subsubsection{Conclusions regarding all of the reptiles as a group}

- The majority of a reptile's range can be delineated with just a few bioclimatic concerns specific to that species.

- Most of the habitat of these reptiles is controlled by a very few, very specific factors for which the reptile is innately suited. As a result of this research, this statement can made with a high level of certainty.

- BIO1O mean temperature of warmest quarter was the most common spatially controlling parameter, followed by $\mathrm{BIO} 17$ precipitation of driest quarter, $\mathrm{BIO} 14$ precipitation of driest month, and BIO18 precipitation of warmest quarter.

- Some bioclimatic concerns that might be expected to be important showed little influence in defining the reptiles' ranges. Specifically, BIO2O consecutive dry months, might be expected to be a concern that clearly would stress a species (particularly reptiles), but it never rose high in importance. Only half of the bioclimatic inputs are required to effectively delineate a reptile's range.

- Bioclimatic parameters with shorter time frames tended to better define a boundary.

- For these seven reptiles, both temperature or precipitation shared equal importance as range-controlling factors.

- As the Maxent importance of a bioclimatic parameter increased, its ability to clearly define a greater amount of habitat boundary also increased. For example, a Maxent importance rating above 30\% would well define a large portion of the boundary with a high level of certainty.

- A significantly greater amount of boundary was bioclimatically defined for turtles (95\%) than for snakes (50\%). Turtles seem to be more sensitive to bioclimatic factors than snakes.

- At a level of $100 \%$ of the reptiles studied, temperature controlled the northern extent and precipitation controlled the western extent of their boundaries.

Using predicted climate-induced changes in the bioclimatic parameters (rather than the Maxent habitat probability map) to easily identify habitat areas at risk proved inconclusive. 


\subsection{Recommendations}

Applying the Maxent analysis to the delineation of species habitat resulted in objective, well-justified definitions of the habitat extent and quality. These qualities are useful to military researchers as well as installation natural resource managers. A more widespread application of the Maxent method is recommended.

This research focused on those bioclimatic concerns that Maxent proposed were of highest importance to each species. Surprisingly, it has been demonstrated that this tack will explain about two-thirds of the species' range. It would be very interesting to investigate those other bioclimatic (and non-bioclimatic) concerns to see how other inputs might contribute and if more of the boundaries could be delineated. It would be even more interesting to identify those areas where none of these factors contribute to the limitations on the species and investigate what the additional controlling factors are in those areas. It was surprising that the results showed that so much of a species' range limits can be explained by such simple and straightforward factors.

This research was limited to a group of seven reptiles. It is recommended to extend this procedure to other species of importance to the military, such as birds and gophers. 


\section{References}

\section{Cited}

Buhlmann, Kurt A., Thomas S.B. Akre, John B. Iverson, Deno Karapatakis, Russell A. Mittermeier, Arthur Georges, Anders G.J. Rhodin, Peter Paul Van Dijk, and J. Whitfield Gibbons. 2009. "A Global Analysis Of Tortoise and Freshwater Turtle Distributions with Identification of Priority Conservation Areas," International Journal of Turtle and Tortoise Research, Chelonian Conservation and Biology, 8(2): 116-149.

Dudík, Miroslav, Steven J. Phillips, R.E. Schapire. 2004. "Performance Guarantees for Regularized Maximum Entropy Density Estimation.” In: Proceedings of the 17th Annual Conference on Computational Learning Theory, 655-662. New York: ACM Press.

Jaynes, Edwin T. 1957. “Information Theory and Statistical Mechanics.” The Physical Review 106(4): 620-630.

Kumar, S. and T.J. Stohlgren. 2009. "Maxent Modeling for Predicting Suitable Habitat for Threatened and Endangered Tree Canacomyrica monticola in New Caledonia." Journal of Ecology and The Natural Environment 1(4): 94-98.

Lozar, Robert C. and James Westervelt. 2014. Application of Maxent Multivariate Analysis to Define Climate-Change Effects on Species Distributions and Changes. ERDC Technical Report TR-14-17. Champaign, IL: U.S. Army Engineer Research and Development Center-Construction Engineering Research Laboratory.

Phillips, Steven J., Robert P. Anderson, and Robert E. Schapire. 2006. "Maximum Entropy Modeling of Species Geographic Distributions." Ecological Modelling $190(3-4): 231-259$.

Phillips, Steven J. and Miroslav Dudík. 2008. "Modeling of Species Distributions with Maxent: New Extensions and a Comprehensive Evaluation.” Ecography 31: 161175 .

Shannon, C.E. 1948. "A Mathematical Theory of Communication.” Bell System Technical Journal 27: 379-423, 623-656.

U.S. Secretary of Defense. February 2010. Quadrennial Defense Review. Washington, DC: Department of Defense.

\section{Uncited}

Austin, M. January 2007. "Species Distribution Models and Ecological Theory: A Critical Assessment and Some Possible New Approaches." Ecological Modelling 200 (12): 1-19. 
Carpenter, G., A.N. Gillison, and J. Winter. 1993. "DOMAIN: a Flexible Modeling Procedure for Mapping Potential Distributions of Plants, Animals." Biodiversity and Conservation 2: 667-680.

Council on Environmental Quality (CEQ). 2010. Draft NEPA Guidance on Consideration of the Effects of Climate Change and Greenhouse Gas Emissions. Washington, DC: The White House.

Intergovernmental Panel on Climate Change. 2007. Summary for Policymakers. In: Climate Change 2007: The Physical Science Basis. Contribution of Working Group I to the Fourth Assessment Report of the Intergovernmental Panel on Climate Change [Solomon, S., D. Qin, M. Manning, Z. Chen, M. Marquis, K.B. Averyt, M.Tignor and H.L. Miller (eds.)]. Cambridge, U.K. and New York City, U.S.: Cambridge University Press.

Intergovernmental Panel on Climate Change. 2007. The Physical Science Basis, Contribution of Working Group I to the Fourth Assessment Report of the Intergovernmental Panel on Climate Change. [Solomon, S., D. Qin, M. Manning, Z. Chen, M. Marquis, K.B. Averyt, M. Tignor and H.L. Miller (eds.)]. Cambridge, U.K. and New York City, U.S.: Cambridge University Press.

Iverson, J.B. 1992. "Species Richness Maps of the Freshwater and Terrestrial Turtles of the World." Smithsonian Herpetological Information Service 88:1-18.

Iverson, J.B., A.R. Kiester, L.E. Hughes, and A.J. Kimerling. 2003. "The EMYSystem World Turtle Database:" http://emys. geo.orst.edu.

Kiester, A.R. and B. Brock. 2007. Internet Tesources for Turtle Research and Vonservation. In: Shaffer, H.B., FitzSimmons, N.N., Georges, A., and Rhodin, A.G.J. (Eds.). Defining Turtle Diversity: Proceedings of a Workshop on Genetics, Ethics, and Taxonomy of Freshwater Turtles and Tortoises. Chelonian Research Monographs 4:168-171.

Lozar, Robert C., Matthew Hiett, and James Westervelt. 2011. Anticipating Climate Change Impacts on Army Installations - Volume 1, ERDC Special Report SR-111. Champaign, IL: U.S. Army Engineer Research and Development CenterConstruction Engineering Research Laboratory.

2013. Anticipating Installation Natural Resource Climate Change Concerns - The Data, ERDC Technical Report TR-13-23. Champaign, IL: U.S. Army Engineer Research and Development Center-Construction Engineering Research Laboratory.

Lozar, Robert C. and James Westervelt. 2015. Multivariate Bioclimatic Ecosystem Change Approaches. ERDC Technical Report TR-15-12. Champaign, IL: U.S. Army Engineer Research and Development Center-Construction Engineering Research Laboratory.

Manel, S, J. Dias, and S. Ormerod. 1999. "Comparing Discriminant Analysis, Neural Networks and Logistic Regression for Predicting Species Distributions: A Case Study with a Himalayan River Bird.” Ecological Modelling 120: 337-347. 
Oksanen, J., and P. Minchin. 2002. "Continuum Theory Revisited: What Shape are Species Responses along Ecological Gradients? Ecological Modelling 157: 119129.

Pearce, J., and S. Ferrier. 2000. "Evaluating the Predictive Performance of Habitat Models Developed Using Logistic Regression.” Ecological Modelling 133: 225245 .

Peterson, A.T., and D.A Kluza. 2003. "New Distributional Modeling Approaches for Gap Analysis.” Animal Conservation 6: 47-54.

Westervelt, James and William Hargrove. 2011. Forecasting Climate-Induced Ecosystem Changes on Army Installations. ERDC/CERL TR-11-36. Champaign, IL: U.S. Army Engineer Research and Development Center-Construction Engineering Research Laboratory. 


\section{Appendix: Example of Alternatives Testing on Seminatrix pygaea}

\section{Use only the county sightings}

For this alternative, only the most basic inputs were submitted. Specifically, the inputs were the centroids of the counties in which the snake was sighted and most of the layers listed in Table 2 and Table 3 . The result of one Maxent run is presented in Figure 50.

Figure 50. Maxent test results for S. pygaea using only the county sightings.

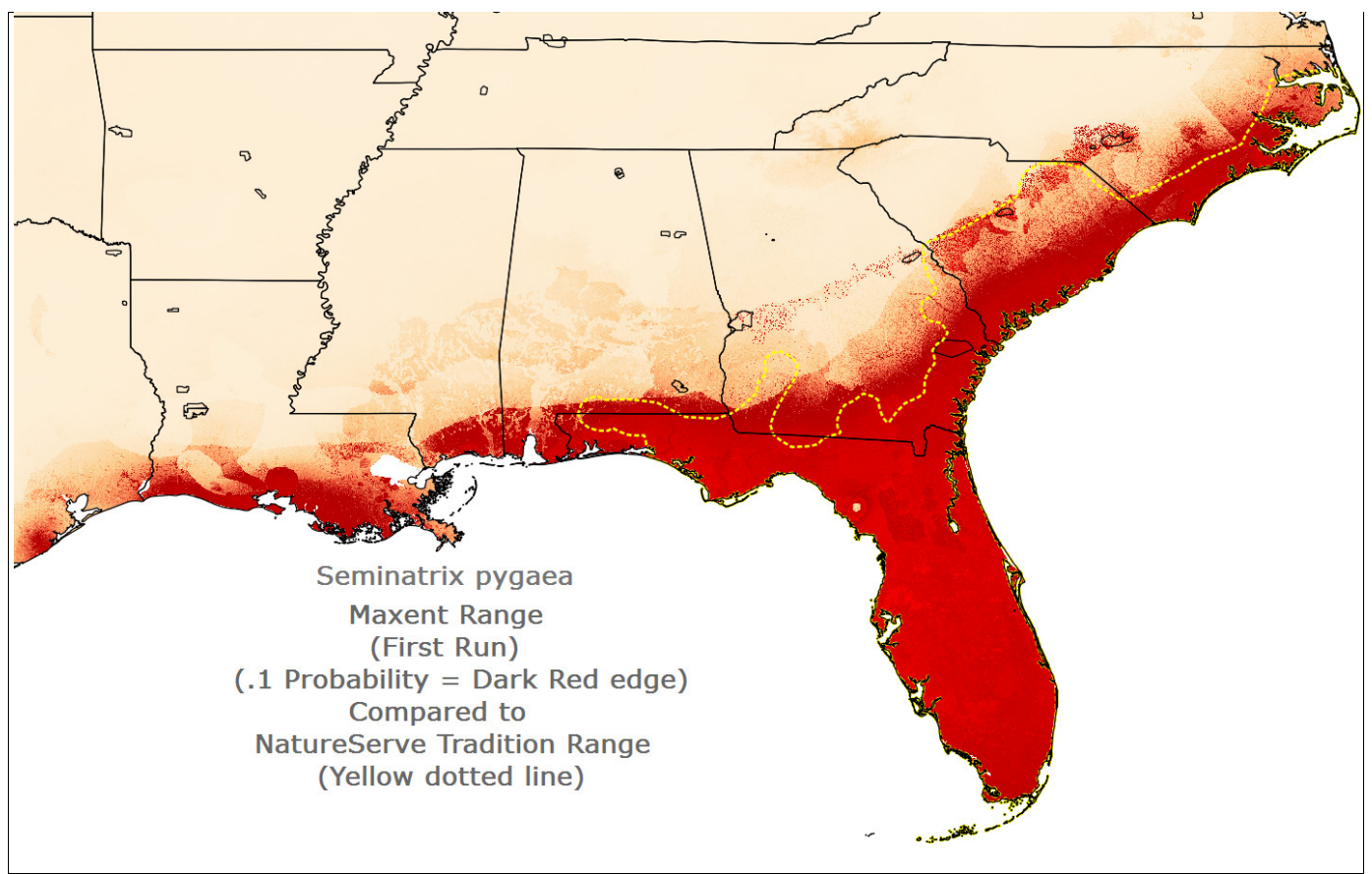

The Maxent range at the normal 0.1 probability level is more generous than that shown in the traditional range from the NatureServe site. The two match well at the 0.1 level through most of the range. Maxent allows the snake habitat throughout lower Alabama, Mississippi, Louisiana, and even into Texas. Bio18 precipitation of warmest quarter and Bio8 mean temperature of wettest quarter were the most important concerns. Furthermore, detail within the range shows that additional layers (probably the GAP land cover which was next in importance) and accumulation already provide good delineation (Figure 51). The different land covers were probably redundant, so it is best to use only the GAP land cover data. This 
first test is remarkably good, considering that the only input were the centroids of the counties.

Figure 51. Detail within the range for $S$. pygaea shows that additional layers, particularly land cover and accumulation, made a difference at the local level.

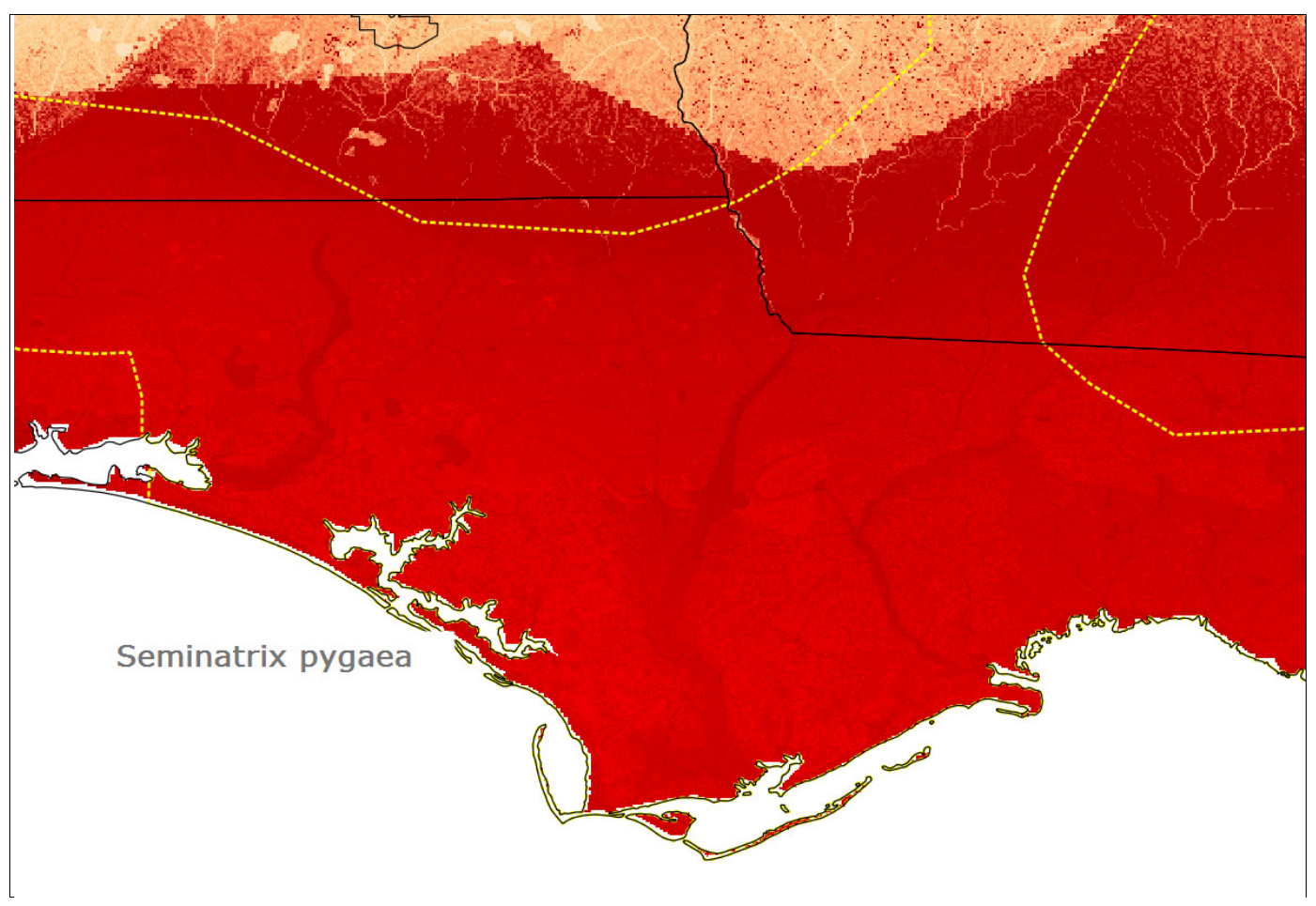

\section{Refine the county distribution based on the NatureServe description, particularly using wetland covers}

This procedure might double weight land cover in the Maxent test run. This effect was examined afterward. To move the county centroid sample locations to wet land areas within each county from the NatGaplc_mod (land cover obtained from the GAP project and processed out human land covers), river/wetland map land cover types locations within a county (Figure 52) were pulled out. 
Figure 52. For S. pygaea this map shows the wet lands within the counties where the species was observed.

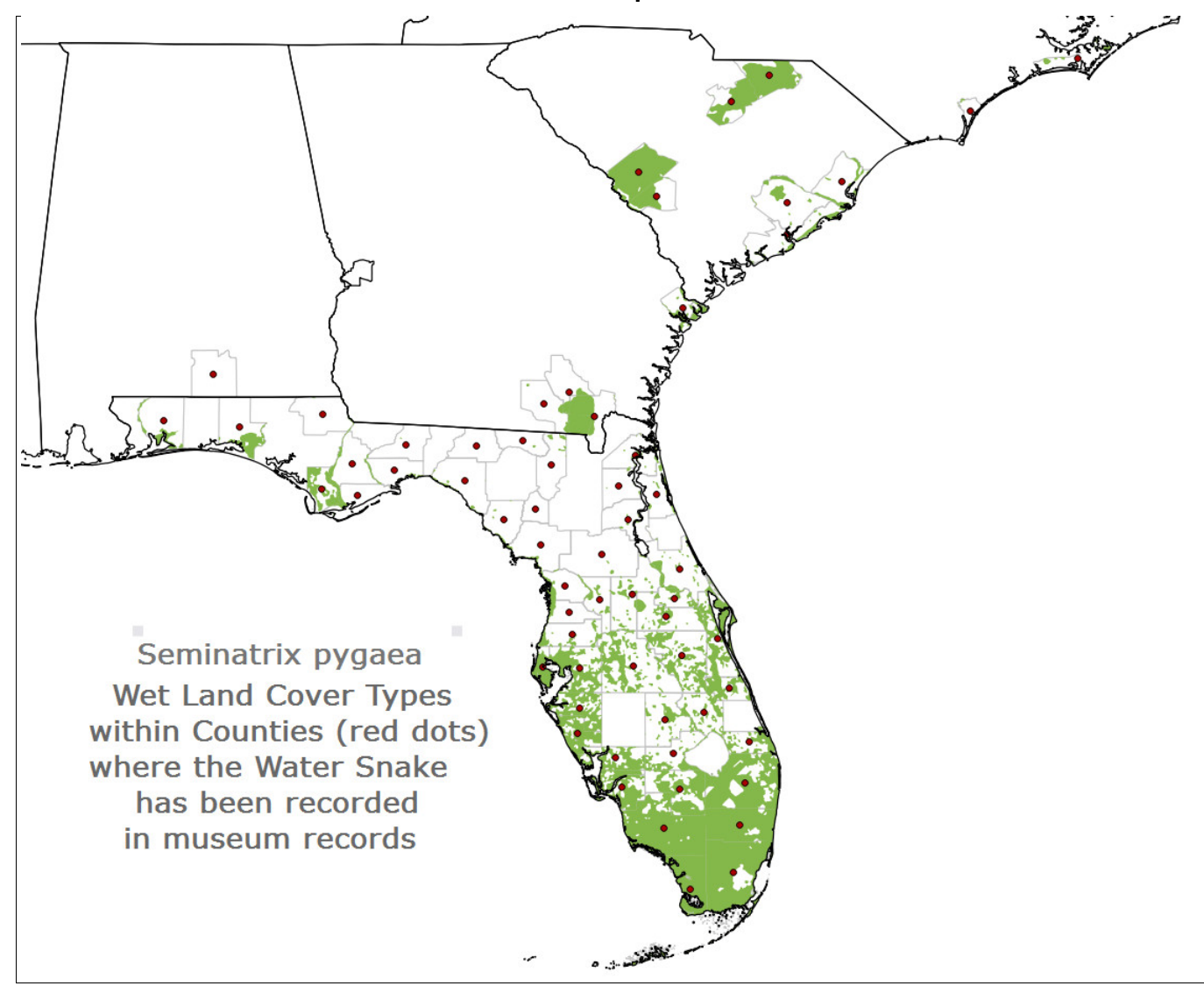

From the locations indicated in Figure 52, random test points were extracted as the samples to be submitted to a Maxent run. 
Figure 53. S. pygaea Maxent range after only wetland areas within a county were used as sample points (blue dots).

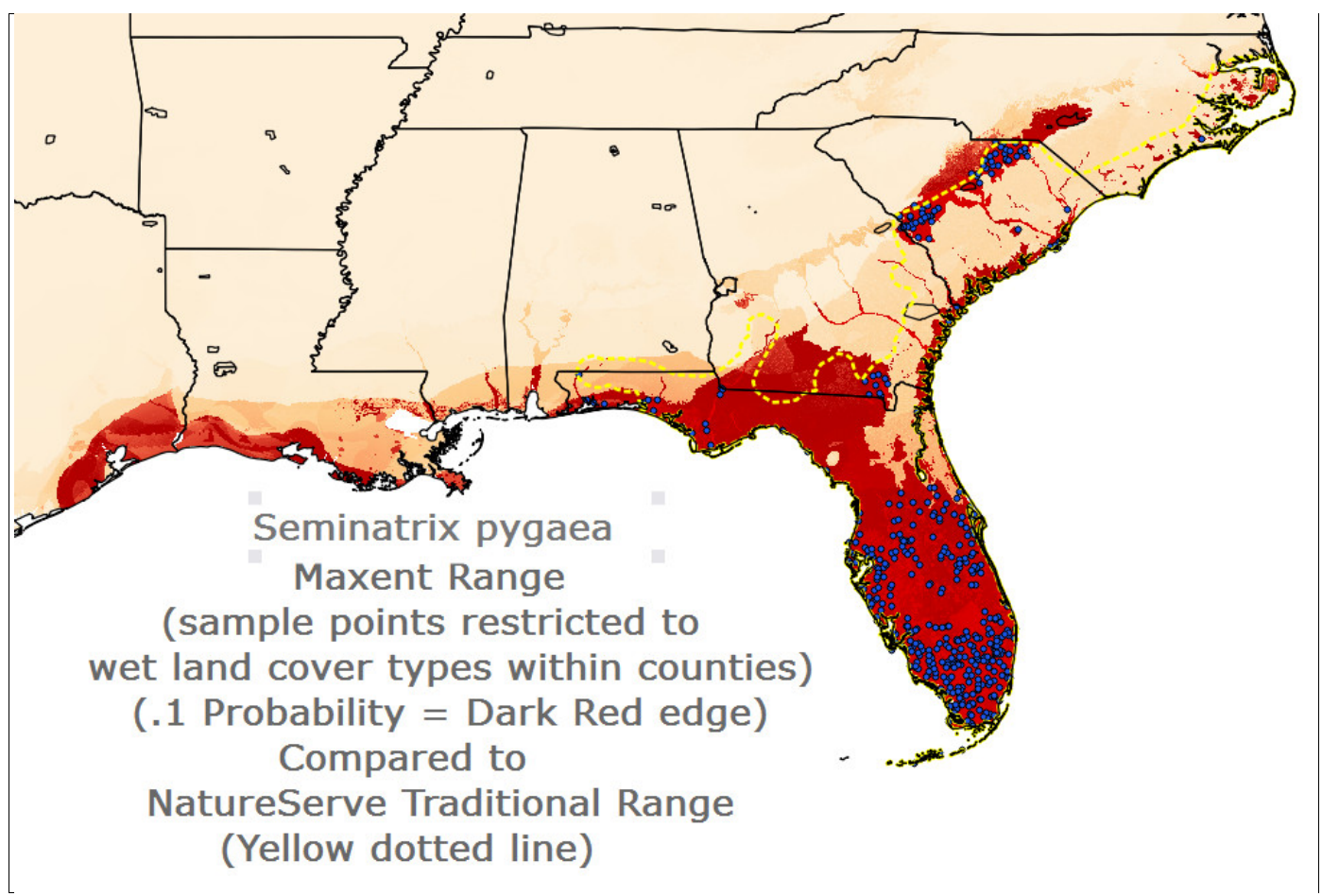

The new map distribution shows a much more restrictive range (same color table as above in Figure 50); it does not match the traditional range as well. Close inspection shows that the random wet types land cover dots within the counties for the snake observations do indeed come close to being fitted within the range in Figure 53. The restricted range, however, is extended farther west into Texas. What the Maxent statistics indicate is that there exists good habitat to the west that the snake has never taken advantage of (or it is out competed by another species in that niche).

Again, the top concerns are Bio18 precipitation of the warmest quarter and Bio8 mean temperature of wettest quarter, as predicted. Since the result from this option seems significantly less likely, it was not adopted.

\section{Refine the county distribution particularly using hydrology}

In this case, the accumulation data was used to refine the sighting locations, specifically using an accumulation value $>4$ within those counties where $S$. pygaea were sighted. From those locations, 555 random points were derived and used as sample input locations for a Maxent run that included the bioclimatic layers (not 16 and 17), the different land cover layers, and the accumulation input. 
Figure 54. Maxent model showing the $S$. pygaea distribution refined particularly by using hydrology.

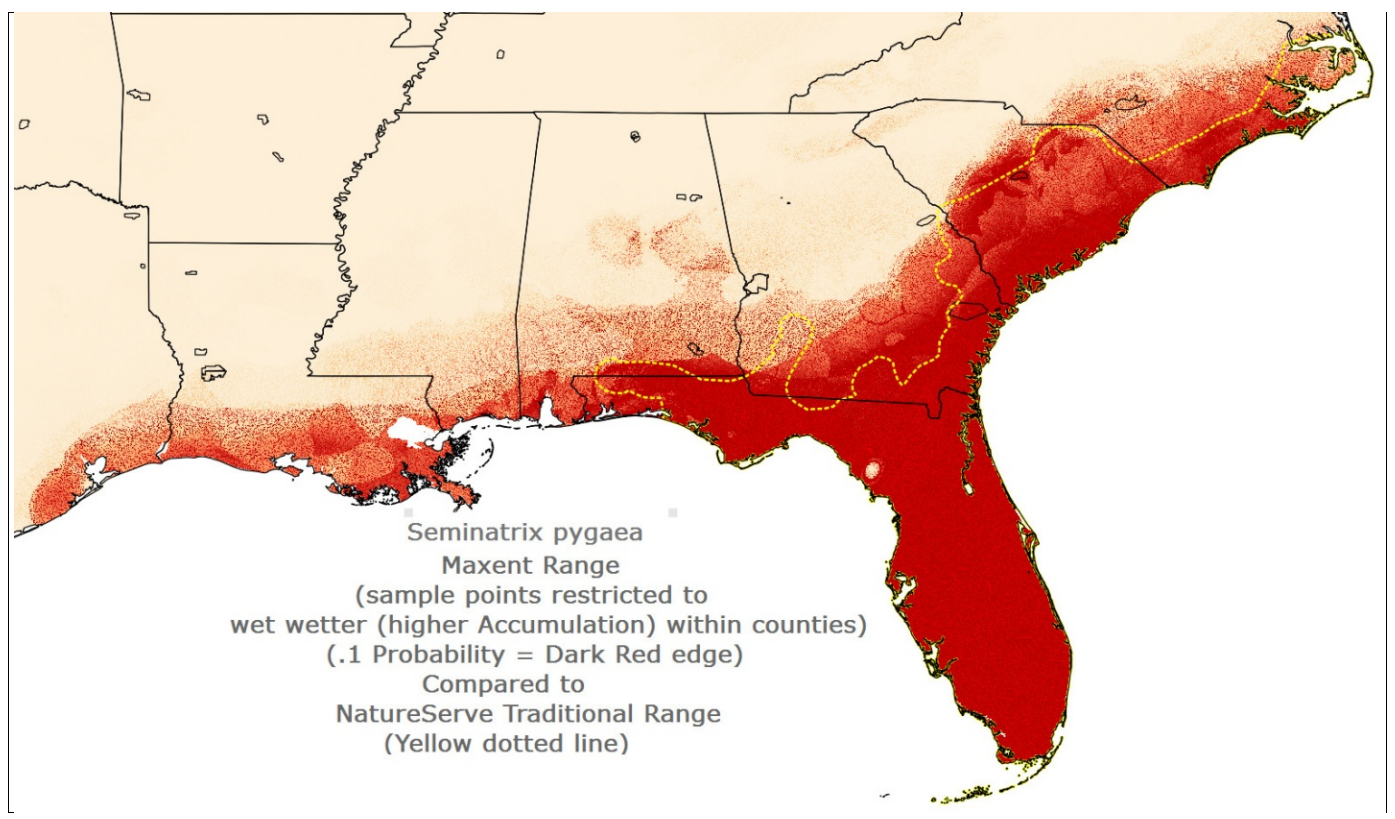

This version of the Swampsnake's range is similar to the first run except that it decreases the quality of good habitat in the western areas where $\mathrm{S}$. pygaea has not been observed and tends to fill in the areas of South Carolina where county observations have not occurred but where it is reasonable that they should have occurred. Further, the close-in detail (Figure 55) is very good in that it enhances riverine areas and deemphasizes land cover types. 
Figure 55. Detail area (same location as in Figure 51 above), showing that accumulation enhances riverine areas and deemphasizes land cover types.

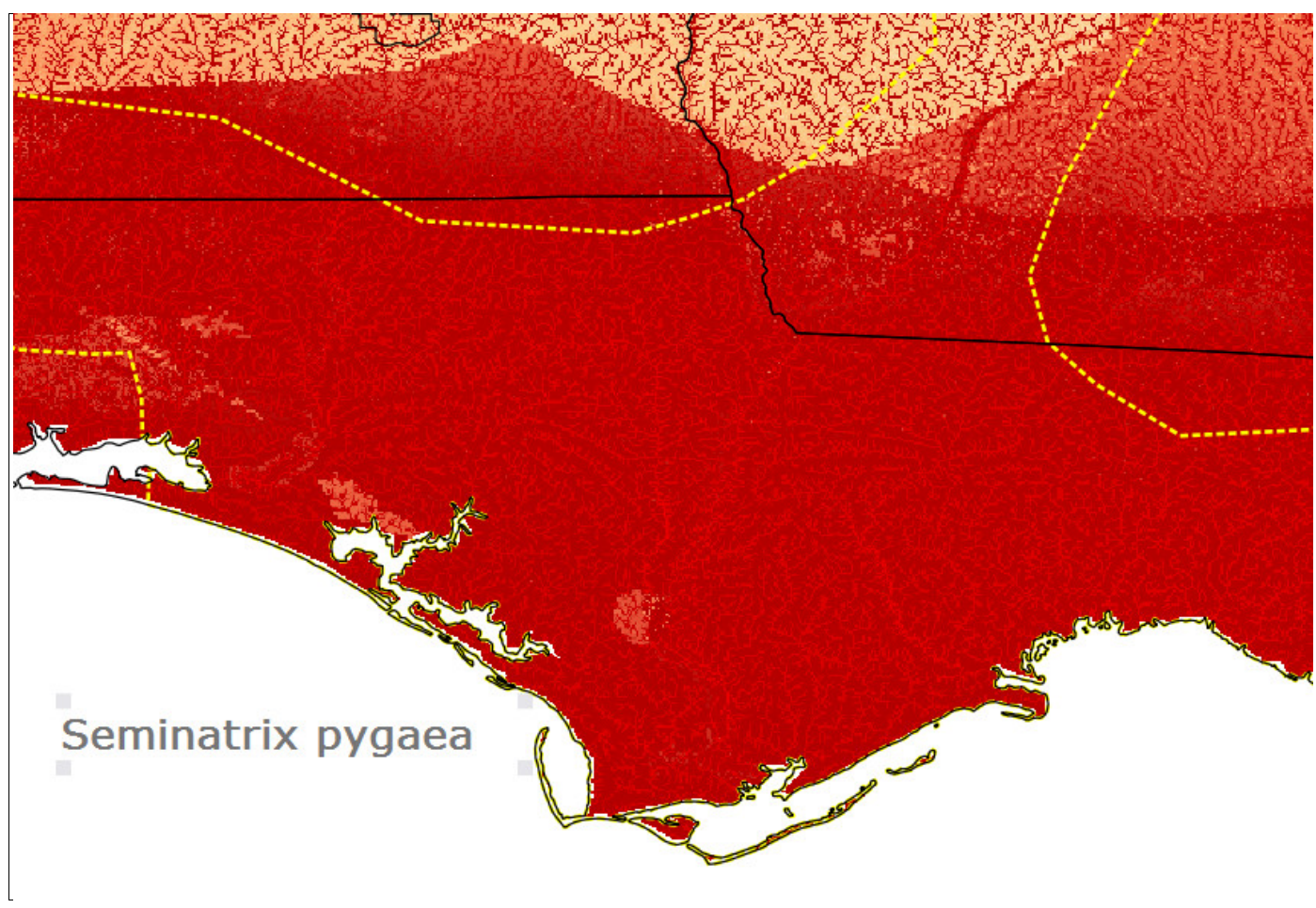

According to the statistics, Bio18 precipitation of the warmest quarter and Bio8 mean temperature of wettest quarter, were again the most important concerns, with the accumulation data in third place (of course it is doubleweighted in this model).

\section{Refine the county distribution using hydrology but leave the accumulation layer out of the list of input layers}

Figure 56 shows that this alternative provides a more generous range for the snake with good (but not as good) detail within the habitat range, compared to the test model which includes the accumulation layer as input. This alternative is much more definitive in making it clear that the western states as far as Texas provide good habitat. 
Figure 56. County-based distribution for S. pygaea using hydrology but leaving the accumulation layer out of the list of input layers.

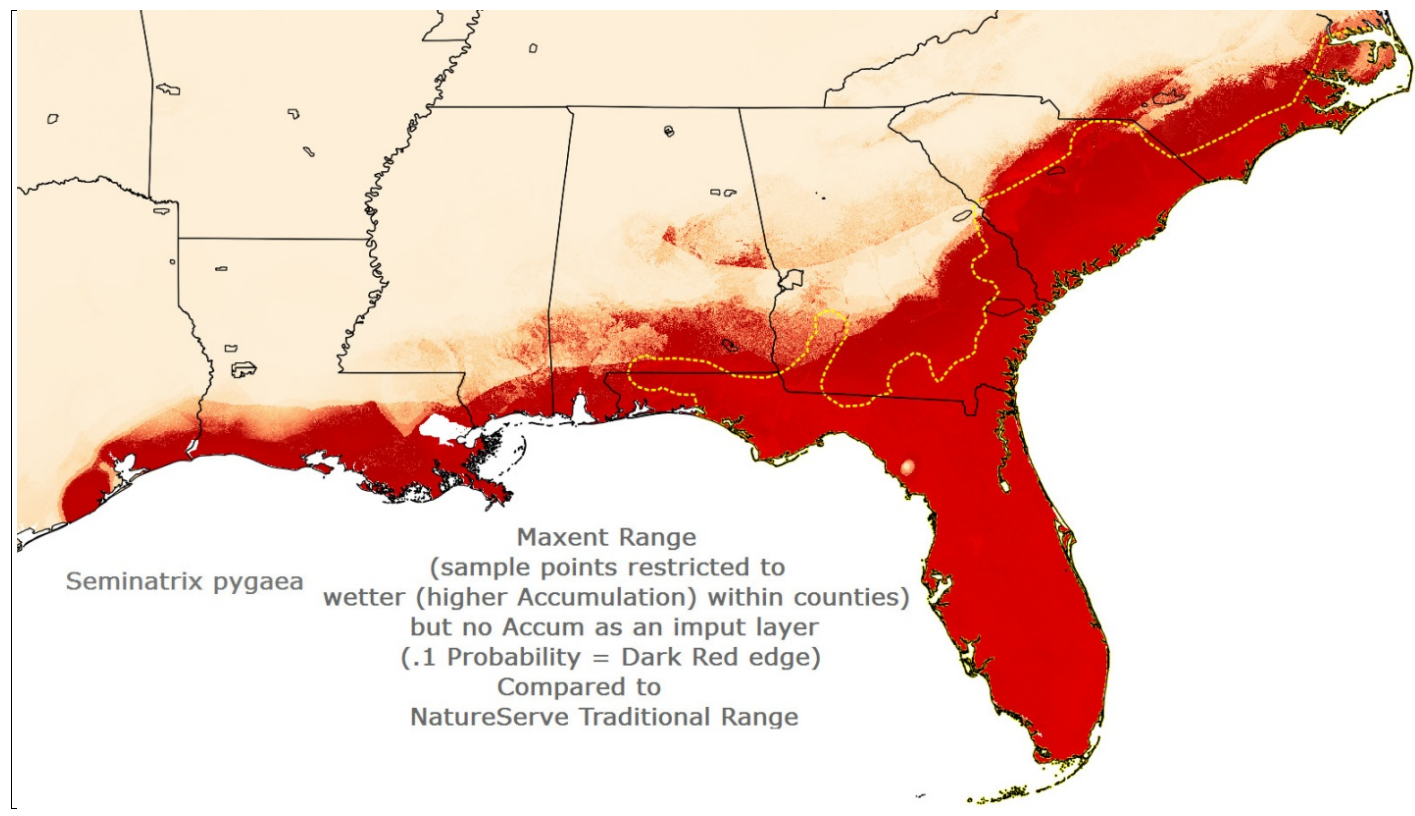

Bio18 precipitation of warmest quarter and Bio8 mean temperature of wettest quarter were again the most important concerns, with Bio11 mean temperature of coldest quarter coming in a very distant third place. Land cover types contributed little to the range, but they modified the internal probability distributions. This alternative is deemed generous and follows the traditional range well but also extends it greatly to the west, into Texas. This option has less internal detail, but it best represents what the bioclimatic layers may be suggesting.

\section{Run the Maxent test model with Accumulation layer integrated into the submitted layers}

The result from 15 runs (Figure 57) presents much the same range at the o.1 probability level as was derived with only one run. 
Figure 57. The Maxent test model with accumulation layer integrated into the submitted layers.

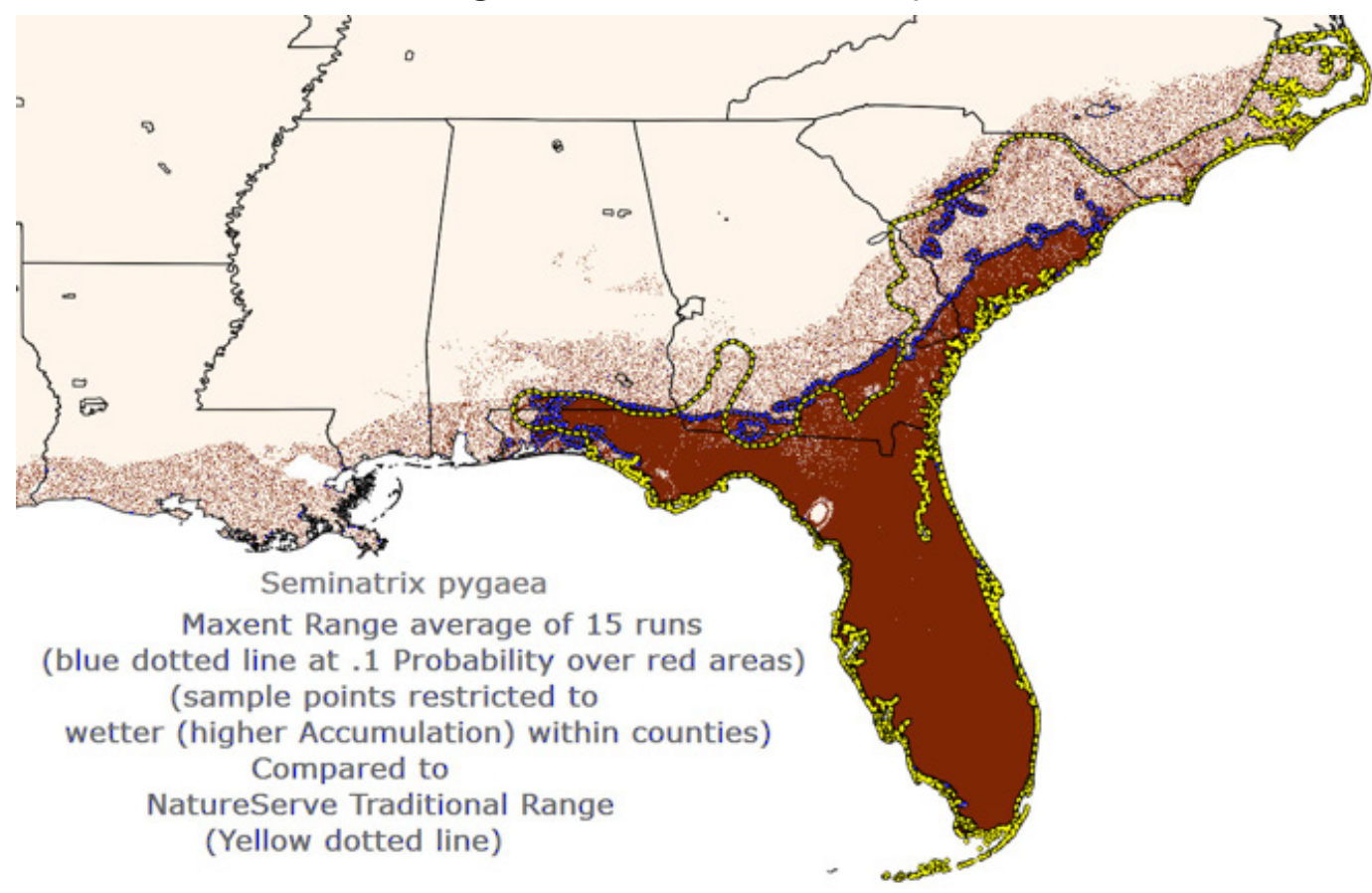

From Figure 57 above it can be seen that, in Florida and Georgia, the Maxent range matches the traditional range well. In South Carolina, the range is primarily restricted to the coastal areas and barely includes the observed outlier counties in the county input sample data. Maxent excludes all of the coastal area in North Carolina that NatureServe claims as within the range but for which there are only two county sightings on which Maxent bases its evaluations. A caveat to this statement is that Maxent definitively includes the coastal North Carolina areas if they are river valleys. This suggests that the range could be set at a higher probability level by simply ignoring the accumulation layer.

It is considered that this alternative masks the influence of the bioclimatic data that is of interest.

\section{Conclusions from this set of tests for S. pygaea}

- Maxent generates a stable basic model with only a few county sample points.

- Increasing the locational accuracy of the input points by using the accumulation layer results in a similar distribution to the simple inputs, with the following observations: 
- It decreases the western extent of the range to more closely match observations.

- Dropping accumulation from the input layers allowed additional habitat, particularly in those areas to the west of the known range.

- It provides greater detail but barely modifies the resultant range.

- This is particularly true because the snake seems to do well in both some upland, cultivated and urban land cover types.

- It also provides a close match to the traditional range.

- It does not provide much additional information, probably because of the following factors:

- Bioclimatic concerns rarely change quickly over a region the size of a county. Therefore the county location is adequate resolution for this work's purposes.

- Refining the inputs beforehand is time wasted because it is refining locations to a level below the resolution of the bioclimatic data.

- The addition of concerns that do not vary as a slow gradient over the country (e.g., accumulation) provides no regional information (only local detail).

- The addition of land cover tied to ecosystem type (e.g., the modified GAP natural land cover - gaplc_mod or physiographic regions) might show a gradient and therefore has the potential to be useful, although it usually does not turn up as important in the Maxent evaluation.

- Refining the inputs beforehand is time wasted because Maxent will tell if a particular input layer is im- 
portant in the final evaluation. This seems not to vary due to refining (except at the local detailed level which is not material in this research).

- Therefore the recommended alternative is option 4, using the bioclimatic data without using the accumulation as one of the input layers (except to refine the input sample locations). 


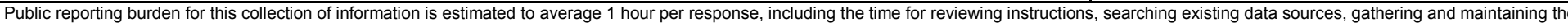

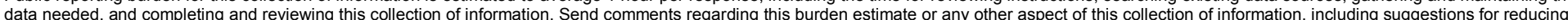

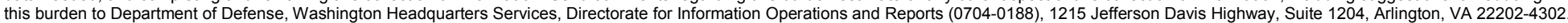

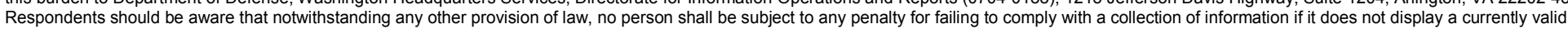
OMB control number. PLEASE DO NOT RETURN YOUR FORM TO THE ABOVE ADDRESS.
1. REPORT DATE (DD-MM-YYYY) June 2016

\section{REPORT TYPE}
Final Technical Report

4. TITLE AND SUBTITLE

Application of Maxent Multivariate Analysis to Define Reptile Species Distributions and

Changes Related to Climate Change
Robert C. Lozar and James D. Westervelt

\section{DATES COVERED (From - To)}

5a. CONTRACT NUMBER

5b. GRANT NUMBER

5c. PROGRAM ELEMENT NUMBER

RDT\&E 896, "Base Facilities

Environmental Quality"

5d. PROJECT NUMBER

335114

5e. TASK NUMBER

5f. WORK UNIT NUMBER

8. PERFORMING ORGANIZATION REPORT NUMBER

ERDC/CERL TR-16-6

10. SPONSOR/MONITOR'S ACRONYM(S)

ASA(ALT)

11. SPONSOR/MONITOR'S REPORT NUMBER(S)

12. DISTRIBUTION / AVAILABILITY STATEMENT

Approved for public release; distribution is unlimited.

\section{SUPPLEMENTARY NOTES}

14. ABSTRACT

The maximum entropy (Maxent) statistical technique was applied to determine the habitat extent of seven reptile species and to objectively delineate distributions and bioclimatic thresholds. For each species, Maxent ranked the relative importance of each of the input bioclimatic concerns and provided charts which were used to define species bioclimatic survival thresholds. It was discovered that the thresholds corresponded with the spatial distribution of the bioclimatic factors almost exactly at those threshold levels through much of the range for each of the species. As a result, it can be shown with a high degree of assurance that the majority of a reptile's range can be delineated with just a few bioclimatic concerns specific to that species and that the northern boundaries of the seven reptiles in this study are all controlled by temperature and the western boundaries are all controlled by the amount of precipitation.

\section{SUBJECT TERMS}

Reptiles, Climatic changes, Habitat (ecology), Multivariate analysis - Computer programs, Maximum entropy method, Environmental management, Military bases, Land management, Climate change impact, Maxent software

\begin{tabular}{|c|c|c|c|c|c|}
\hline \multicolumn{3}{|c|}{ 16. SECURITY CLASSIFICATION OF: } & \multirow{2}{*}{$\begin{array}{l}\text { 17. LIMITATION } \\
\text { OF ABSTRACT }\end{array}$} & \multirow{2}{*}{$\begin{array}{l}\text { 18. NUMBER } \\
\text { OF PAGES }\end{array}$} & 19a. NAME OF RESPONSIBLE PERSON \\
\hline $\begin{array}{l}\text { a. REPORT } \\
\text { Unclassified }\end{array}$ & $\begin{array}{l}\text { b. ABSTRACT } \\
\text { Unclassified }\end{array}$ & $\begin{array}{l}\text { c. THIS PAGE } \\
\text { Unclassified }\end{array}$ & & & $\begin{array}{l}\text { 19b. TELEPHONE NUMBER (in- } \\
\text { clude area code) }\end{array}$ \\
\hline
\end{tabular}

Standard Form 298 (Rev. 8-98) 